Supporting Information

\title{
An Approach to Quinoline-Fused Imidazopyridines via CDC of Ethers with Imidazopyridines under Metal-Free Conditions
}

\author{
Guifang Lian, Jingyu Li, Ping Liu, ${ }^{*}$ and Peipei Sun* \\ School of Chemistry and Materials Science, Jiangsu Provincial Key Laboratory of Material Cycle \\ Processes and Pollution Control, Jiangsu Collaborative Innovation Center of Biomedical \\ Functional Materials, Nanjing Normal University, Nanjing 210023, China \\ pingliu@njnu.edu.cn; sunpeipei@njnu.edu.cn
}

\section{Contents}

1. The Control Experiments........................................ $S 2-S 3$

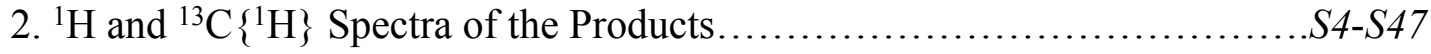




\section{The Control Experiment}

(a) Radical Trapping Experiment

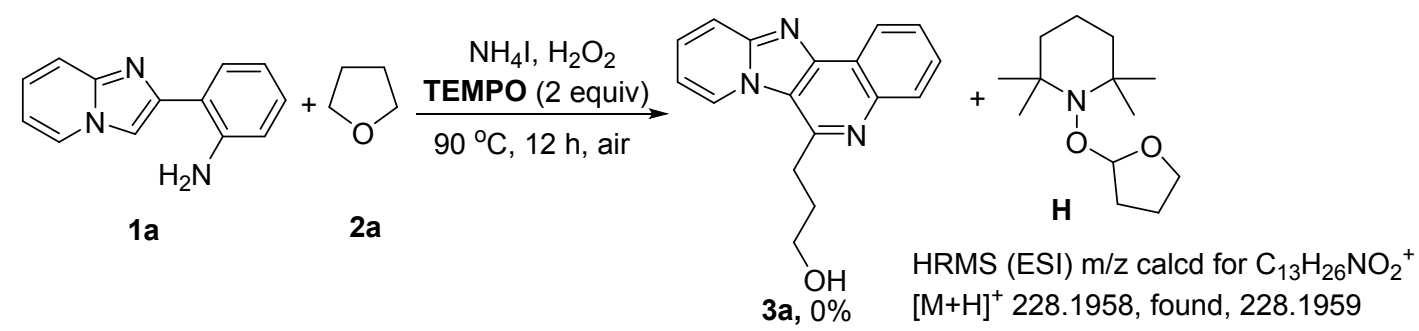

To a sealed tube were added 2-(imidazo[1,2-a]pyridin-2-yl)aniline 1a (41.8 mg, $0.2 \mathrm{mmol}), \mathrm{NH}_{4} \mathrm{I}$ (5.8 mg, $0.04 \mathrm{mmol}, 20 \mathrm{~mol} \%$ ), THF $(2 \mathrm{~mL}), \mathrm{H}_{2} \mathrm{O}_{2}\left(61 \mu \mathrm{L}, 3.0\right.$ equiv, $30 \%$ in $\mathrm{H}_{2} \mathrm{O}$ ) and TEMPO (62.5 mg, $0.4 \mathrm{mmol})$. The reaction mixture was stirred at $90{ }^{\circ} \mathrm{C}$ for $12 \mathrm{~h}$. After the reaction was finished, no desired product 3a was observed by TLC and HRMS, indicating that the reaction was completely inhibited. Meanwhile, the adduct $\mathbf{H}$ was detected by HRMS analysis (Figure S1).

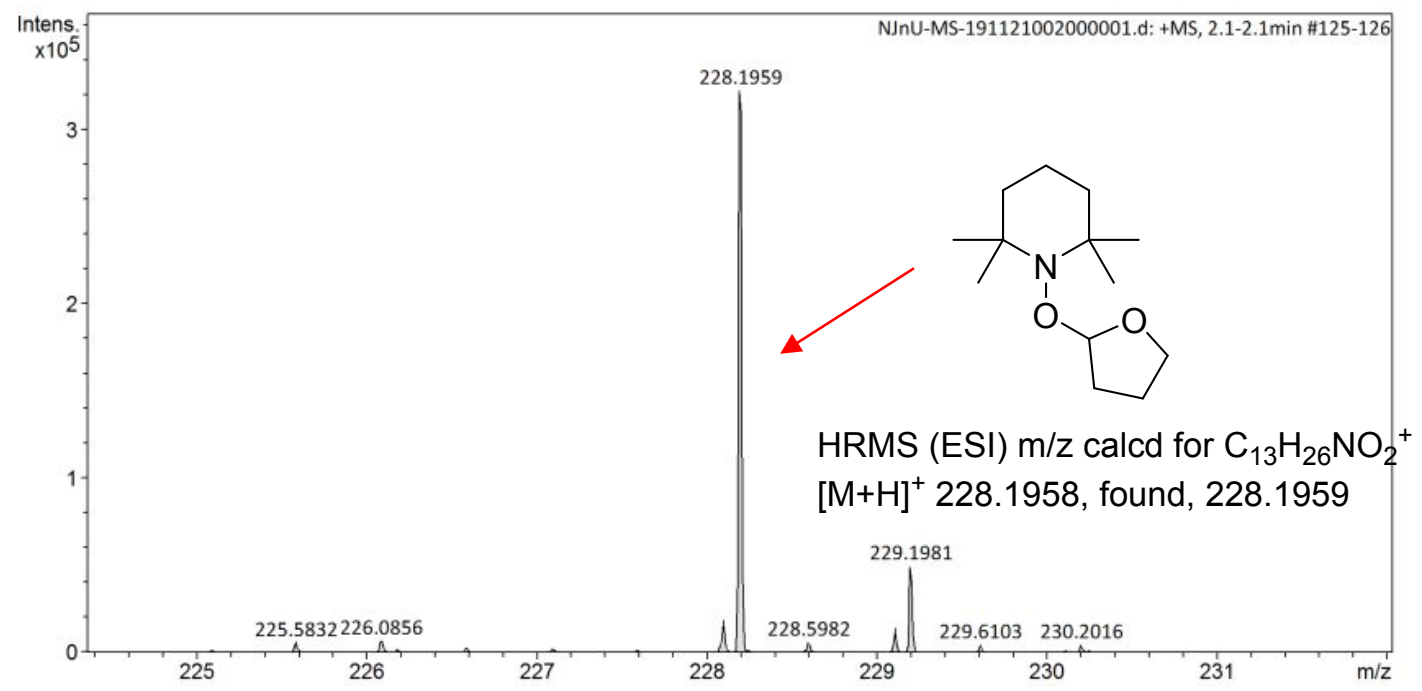

Figure S1. HRMS analysis of adduct $\mathbf{H}$.

(b) The Probable Intermediate Detected Experiment

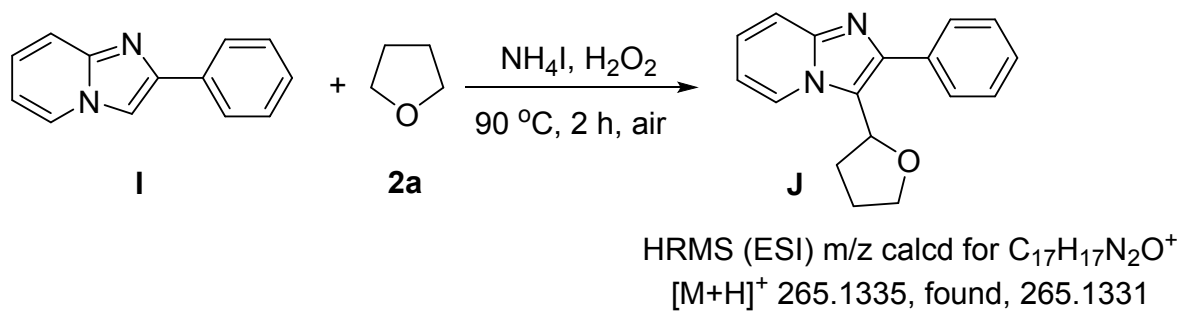

To a sealed tube were added 2-phenylimidazo[1,2-a]pyridine (I) (38.8 mg, $0.2 \mathrm{mmol}), \mathrm{NH}_{4} \mathrm{I}$ (5.8 mg, $0.04 \mathrm{mmol}, 20 \mathrm{~mol} \%)$, THF $(2 \mathrm{~mL})$ and $\mathrm{H}_{2} \mathrm{O}_{2}\left(61 \mu \mathrm{L}, 3.0\right.$ equiv, $30 \%$ in $\left.\mathrm{H}_{2} \mathrm{O}\right)$. The reaction mixture was stirred at $90{ }^{\circ} \mathrm{C}$ for $2 \mathrm{~h}$. The product $\mathbf{J}$ was detected by HRMS analysis (Figure S2). 


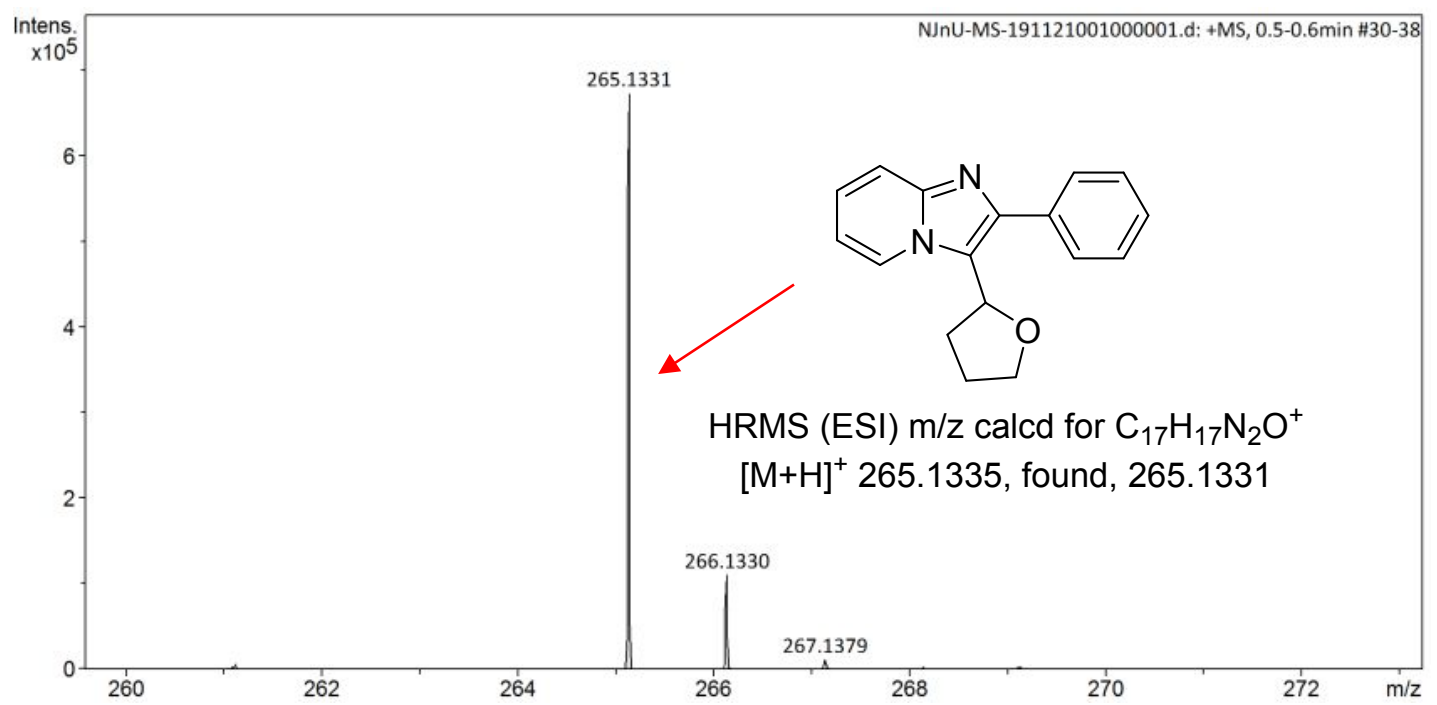

Figure S2. HRMS analysis of product $\mathbf{J}$.

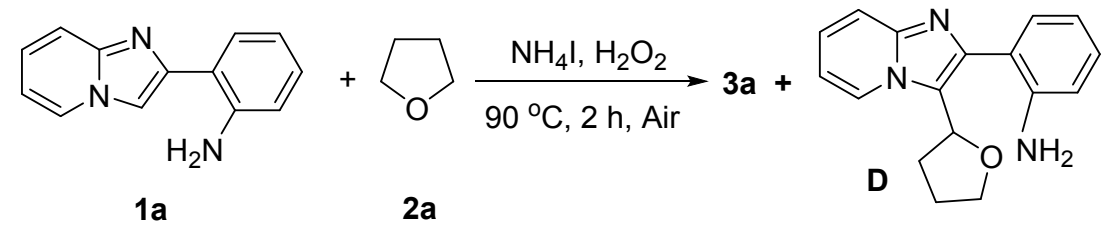

HRMS (ESI) $\mathrm{m} / \mathrm{z}$ calcd for $\mathrm{C}_{17} \mathrm{H}_{18} \mathrm{~N}_{3} \mathrm{O}^{+}$

$[\mathrm{M}+\mathrm{H}]^{+} 280.1444$, found, 280.1445

To a sealed tube were added 2-(imidazo[1,2-a]pyridin-2-yl)aniline (1a) $(41.8 \mathrm{mg}, 0.2 \mathrm{mmol}$ ), $\mathrm{NH}_{4} \mathrm{I}(5.8 \mathrm{mg}, 0.04 \mathrm{mmol}, 20 \mathrm{~mol} \%)$, THF ( $\left.2 \mathrm{~mL}\right)$ and $\mathrm{H}_{2} \mathrm{O}_{2}\left(61 \mu \mathrm{L}, 3.0\right.$ equiv, $30 \%$ in $\left.\mathrm{H}_{2} \mathrm{O}\right)$. The reaction mixture was stirred at $90{ }^{\circ} \mathrm{C}$ for $2 \mathrm{~h}$. The desired product 3a was observed by TLC. Meanwhile, the probable intermediate D was detected by HRMS analysis (Figure S3).

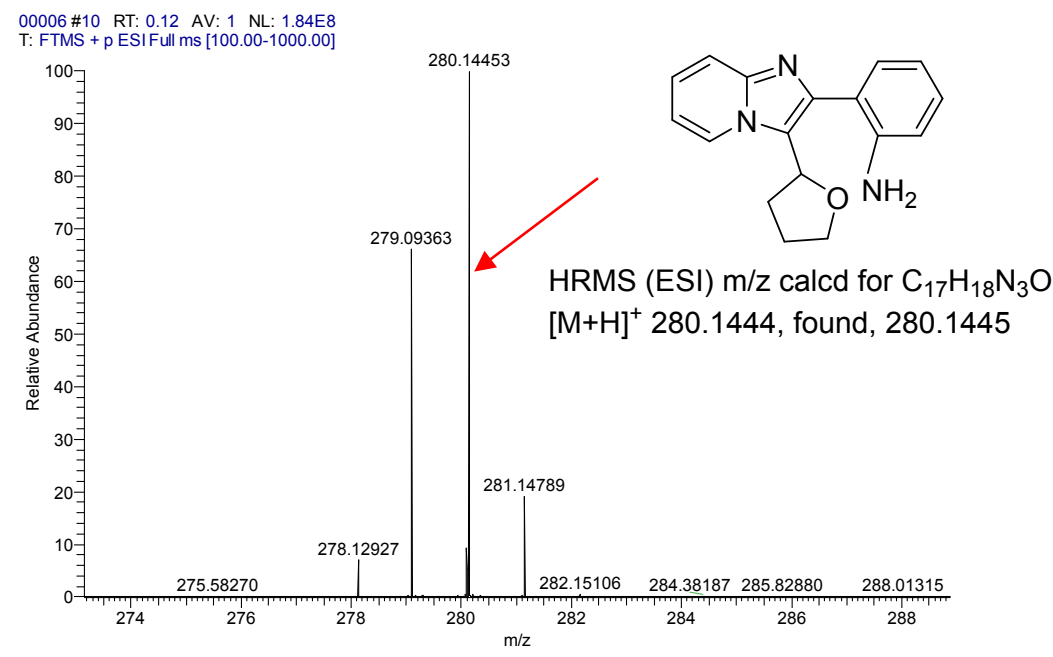

Figure S3. HRMS analysis of intermediate product D. 
$2^{1} \mathrm{H}$ and ${ }^{13} \mathrm{C}\left\{{ }^{1} \mathrm{H}\right\}$ Spectra of the Products

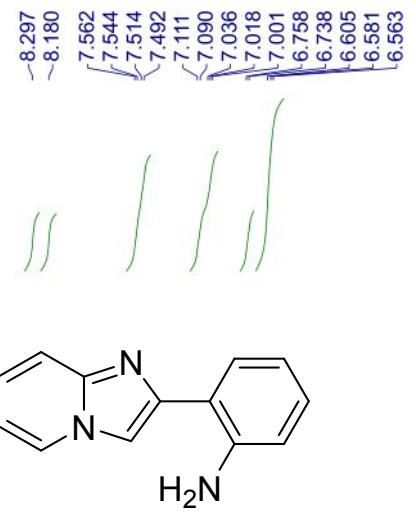

$1 b$ ( ${ }^{1} \mathrm{H}$ NMR)

Solvent: DMSO- $d_{6}$

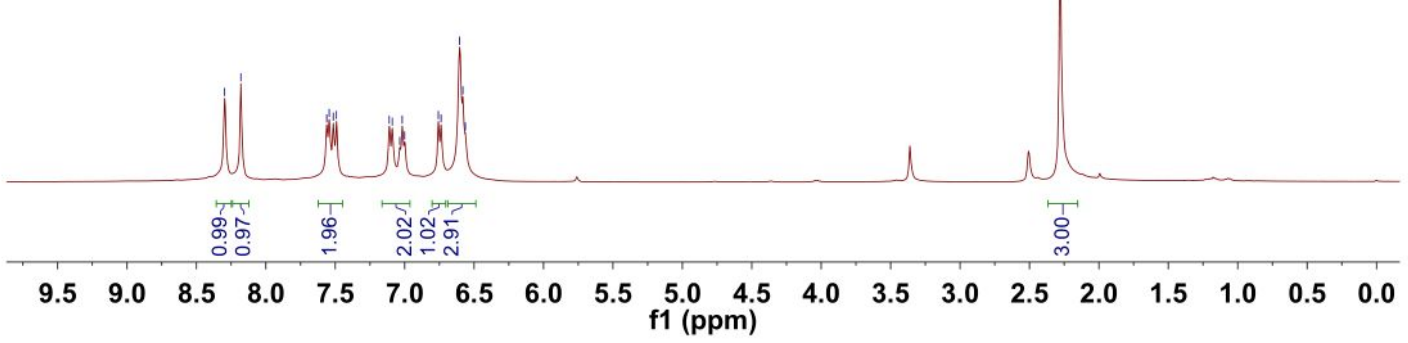

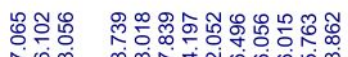

守得势

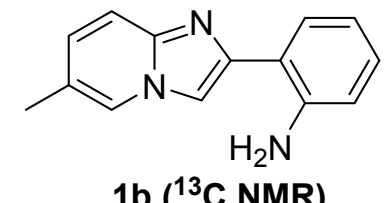

Solvent: DMSO- $d_{6}$
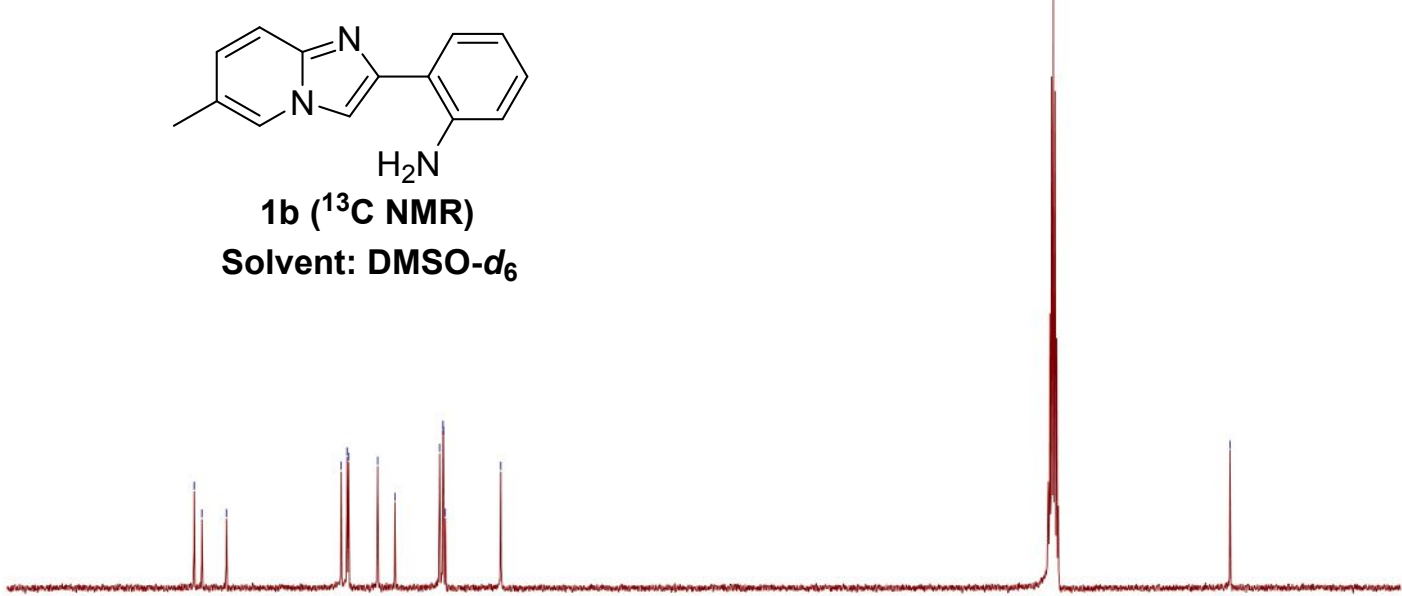

$\begin{array}{llllllllllllllllll}70 & 160 & 150 & 140 & 130 & 120 & 110 & 100 & \underset{f 1}{90}\left(\begin{array}{c}80 \\ (\mathrm{ppm})\end{array}\right. & 70 & 60 & 50 & 40 & 30 & 20 & 10 & 0\end{array}$ 


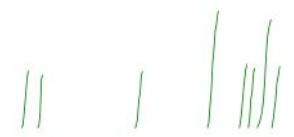<smiles>Cc1cccn2cc(-c3ccccc3N)nc12</smiles>

1d ( ${ }^{1} \mathrm{H}$ NMR)

Solvent: DMSO- $d_{6}$

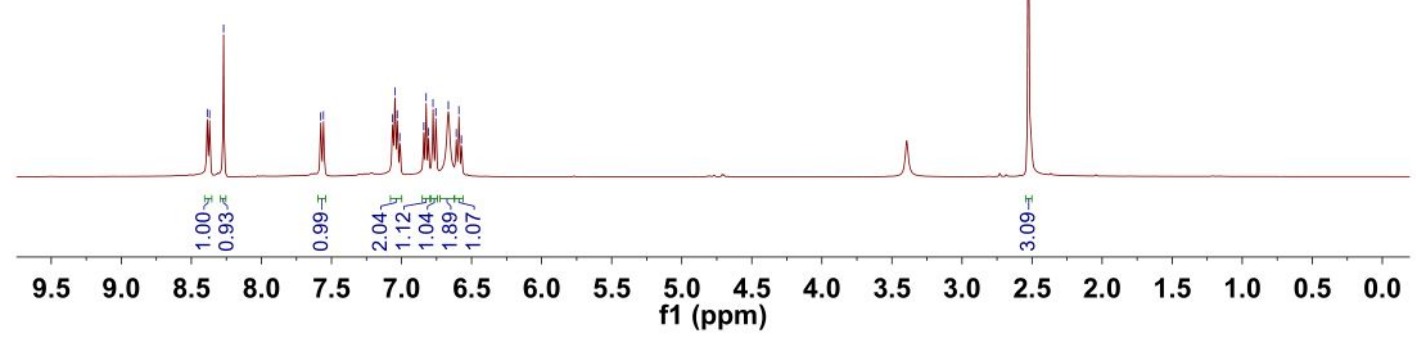

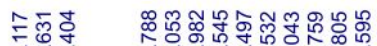

章守守

$\underset{\substack{0 \\ \hdashline}}{\stackrel{1}{1}}$

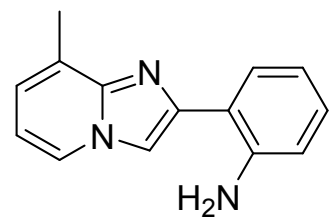

1d ( ${ }^{13} \mathrm{C}$ NMR)

Solvent: DMSO- $d_{6}$

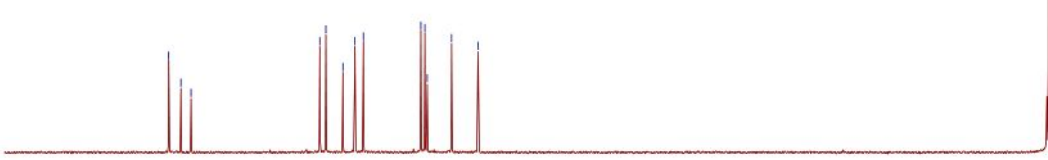

$\begin{array}{lllllllllllllllll}160 & 150 & 140 & 130 & 120 & 110 & 100 & \underset{\mathrm{f} 1(\mathrm{ppm})}{80} & 70 & 60 & 50 & 40 & 30 & 20 & 10 & 0\end{array}$ 


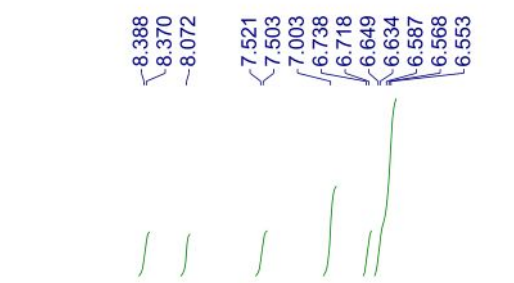<smiles>COc1ccn2cc(-c3ccccc3N)nc2c1</smiles>

1e ( ${ }^{1} \mathrm{H}$ NMR)

Solvent: DMSO-d $d_{6}$

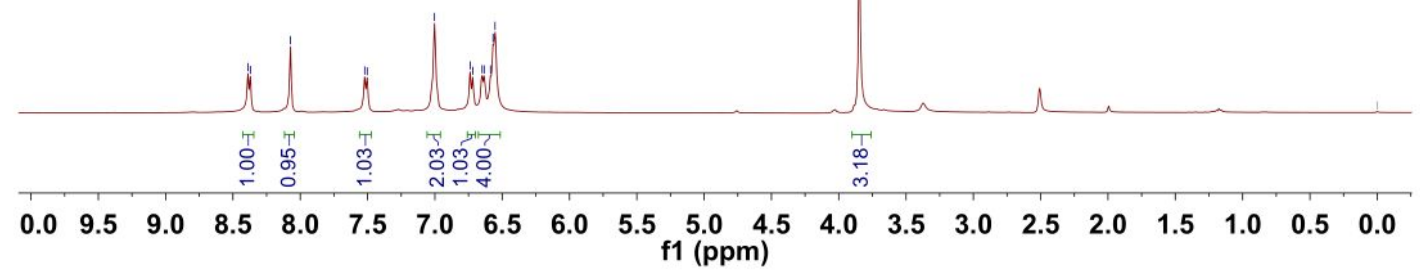

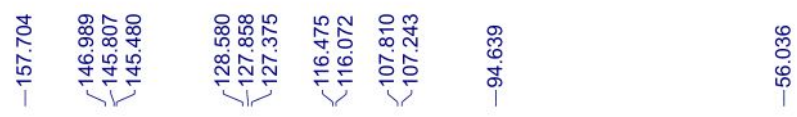

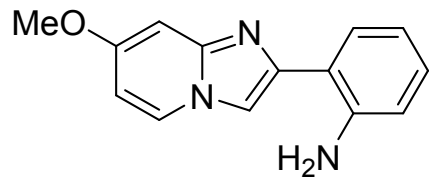

1e ( ${ }^{13} \mathrm{C}$ NMR)

Solvent: DMSO- $d_{6}$

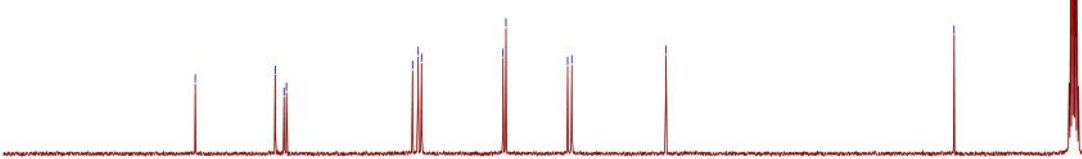

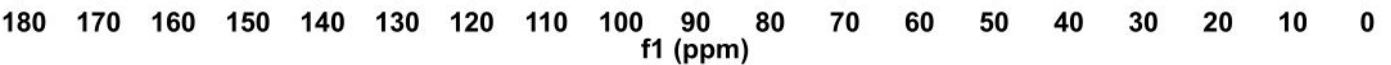




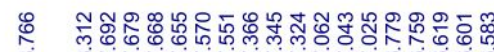

o

|||| $\mid$<smiles>Nc1ccccc1-c1cn2cc(F)ccc2n1</smiles>

1f ( ${ }^{1} \mathrm{H}$ NMR)

Solvent: DMSO- $d_{6}$

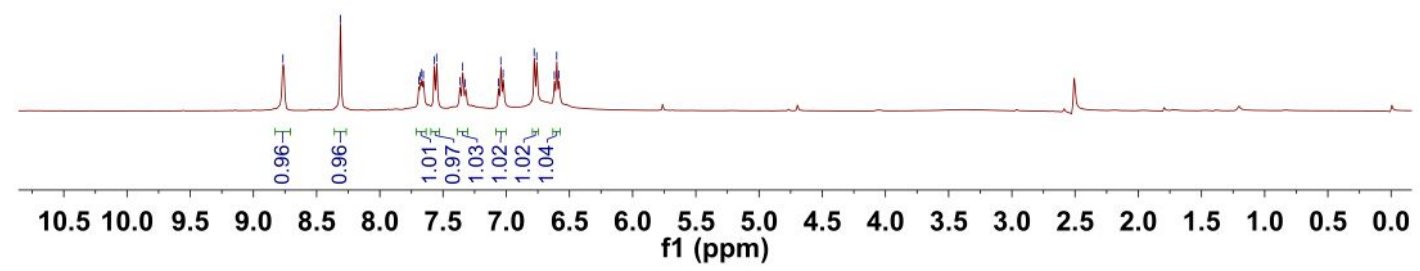

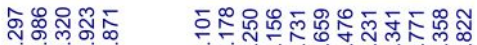

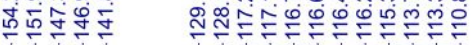

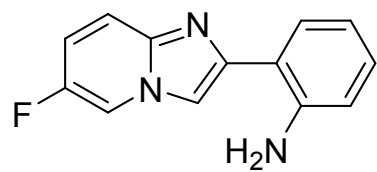

if $\left({ }^{13} \mathrm{C}\right.$ NMR $)$

Solvent: DMSO- $d_{6}$

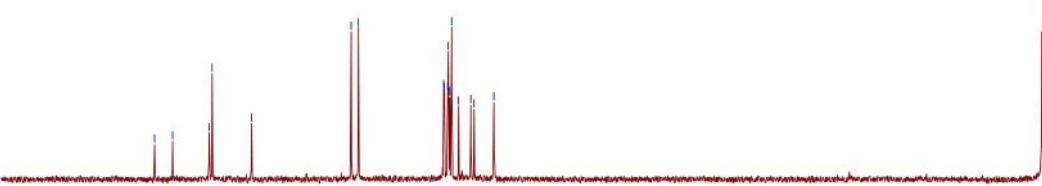

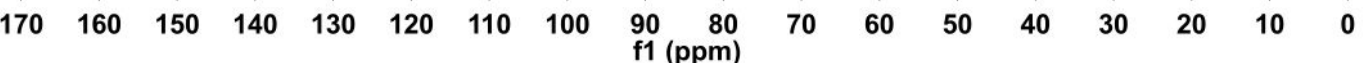




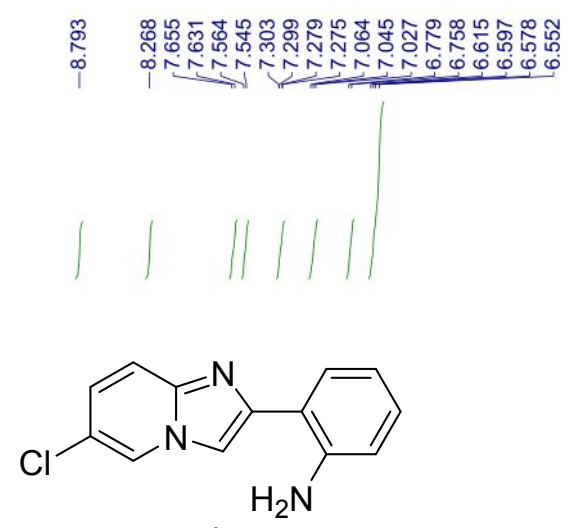

$\lg \left({ }^{1} \mathrm{H}\right.$ NMR)

Solvent: DMSO- $d_{6}$

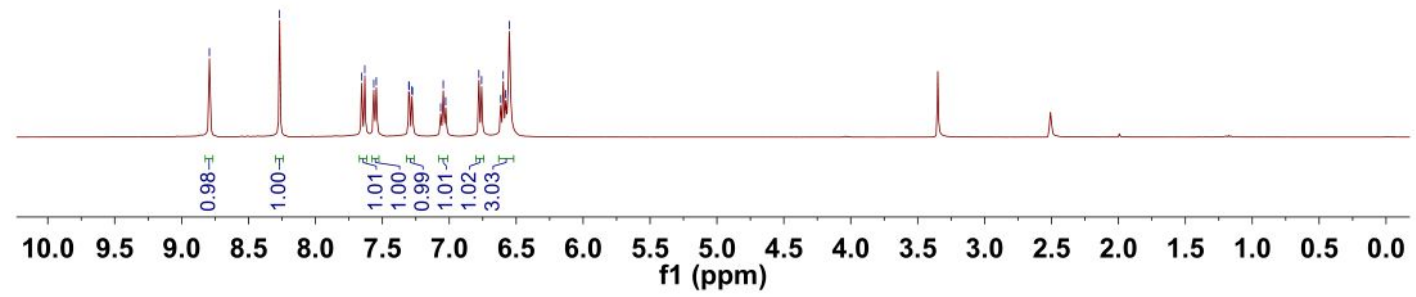

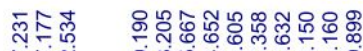

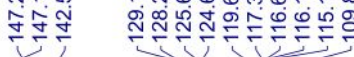

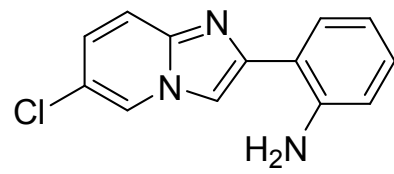

$1 \mathrm{~g}\left({ }^{13} \mathrm{C}\right.$ NMR)

Solvent: DMSO- $d_{6}$

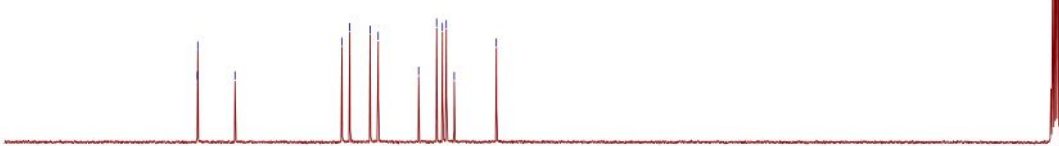

$\begin{array}{llllllllllllllllll}70 & 160 & 150 & 140 & 130 & 120 & 110 & 100 & \underset{9}{90} \begin{array}{r}80 \\ \mathrm{f} 1(\mathrm{ppm})\end{array} & 70 & 60 & 50 & 40 & 30 & 20 & 10 & 0\end{array}$ 

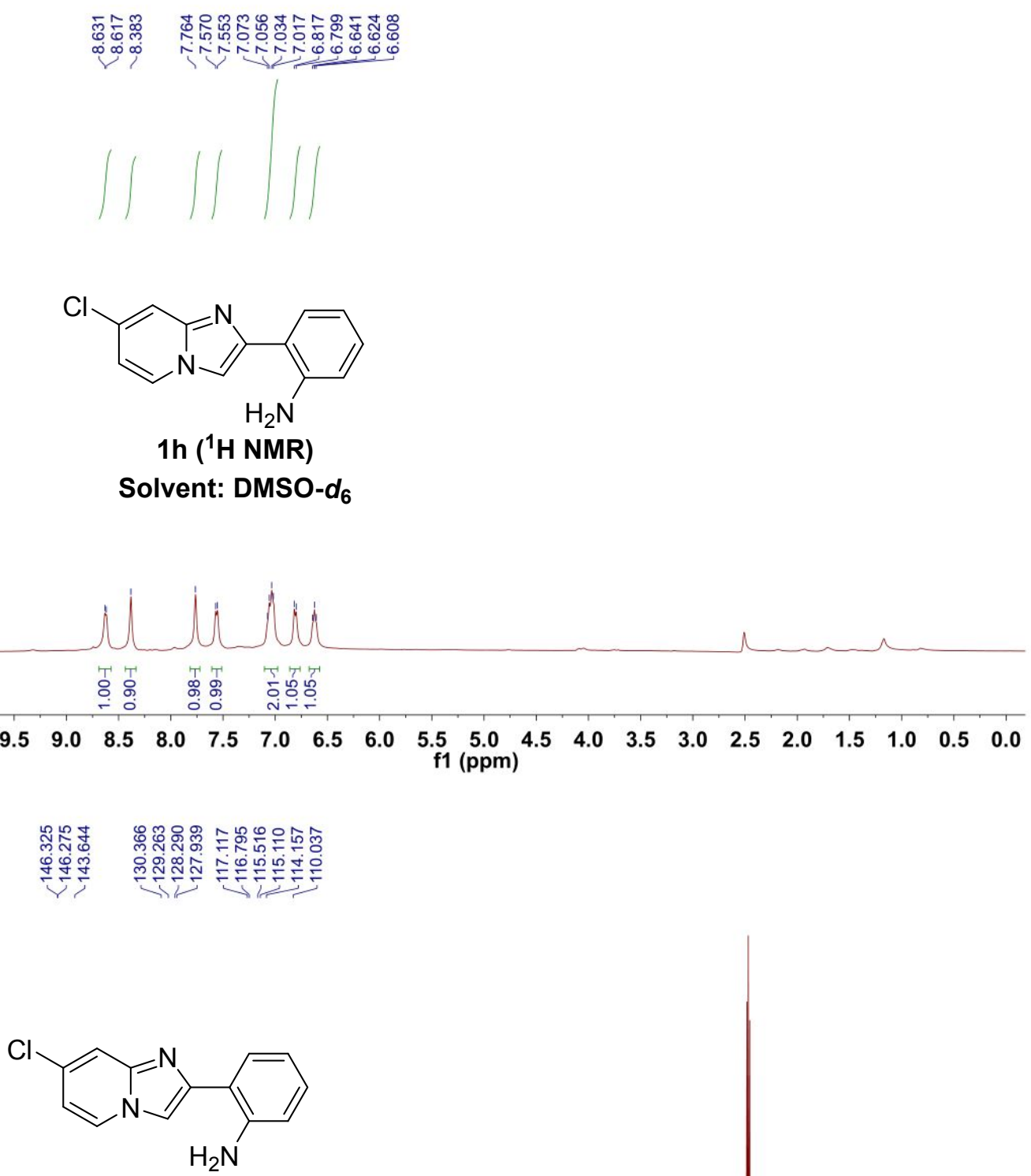

1h ( ${ }^{13} \mathrm{C}$ NMR)

Solvent: DMSO- $d_{6}$

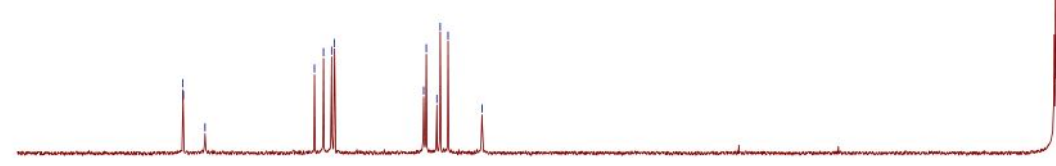

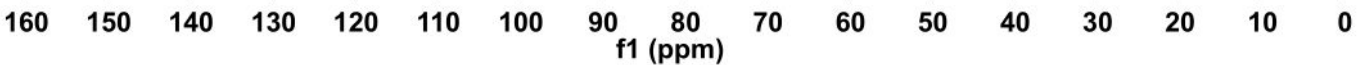



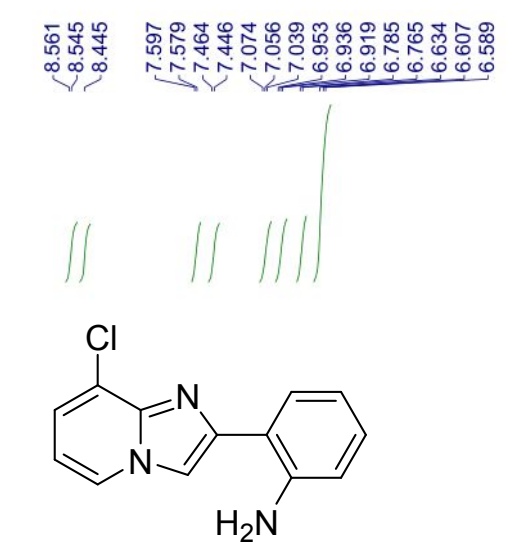

$1 i$ ( ${ }^{1} \mathrm{H}$ NMR)

Solvent: DMSO- $d_{6}$

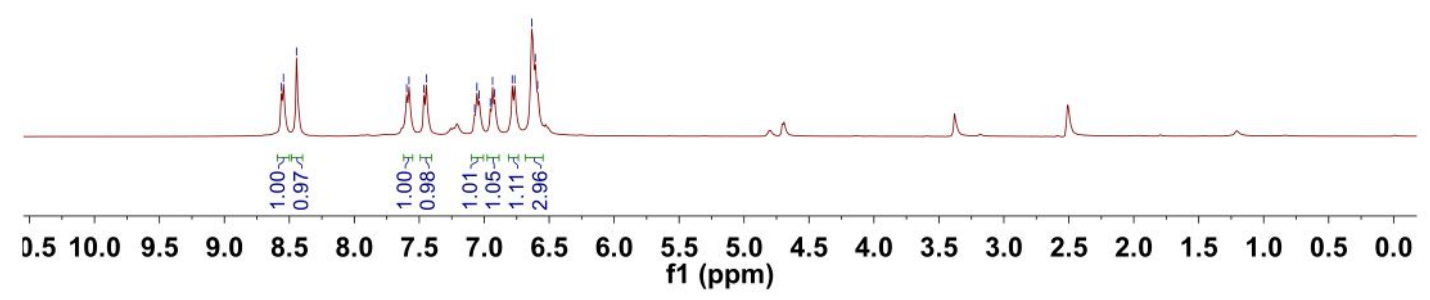

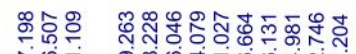

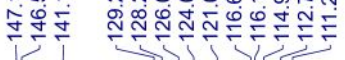

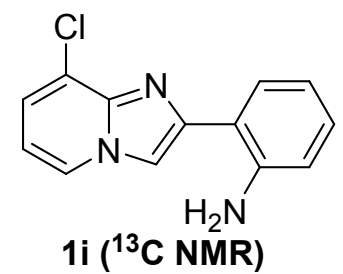

Solvent: DMSO- $d_{6}$

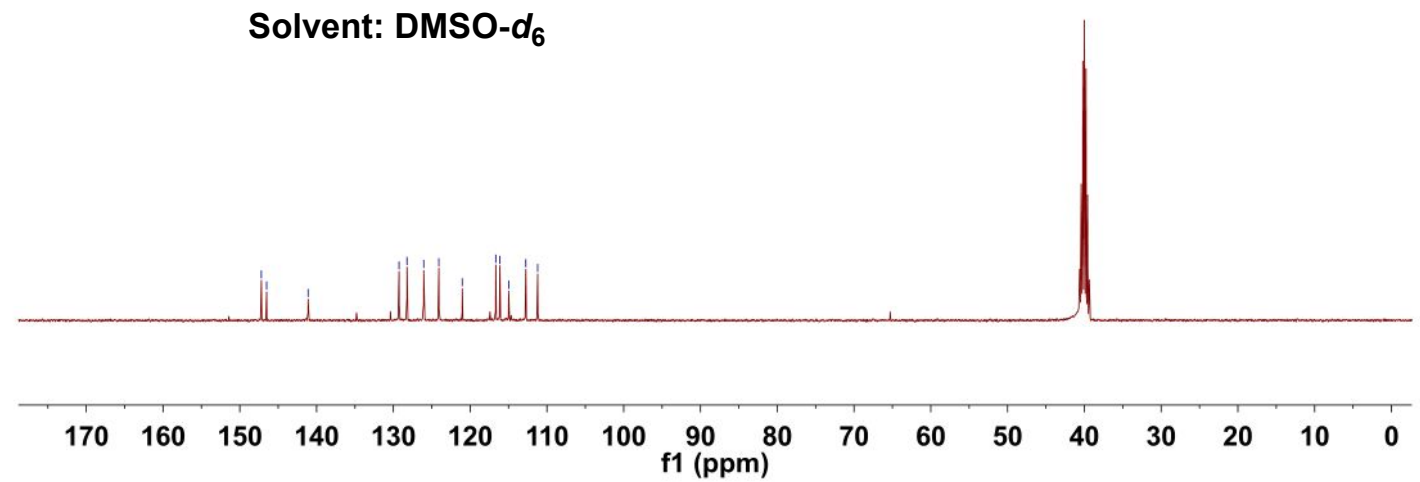



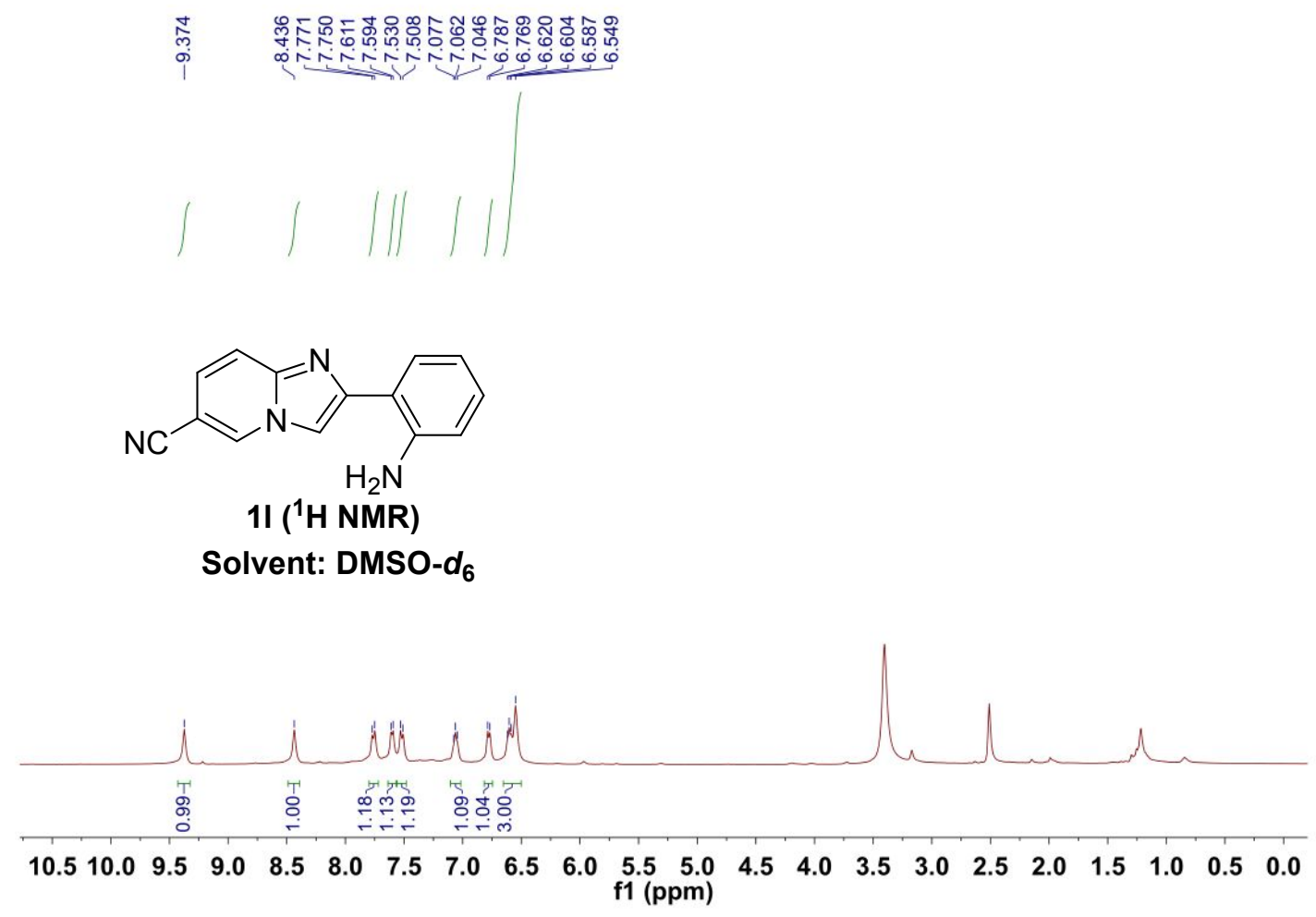

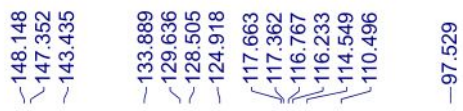<smiles>N#Cc1ccc2nc(-c3ccccc3N)cn2c1</smiles>

1 ( $\left({ }^{13} \mathrm{C}\right.$ NMR)

Solvent: DMSO-d 6

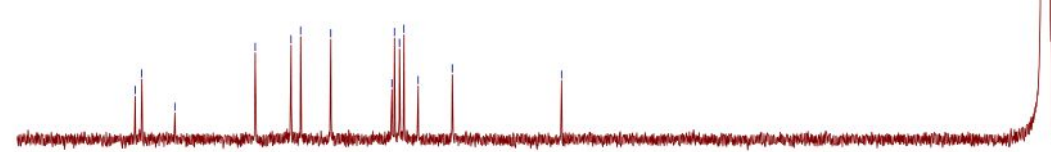

$\begin{array}{lllllllllllllllll}160 & 150 & 140 & 130 & 120 & 110 & 100 & 90 & \underset{\mathrm{f} 1}{\stackrel{8(\mathrm{ppm})}{80}} \mathbf{7 0} & 60 & 50 & 40 & 30 & 20 & 10 & 0\end{array}$ 

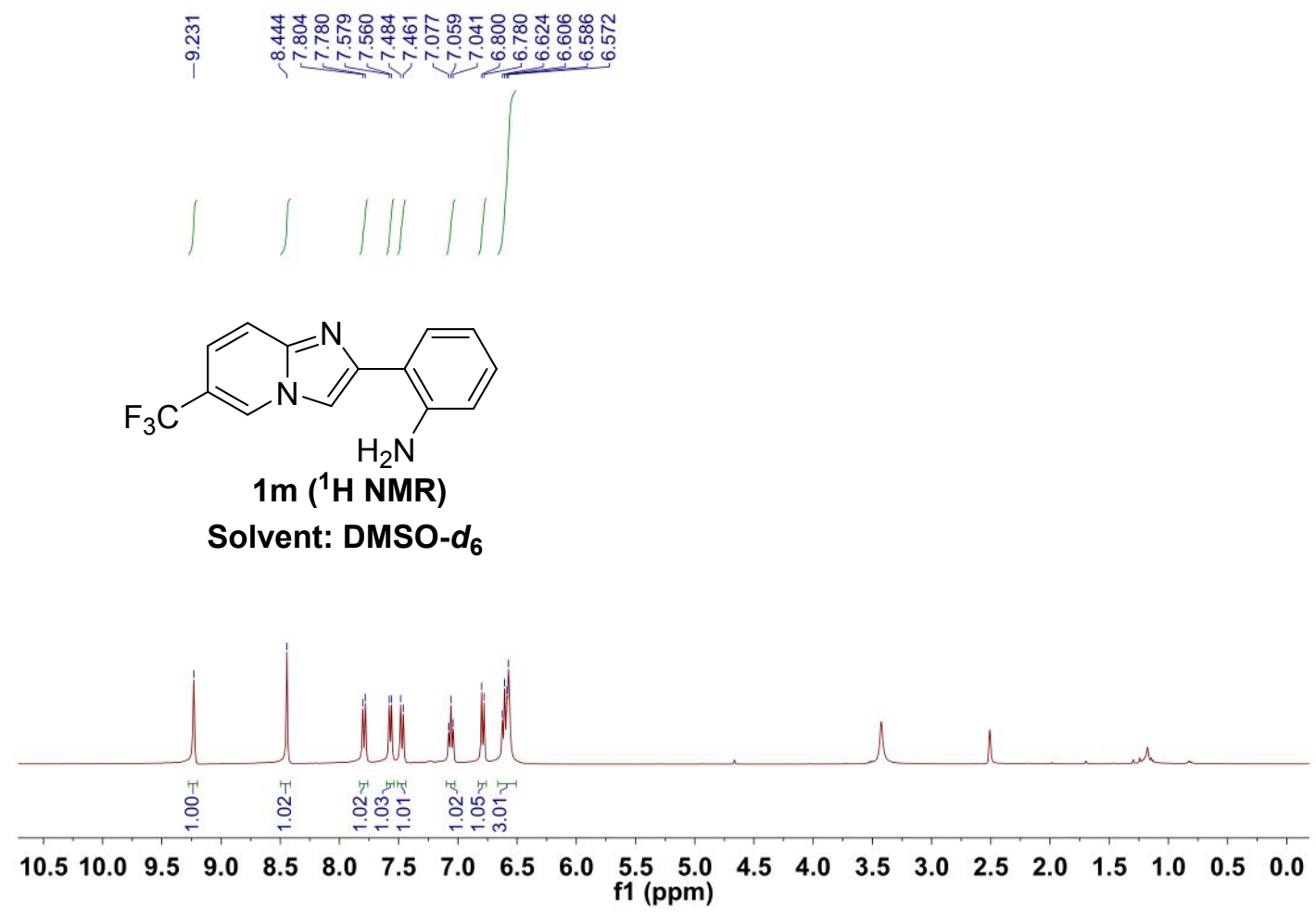

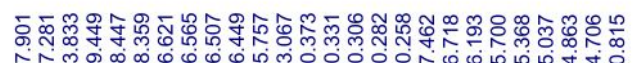

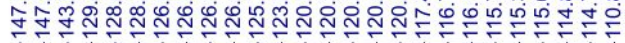<smiles>Nc1ccccc1-c1cn2cc(C(F)(F)F)ccc2n1</smiles>

$1 \mathrm{~m}\left({ }^{13} \mathrm{C}\right.$ NMR $)$

Solvent: DMSO-d $d_{6}$

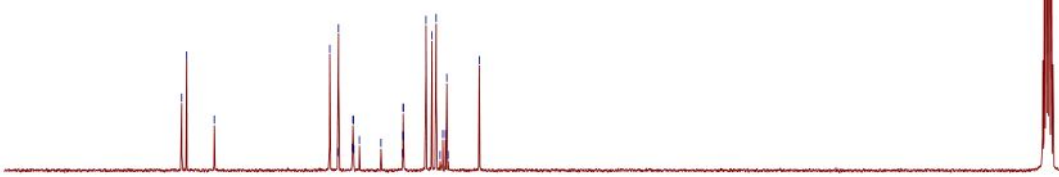

$\begin{array}{lllllllllllllllll}160 & 150 & 140 & 130 & 120 & 110 & 100 & \underset{\mathrm{f} 1}{90} \begin{array}{c}80 \\ \mathrm{ppm})\end{array} & 70 & 60 & 50 & 40 & 30 & 20 & 10 & 0\end{array}$ 


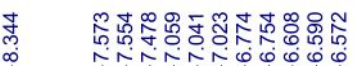

1)

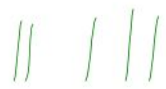<smiles>Cc1cc(Br)c2nc(-c3ccccc3N)cn2c1</smiles>

1n ( ${ }^{1} \mathrm{H}$ NMR)

Solvent: DMSO- $d_{6}$

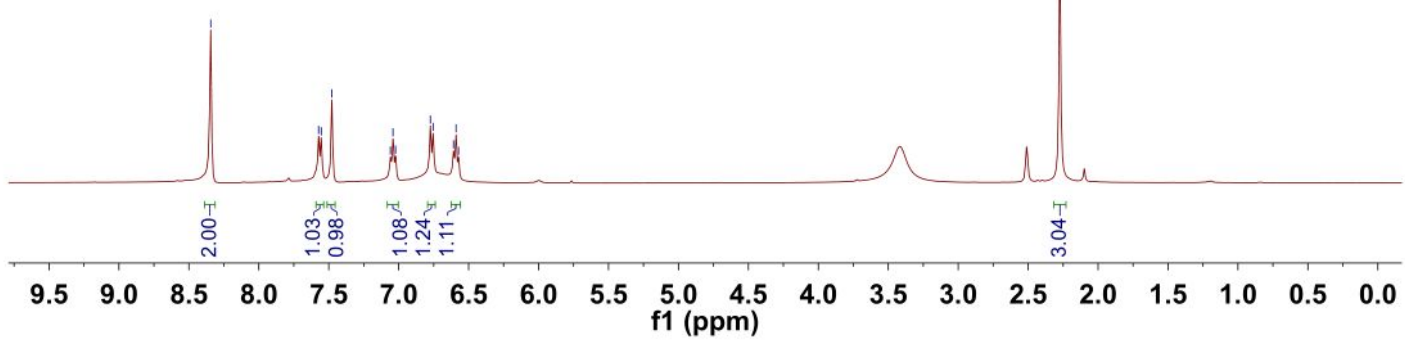

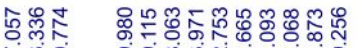

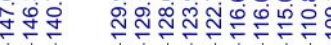

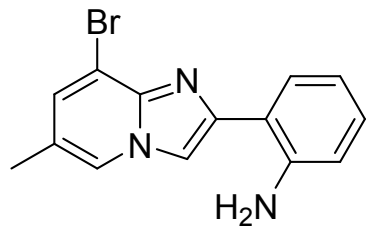

1n $\left({ }^{13} \mathrm{C}\right.$ NMR $)$

Solvent: DMSO- $d_{6}$

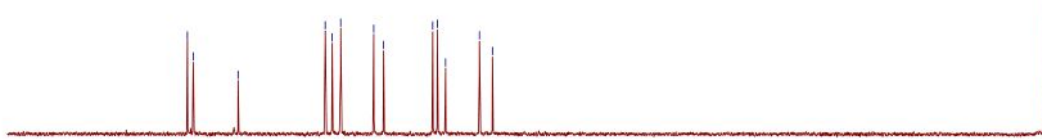

$\begin{array}{lllllllllllllllll}160 & 150 & 140 & 130 & 120 & 110 & 100 & \underset{\mathrm{f} 1(\mathrm{ppm})}{80} & 70 & 60 & 50 & 40 & 30 & 20 & 10 & 0\end{array}$ 


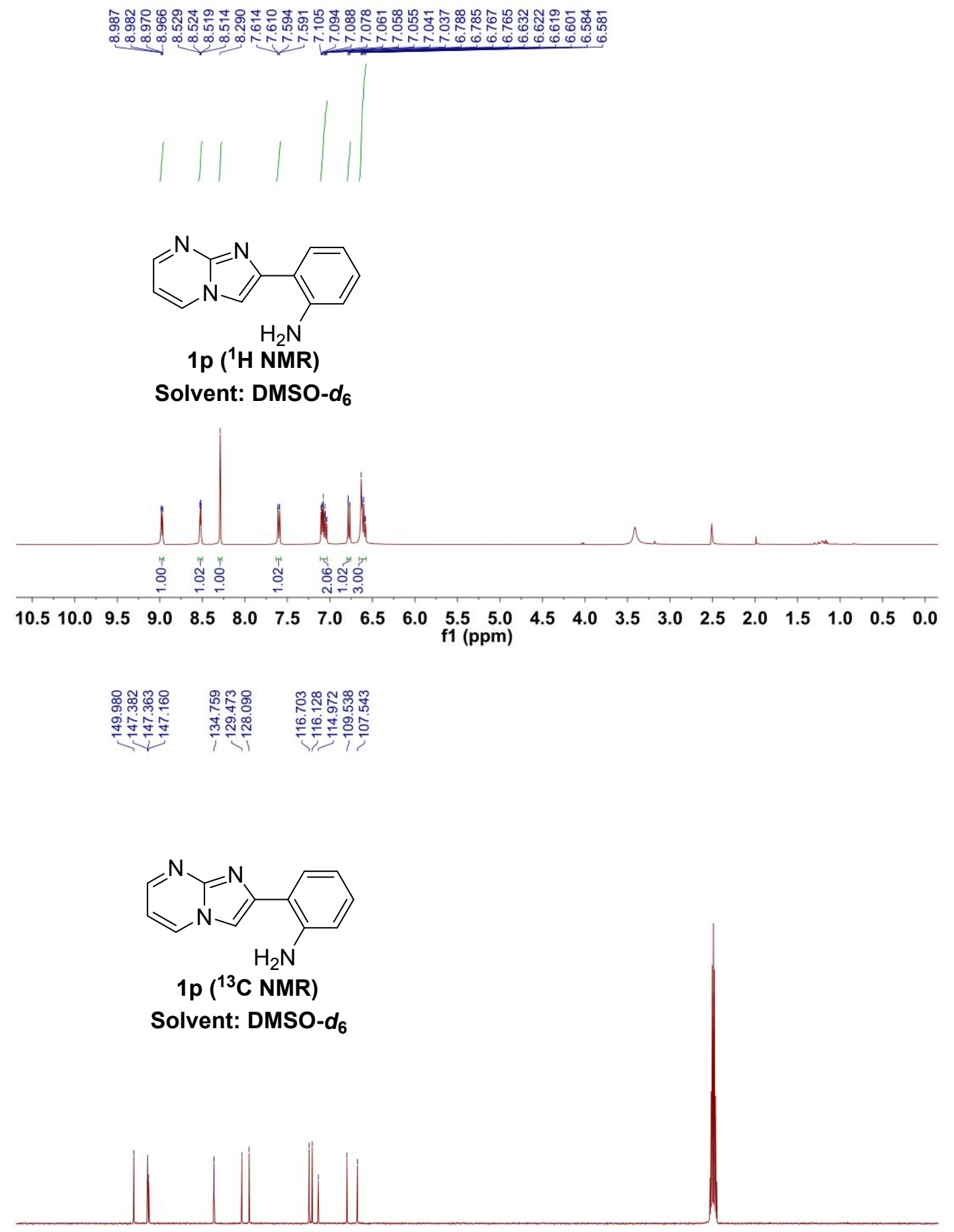

$\begin{array}{llllllllllllllllll}170 & 160 & 150 & 140 & 130 & 120 & 110 & 100 & \underset{90}{91(\mathrm{ppm})} & \begin{aligned} 80 \\ \mathrm{fo}\end{aligned} & 60 & 50 & 40 & 30 & 20 & 10 & 0\end{array}$ 


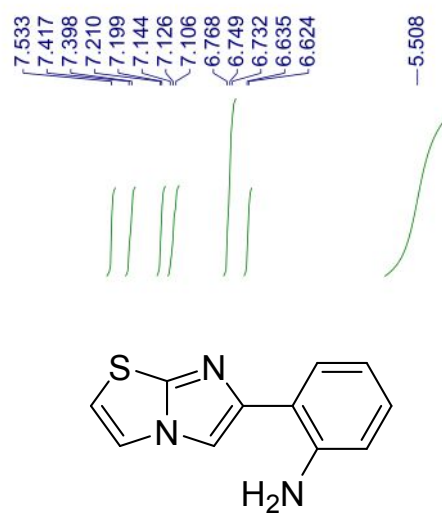

1q ( ${ }^{1} \mathrm{H}$ NMR)

Solvent: $\mathrm{CDCl}_{3}$

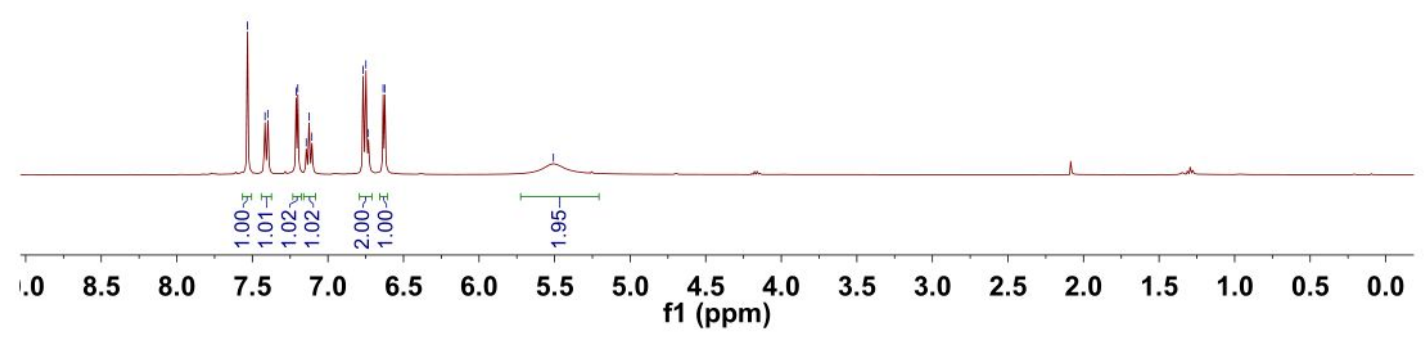

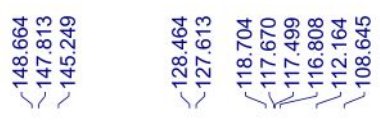

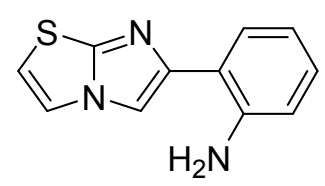

1q ( ${ }^{13} \mathrm{C}$ NMR)

Solvent: $\mathrm{CDCl}_{3}$

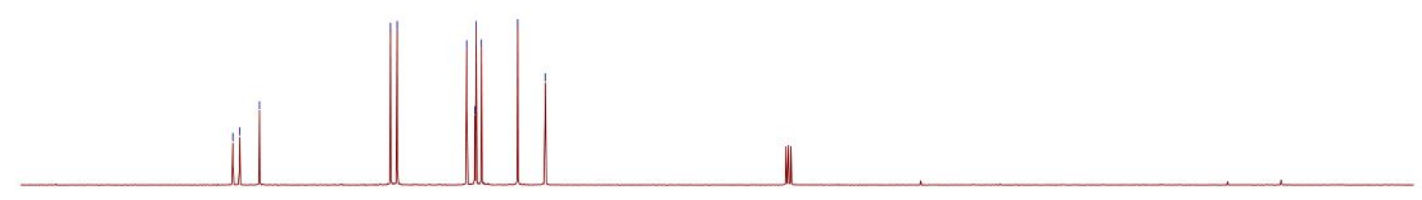

$\begin{array}{llllllllllllllllll}170 & 160 & 150 & 140 & 130 & 120 & 110 & 100 & \begin{array}{c}90 \\ \mathrm{f} 1(\mathrm{ppm})\end{array} & 70 & 60 & 50 & 40 & 30 & 20 & 10 & 0\end{array}$ 


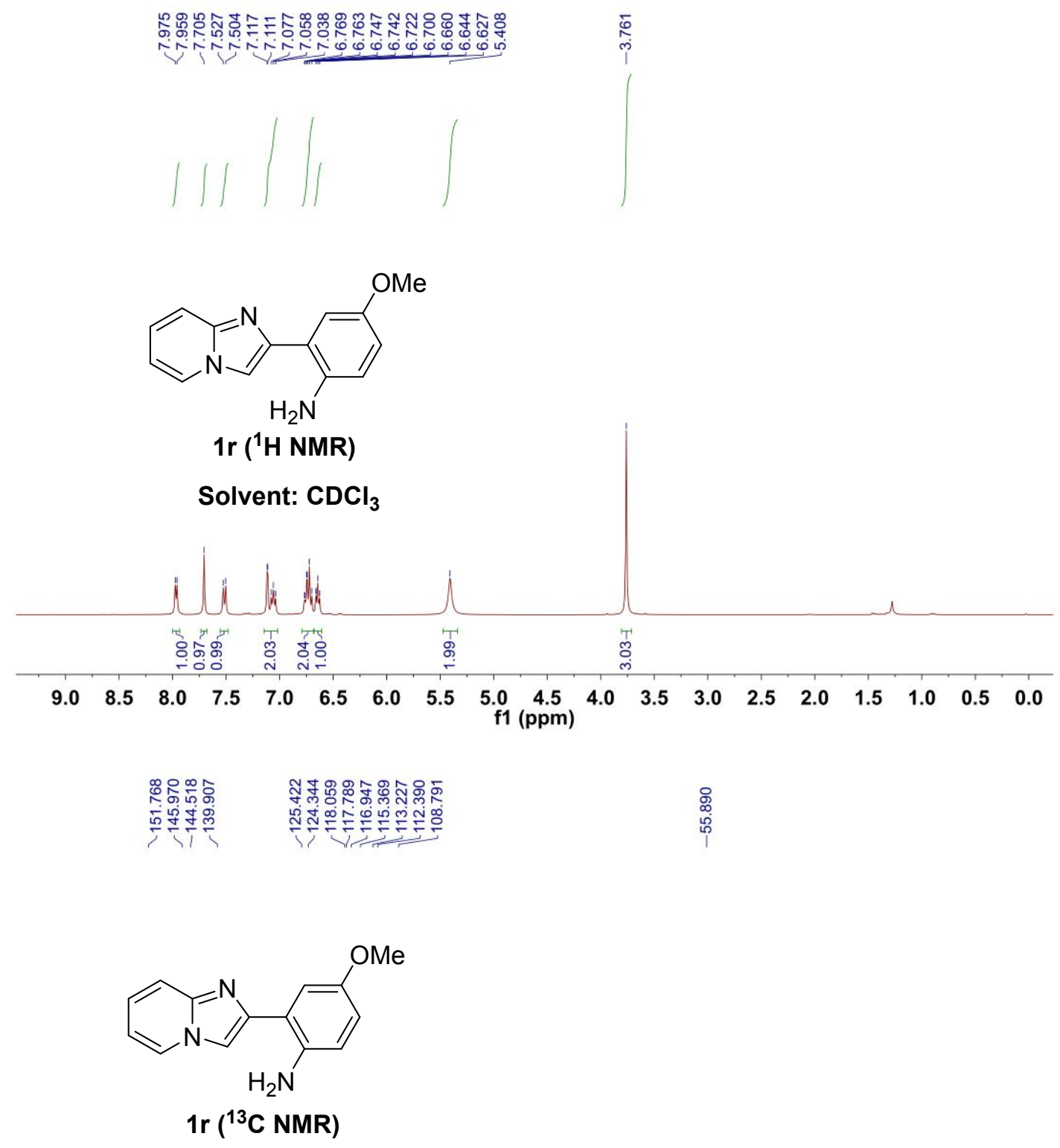

Solvent: $\mathrm{CDCl}_{3}$

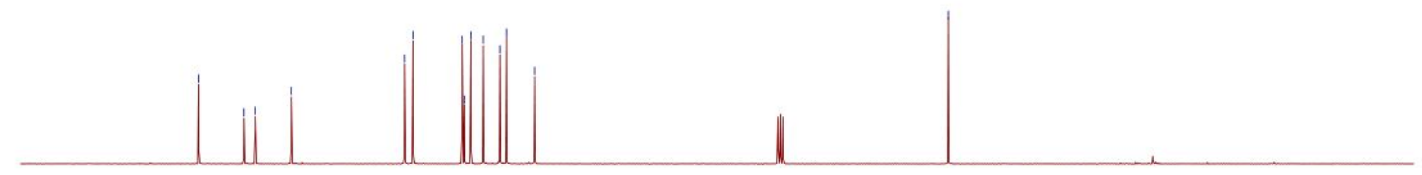

$\begin{array}{llllllllllllllllll}170 & 160 & 150 & 140 & 130 & 120 & 110 & 100 & \underset{f 1}{90}(\mathrm{ppm}) & 80 & 70 & 60 & 50 & 40 & 30 & 20 & 10 & 0\end{array}$ 

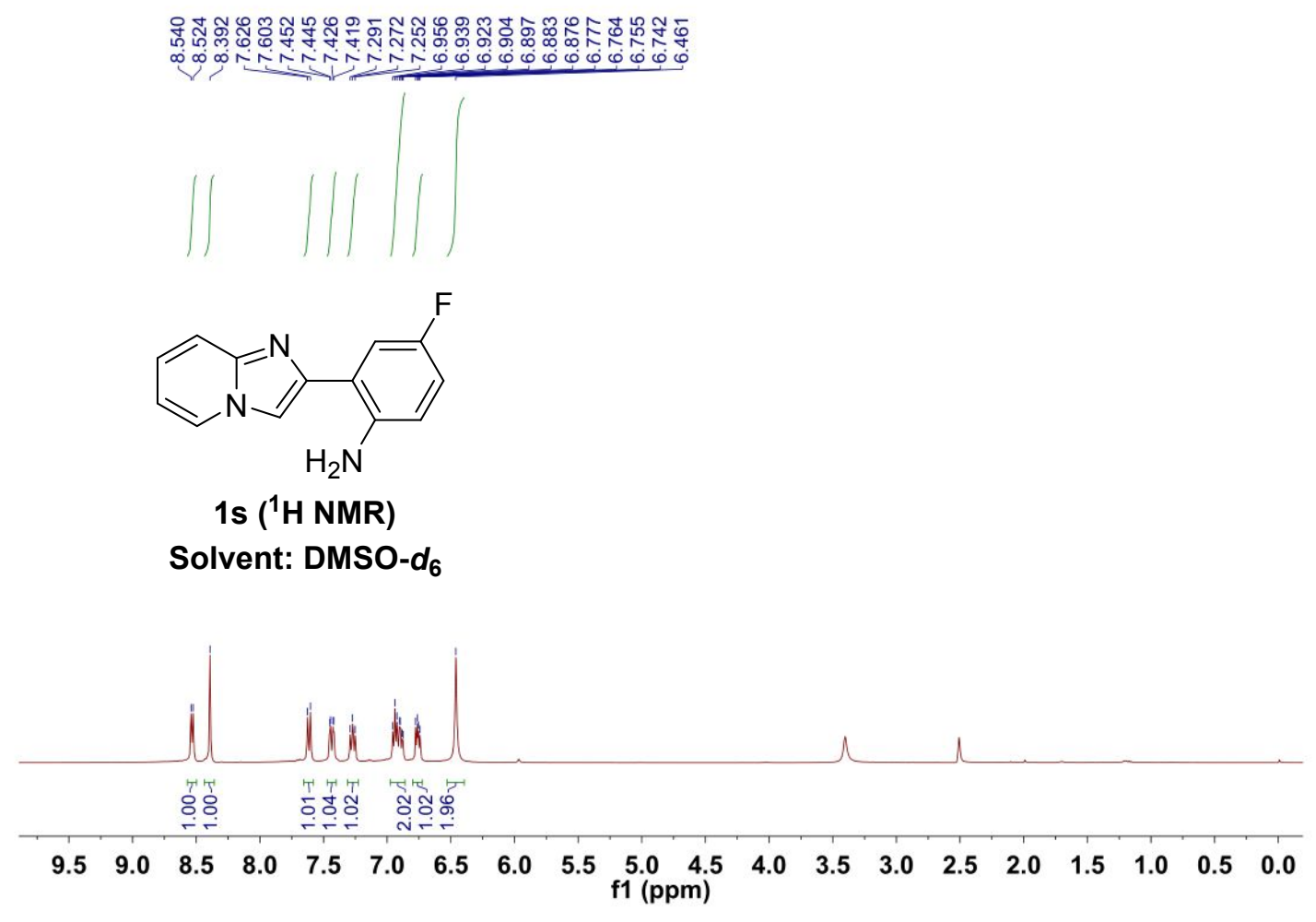

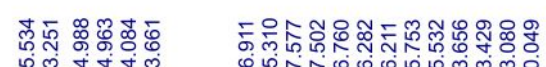

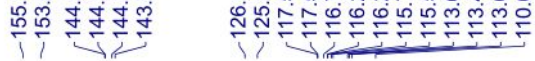<smiles>Nc1ccc(F)cc1-c1cn2ccccc2n1</smiles>

1s ( ${ }^{13} \mathrm{C}$ NMR)

Solvent: DMSO- $d_{6}$

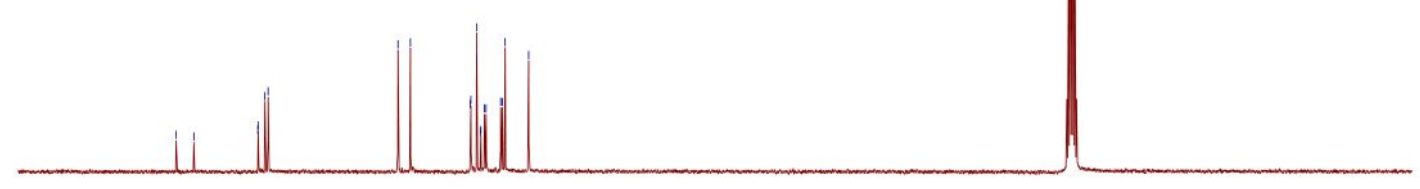

$\begin{array}{llllllllllllllllll}170 & 160 & 150 & 140 & 130 & 120 & 110 & 100 & \begin{array}{c}90 \\ \mathrm{f} 1(\mathrm{ppm})\end{array} & 70 & 60 & 50 & 40 & 30 & 20 & 10 & 0\end{array}$ 
<smiles>Nc1ccc(Cl)cc1-c1cn2ccccc2n1</smiles>

1t ( ${ }^{1} \mathrm{H}$ NMR)

Solvent: $\mathrm{CDCl}_{3}$

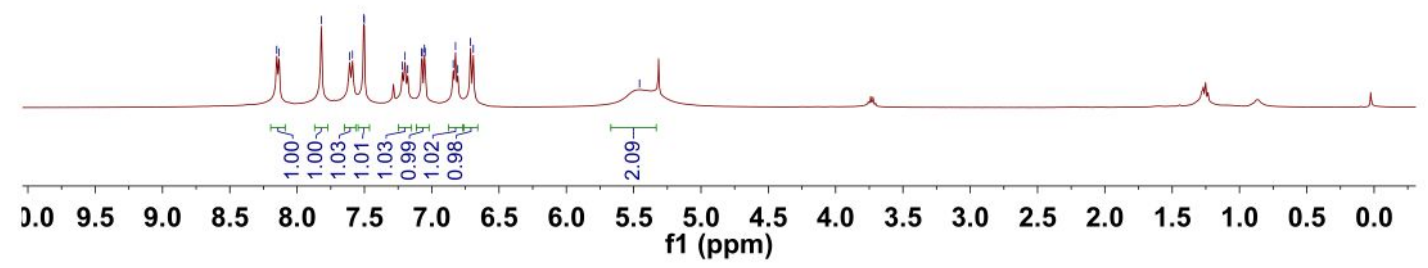

ఊ⿻弋

莳寺<smiles>Nc1ccc(Cl)cc1-c1cn2ccccc2n1</smiles>

1t ( ${ }^{13} \mathrm{C}$ NMR)

Solvent: $\mathrm{CDCl}_{3}$

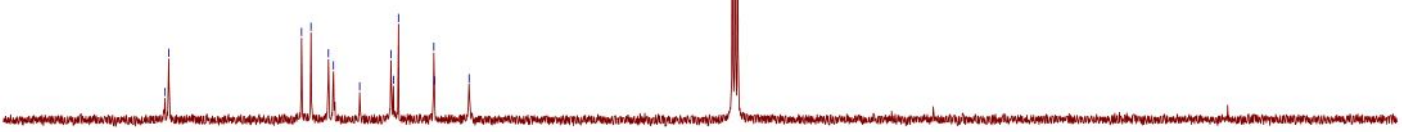

$\begin{array}{lllllllllllllllll}160 & 150 & 140 & 130 & 120 & 110 & 100 & 90 \underset{\mathrm{f} 1(\mathrm{ppm})}{80} & 70 & 60 & 50 & 40 & 30 & 20 & 10 & 0\end{array}$ 


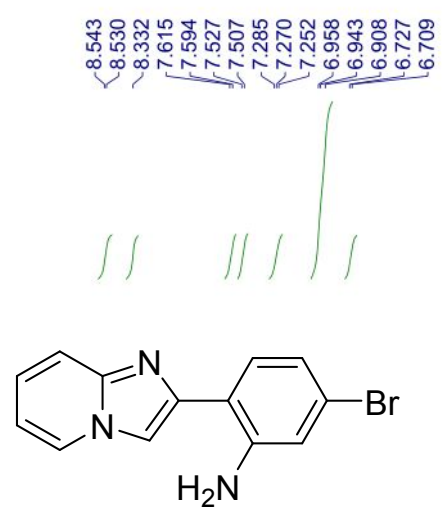

1u ( ${ }^{1} \mathrm{H}$ NMR)

Solvent: DMSO-d $d_{6}$

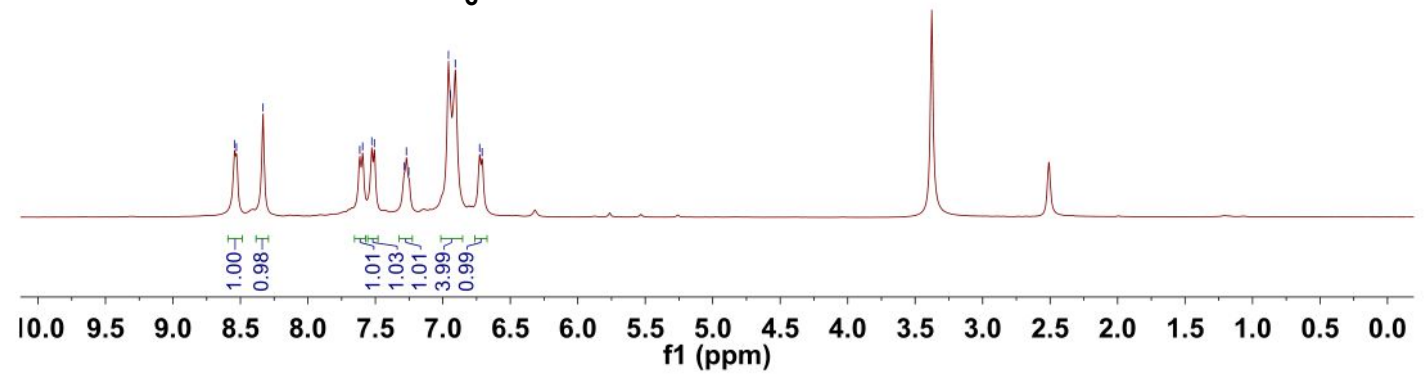

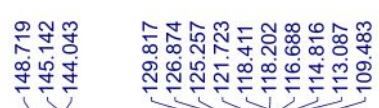

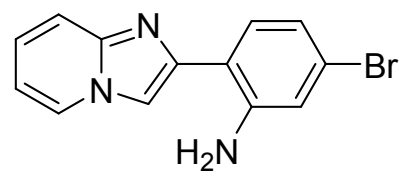

1u $\left({ }^{13} \mathrm{C}\right.$ NMR)

Solvent: DMSO- $d_{6}$

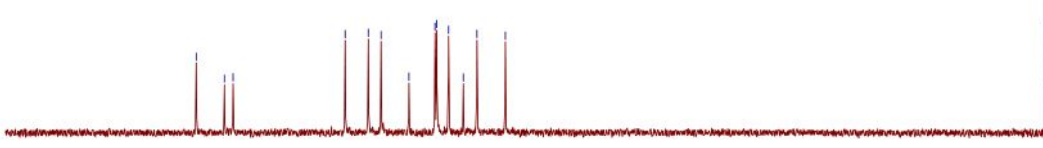

$\begin{array}{llllllllllllllllll}170 & 160 & 150 & 140 & 130 & 120 & 110 & 100 & \begin{array}{c}90 \\ \mathrm{f} 1(\mathrm{ppm})\end{array} & 70 & 60 & 50 & 40 & 30 & 20 & 10 & 0\end{array}$ 

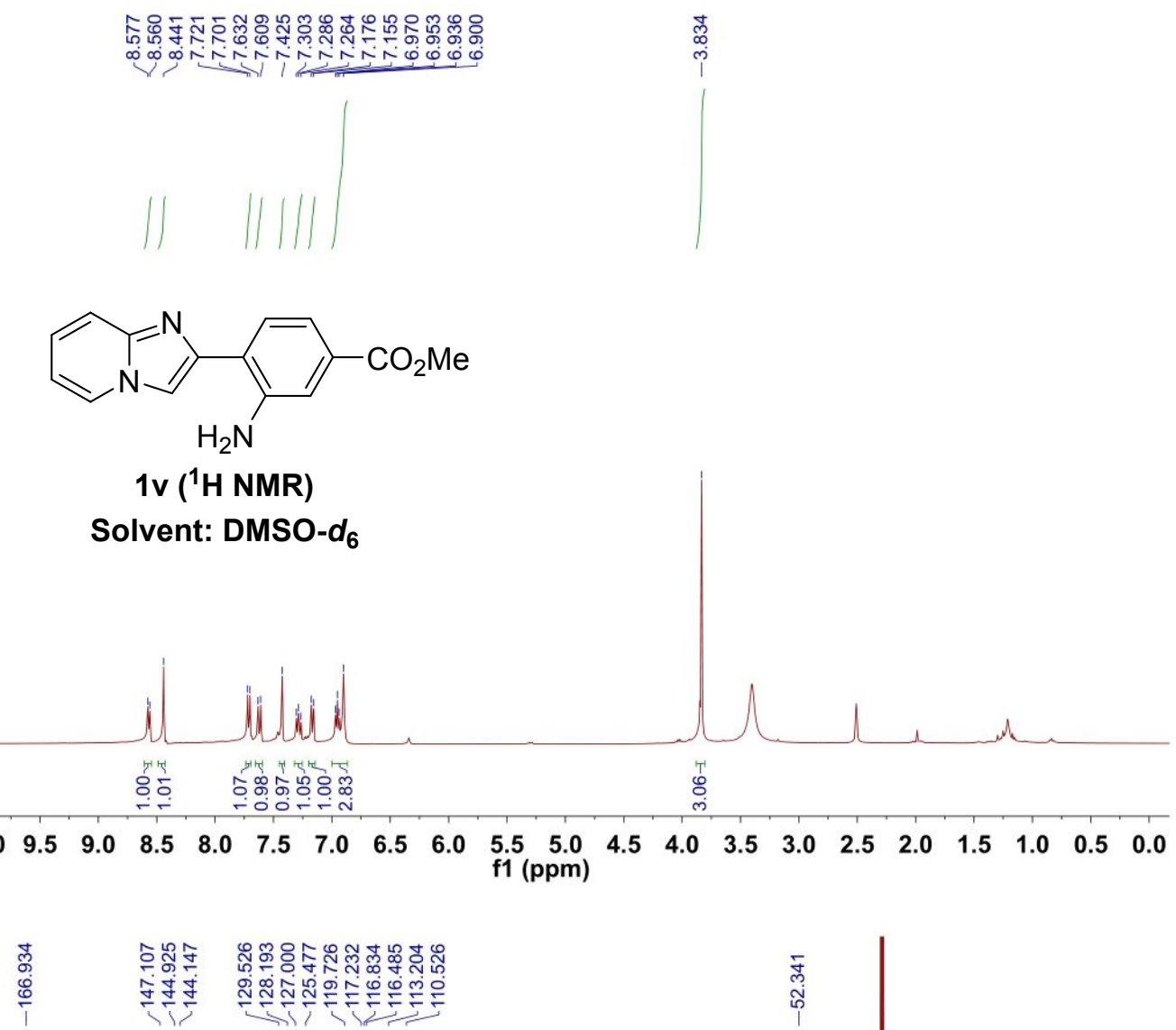

ฐ্̃<smiles>CC(=O)c1ccc(-c2cn3ccccc3n2)c(N)c1</smiles>

1v ( ${ }^{13} \mathrm{C}$ NMR)

Solvent: DMSO-d $d_{6}$

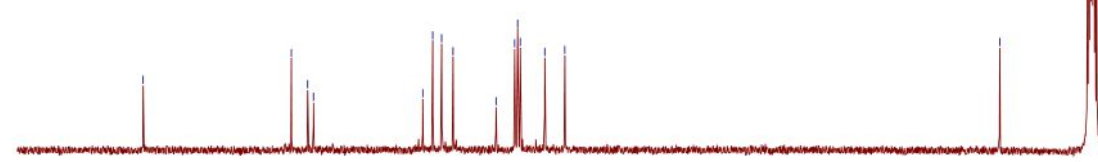

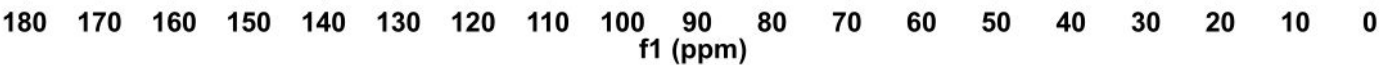



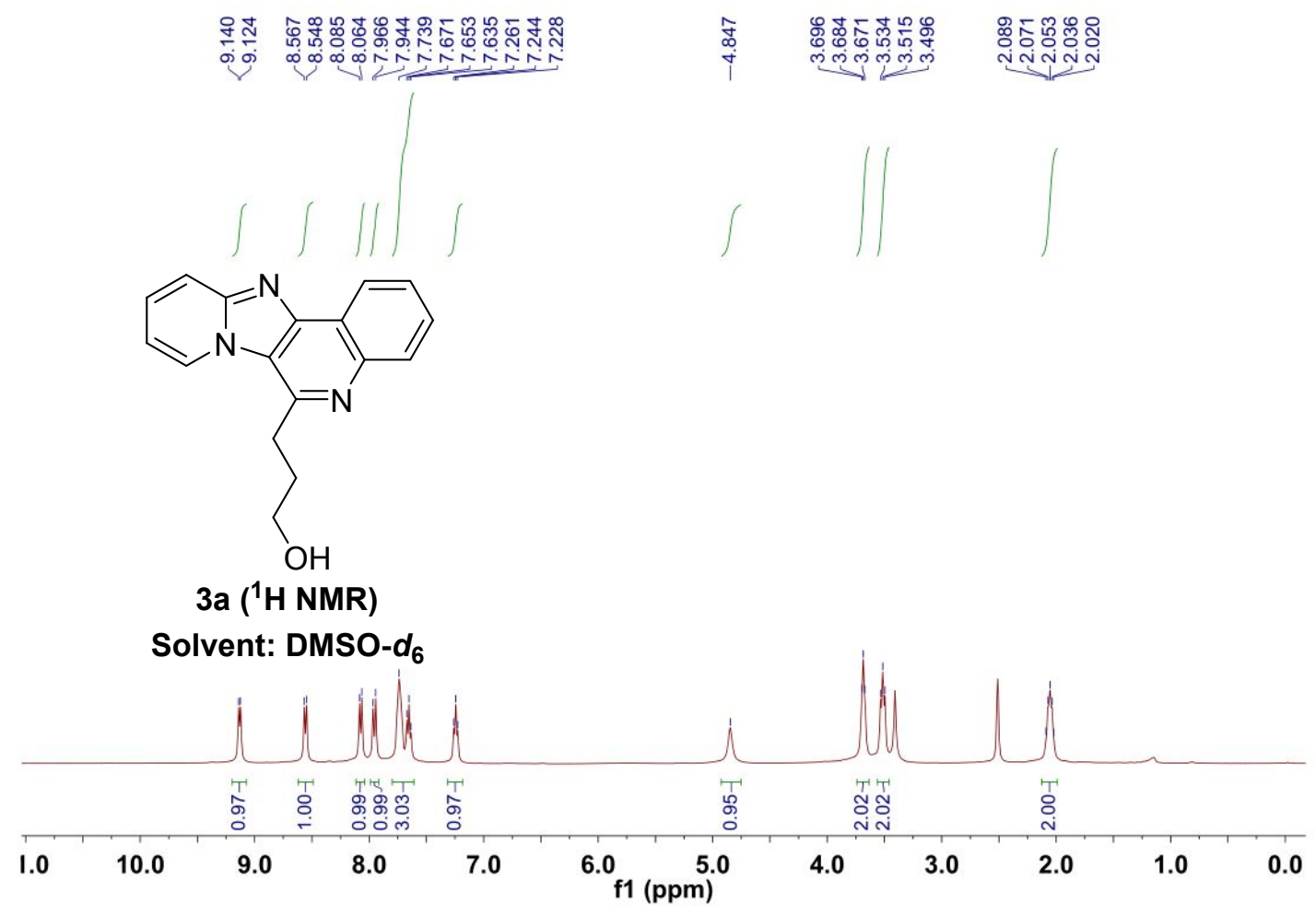

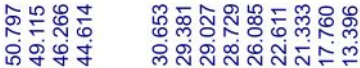

는

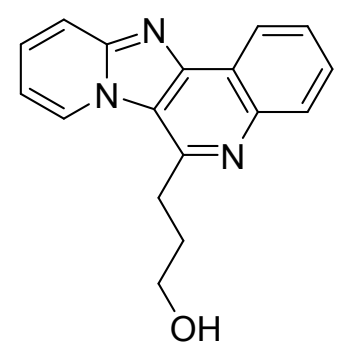

3a $\left({ }^{13} \mathrm{C}\right.$ NMR)

Solvent: DMSO-d

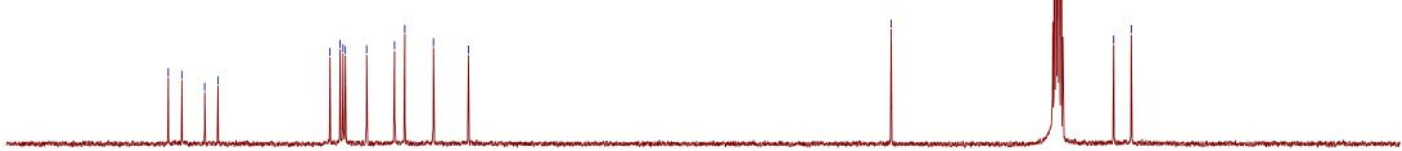

$\begin{array}{llllllllllllllllll}70 & 160 & 150 & 140 & 130 & 120 & 110 & 100 & \underset{90}{\mathrm{f} 1(\mathrm{ppm})} & \begin{array}{l}80 \\ (\mathrm{ppm})\end{array} & 60 & 50 & 40 & 30 & 20 & 10 & 0\end{array}$ 


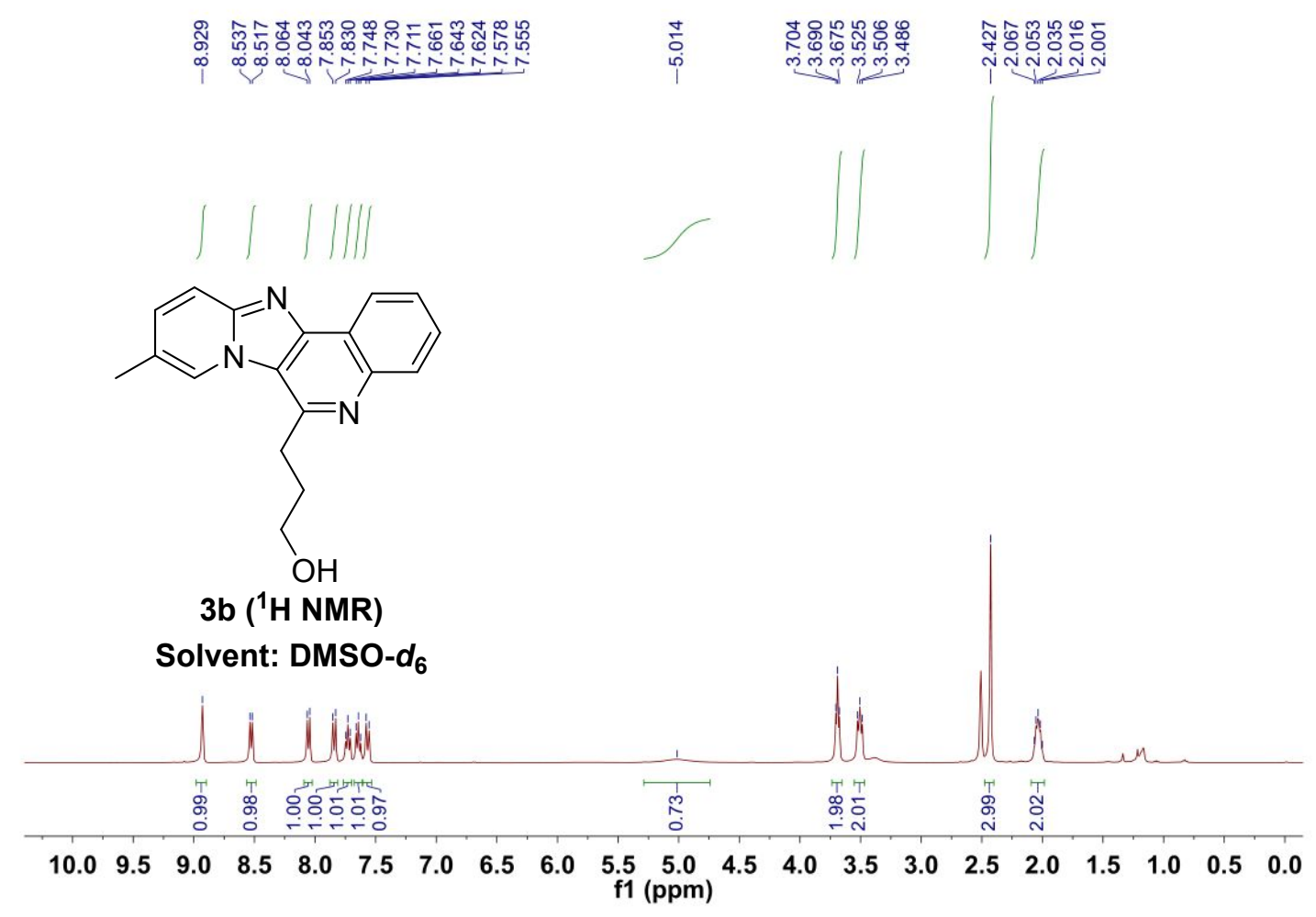

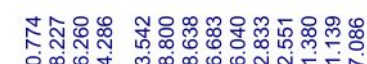

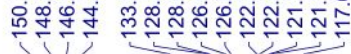

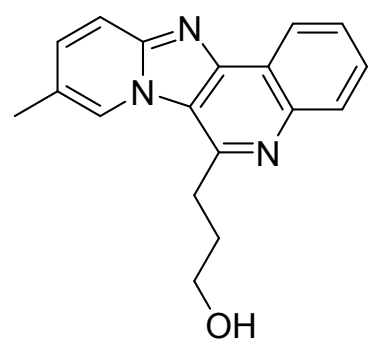

$3 b\left({ }^{13} \mathrm{C}\right.$ NMR)

Solvent: DMSO- $d_{6}$
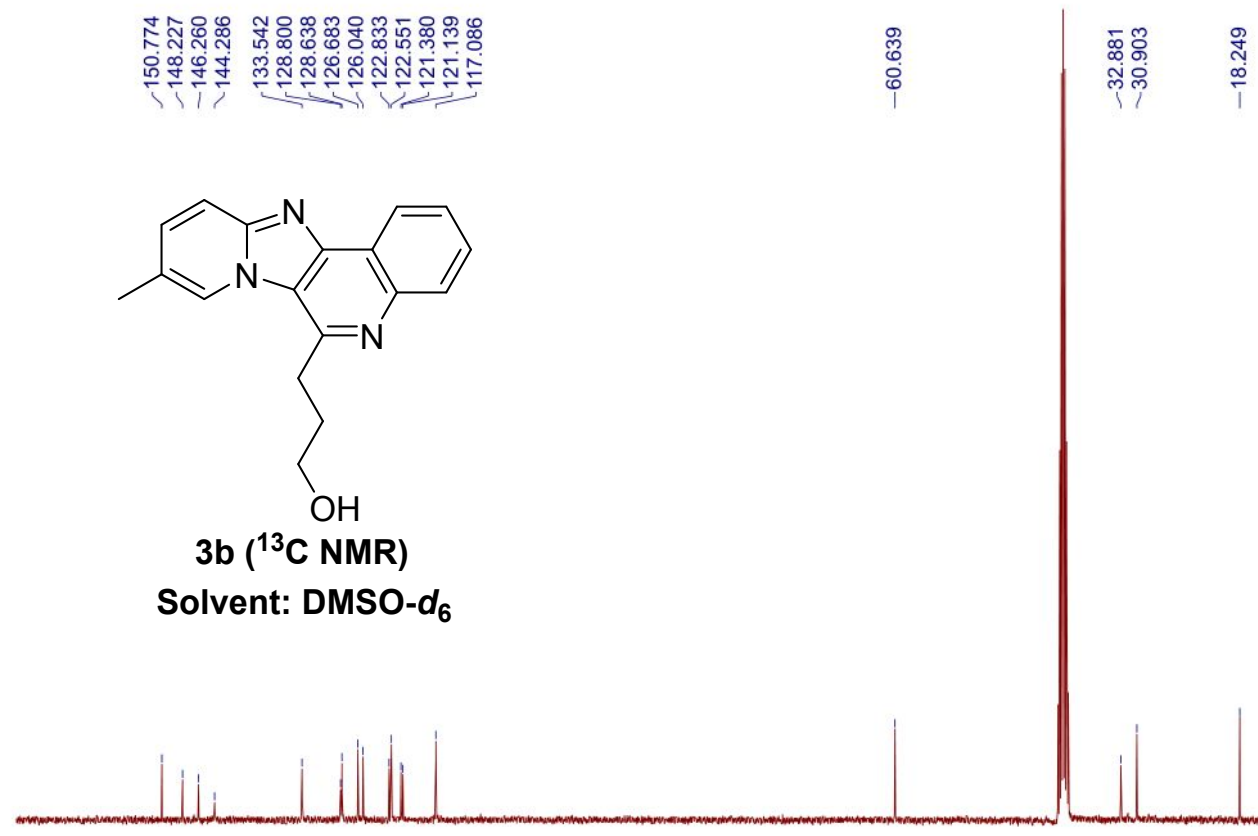

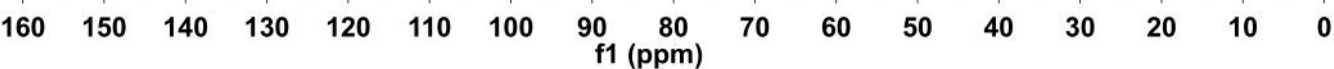




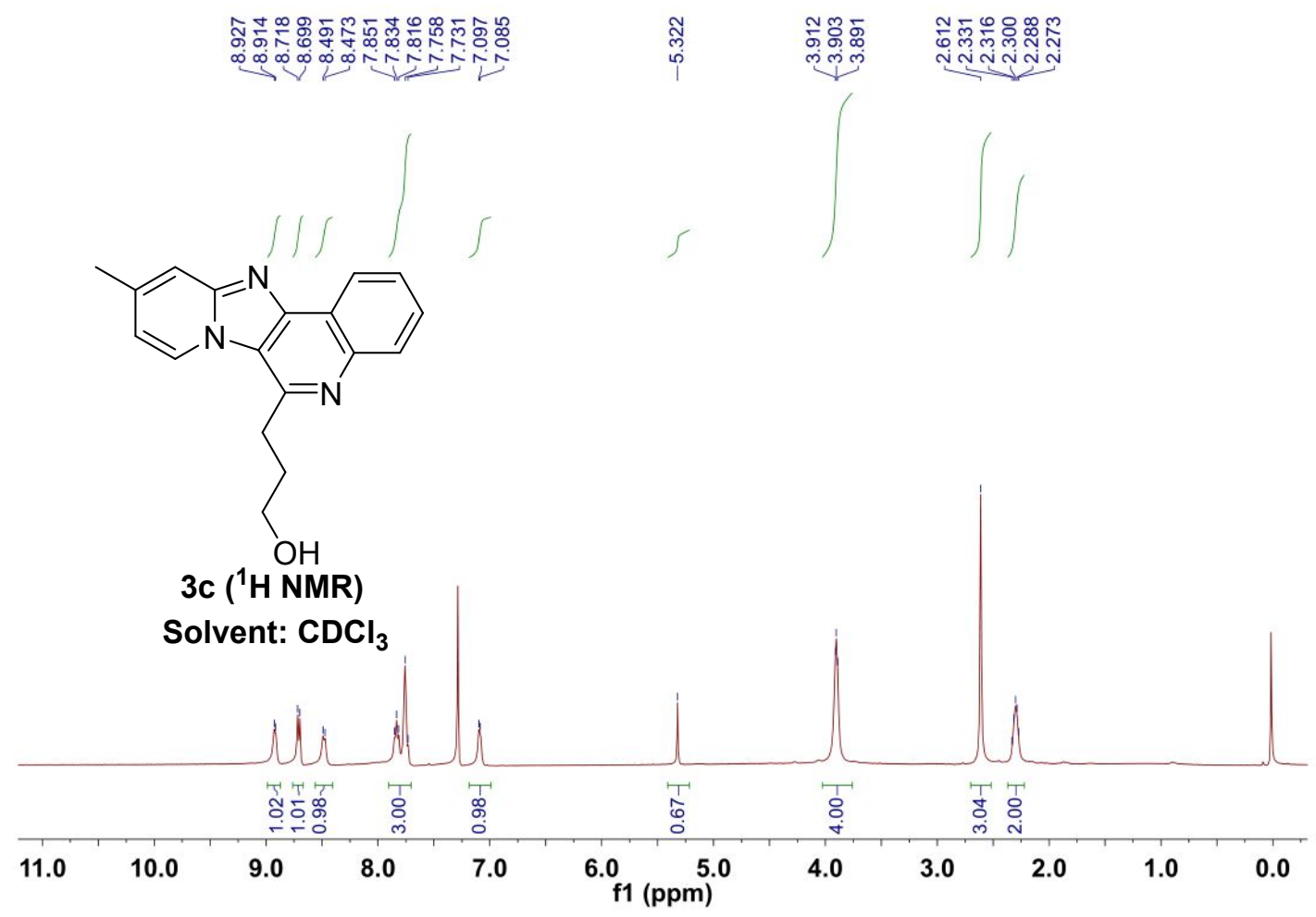

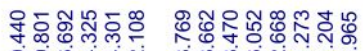

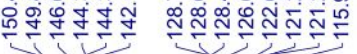

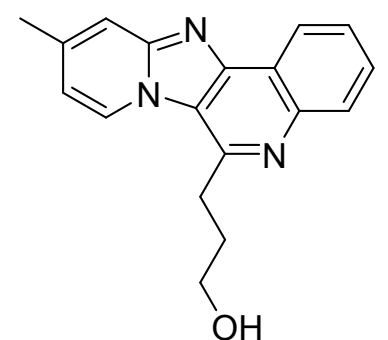

$3 c\left({ }^{13} \mathrm{C}\right.$ NMR)

Solvent: DMSO- $d_{6}$

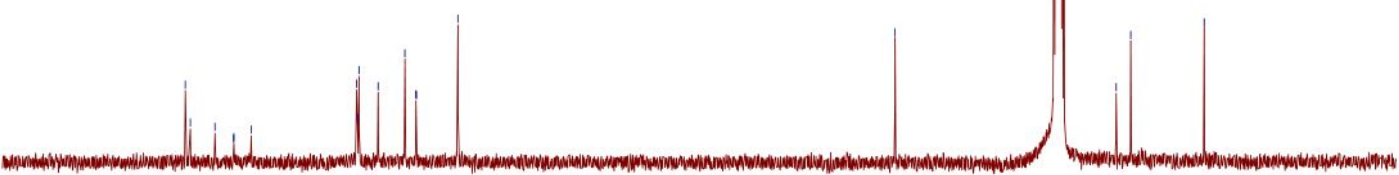

170160

$150 \quad 140 \quad 130$

$\begin{array}{lll}120 & 110 & 100\end{array}$

$\begin{array}{lrllllllll}90 & 80 & 70 & 60 & 50 & 40 & 30 & 20 & 10 & 0\end{array}$ 


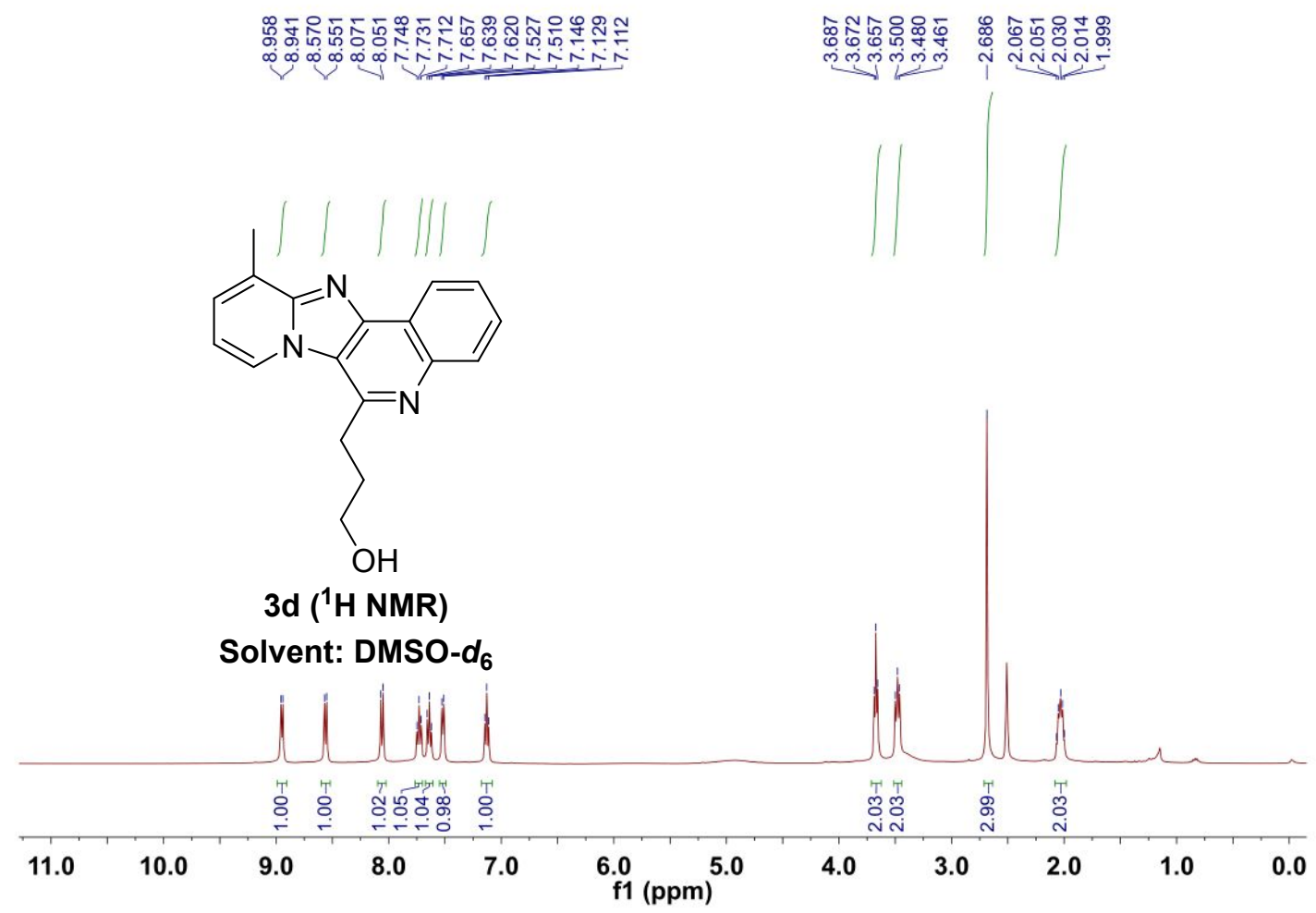

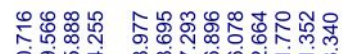

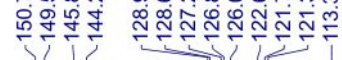

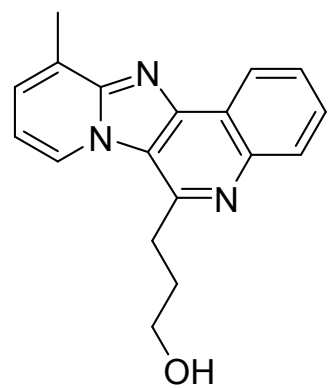

3d ( ${ }^{13} \mathrm{C}$ NMR)

Solvent: DMSO-d $d_{6}$

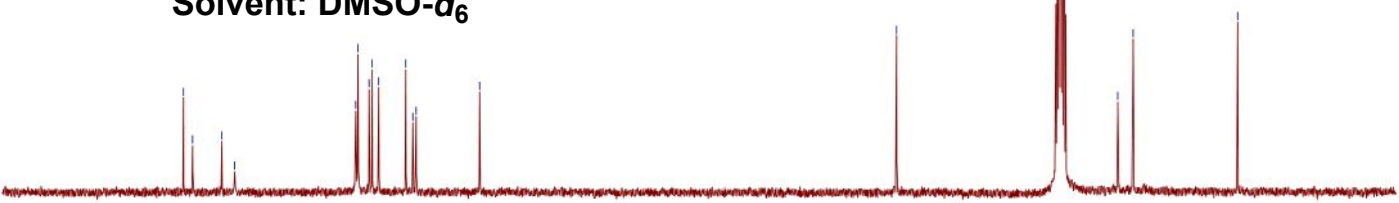

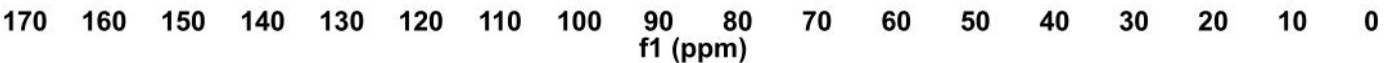




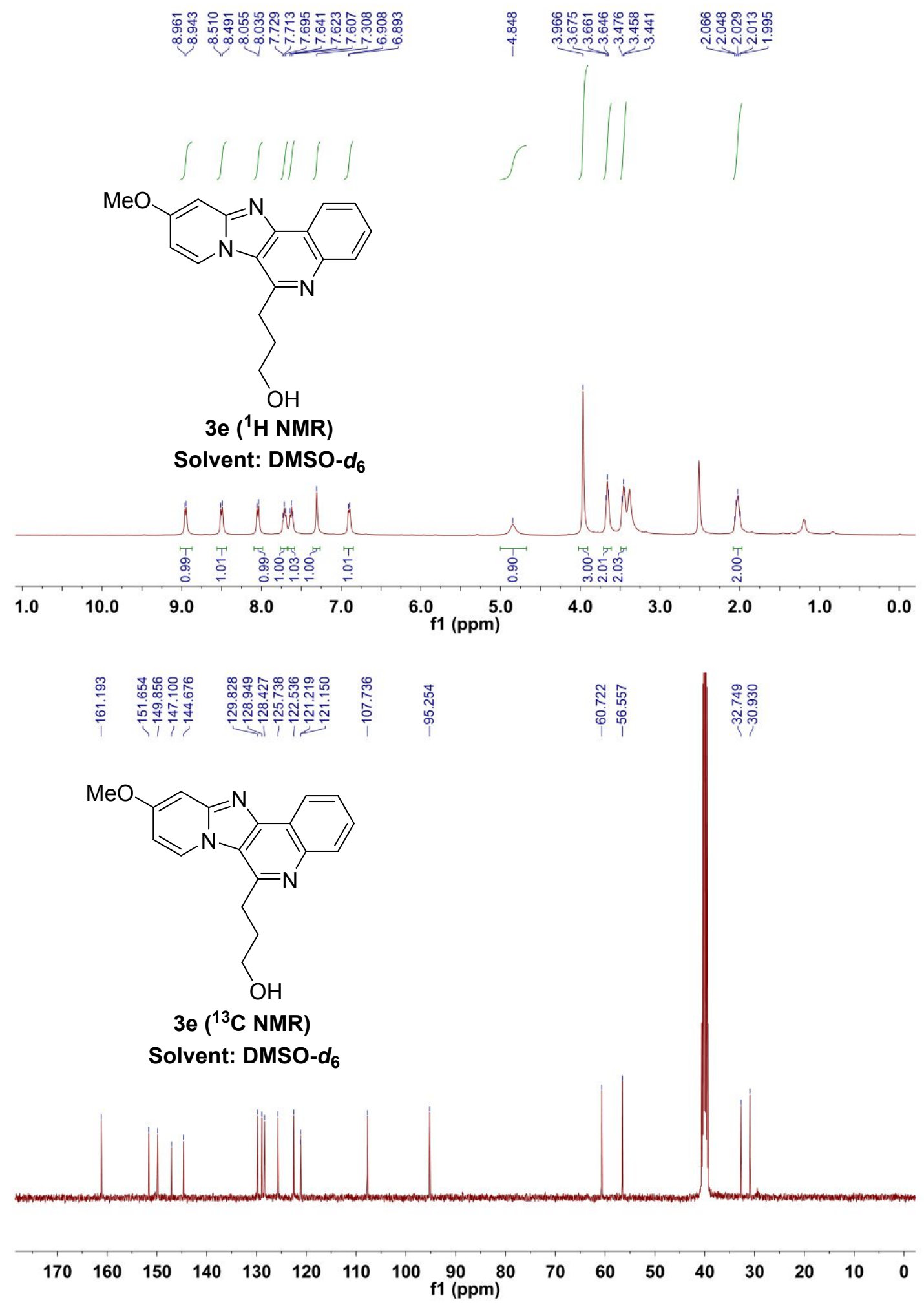




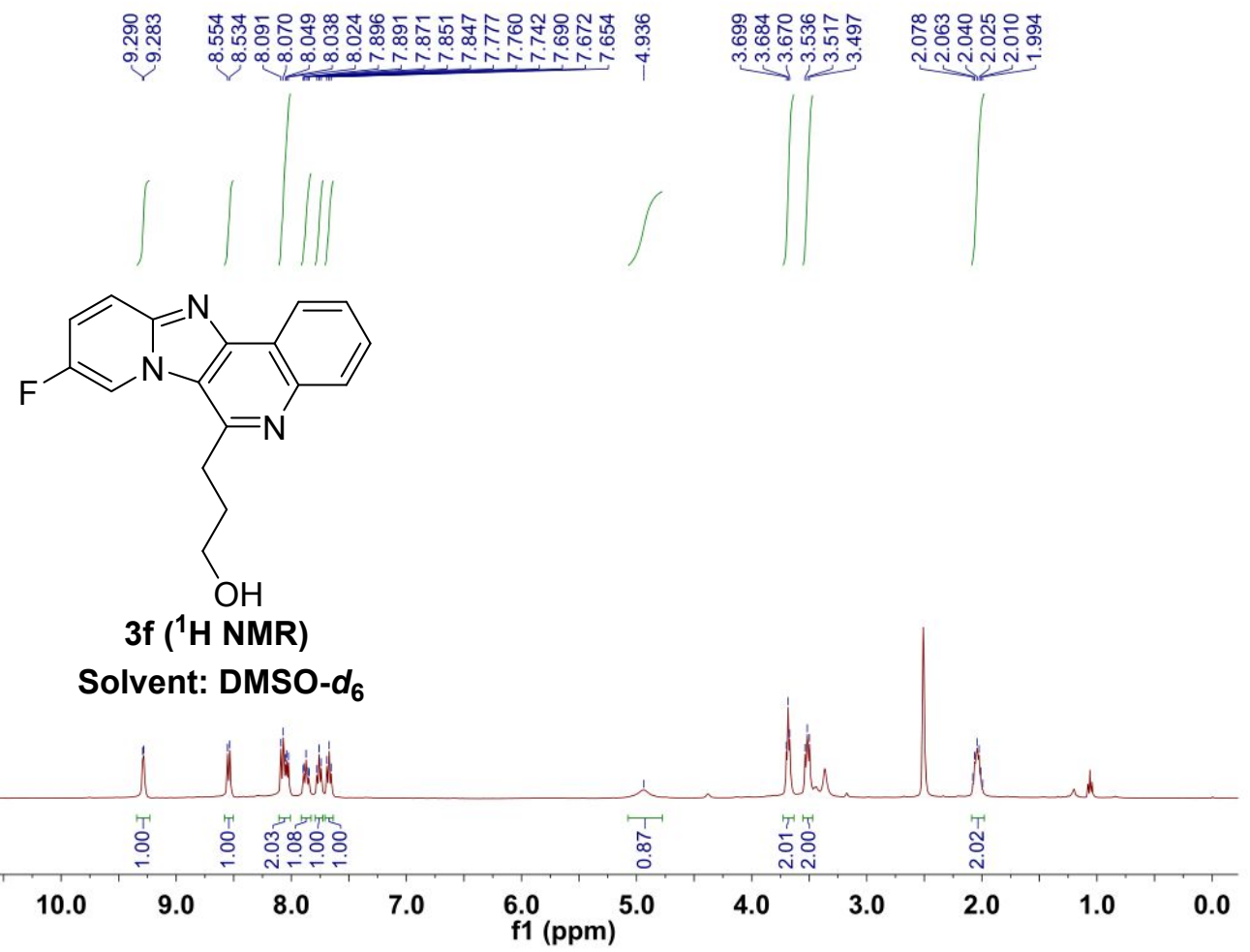

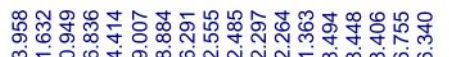

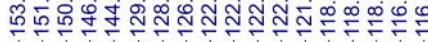

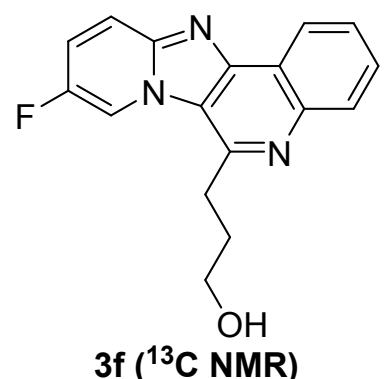

Solvent: DMSO-d $d_{6}$

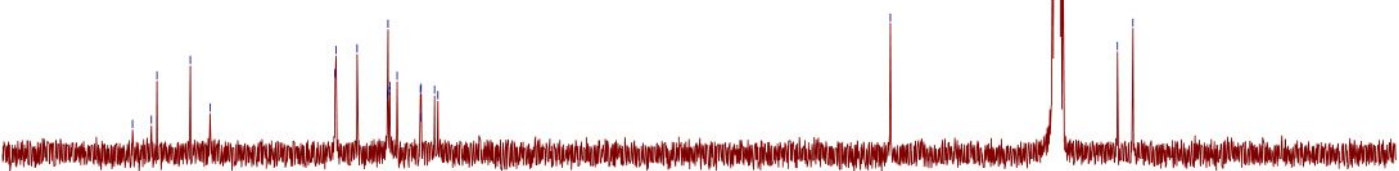

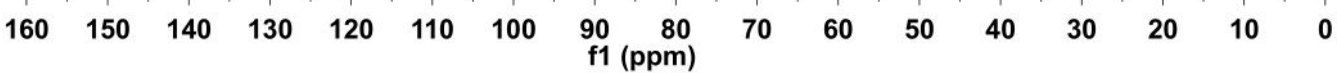



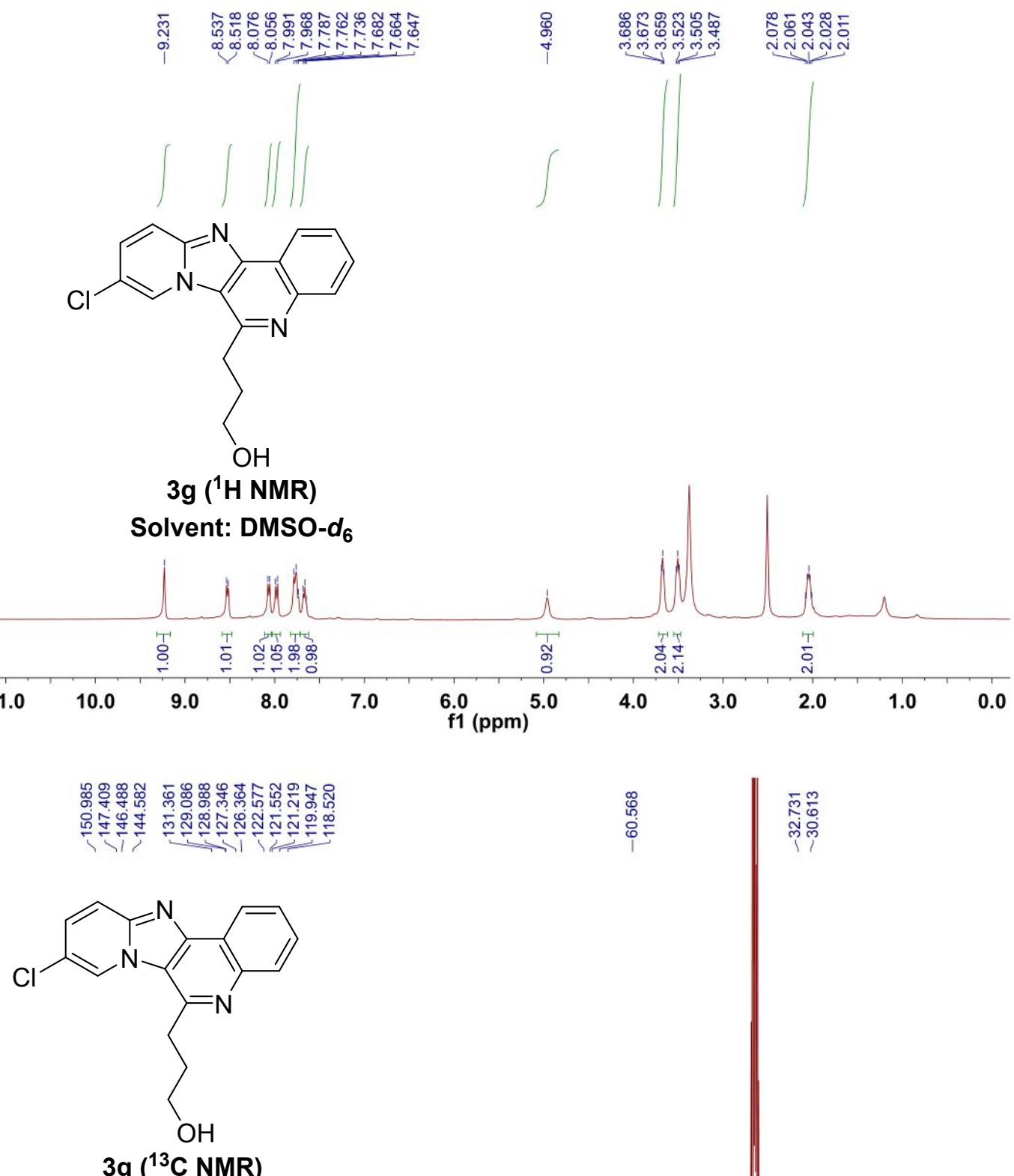

Solvent: DMSO- $d_{6}$

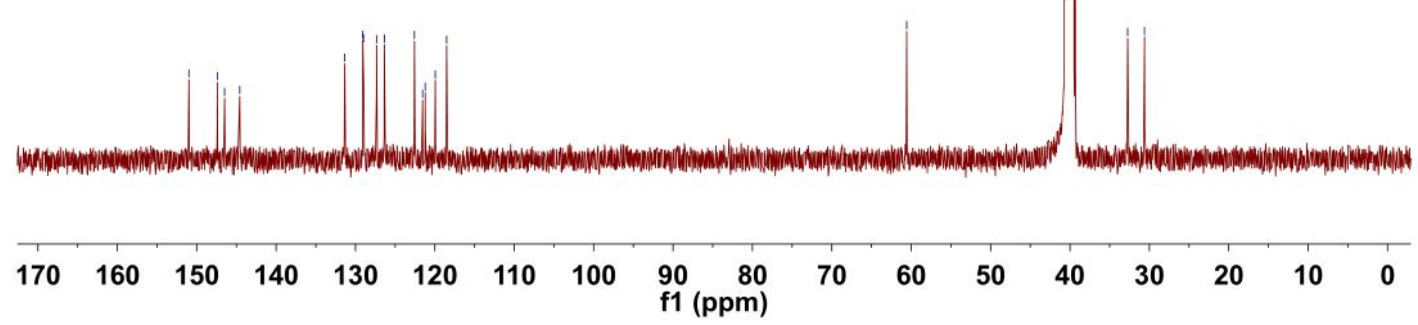




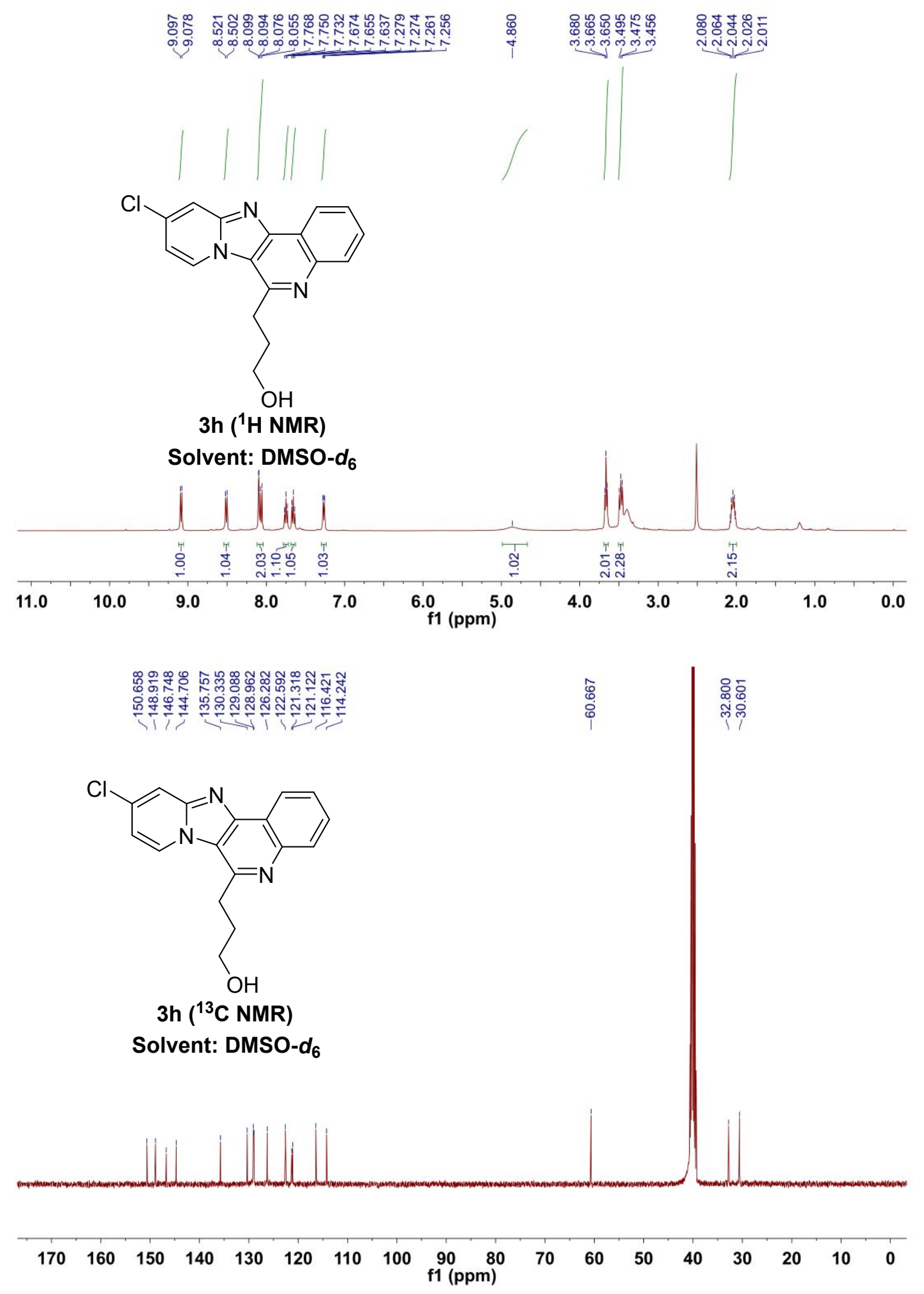




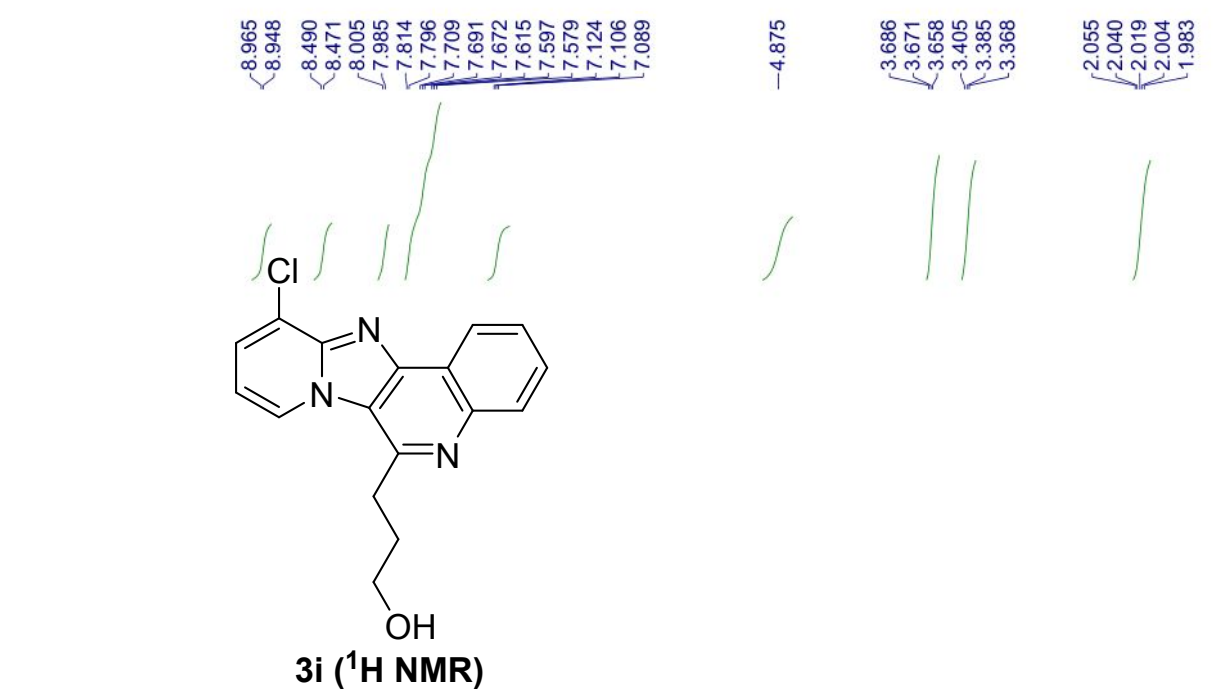

Solvent: DMSO- $d_{6}$

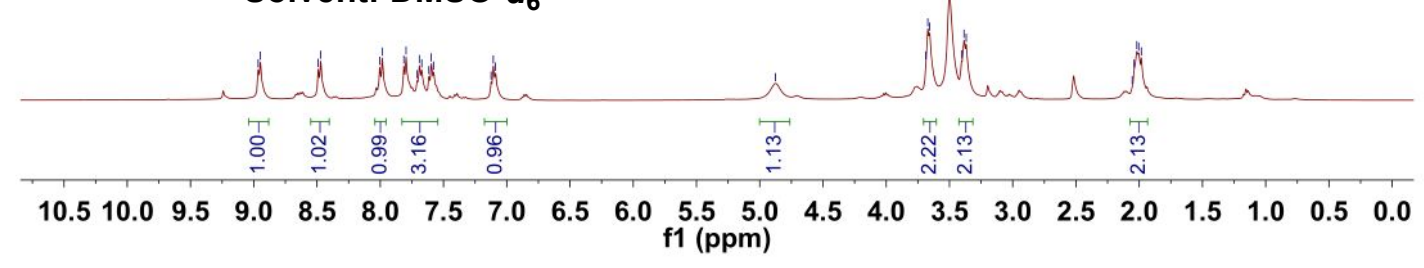

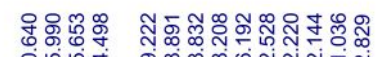

它垨告过
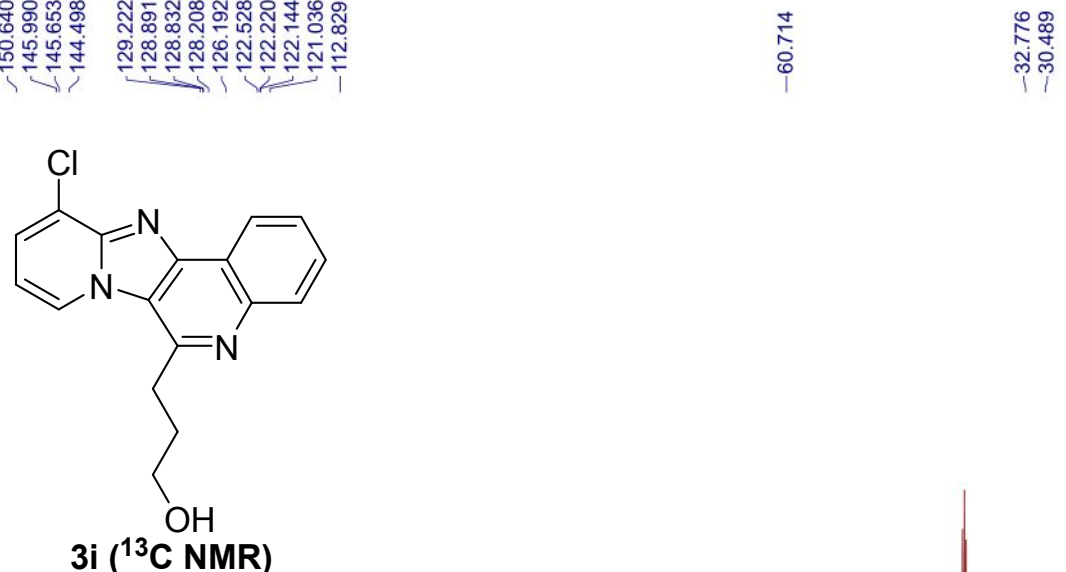

Solvent: DMSO- $d_{6}$

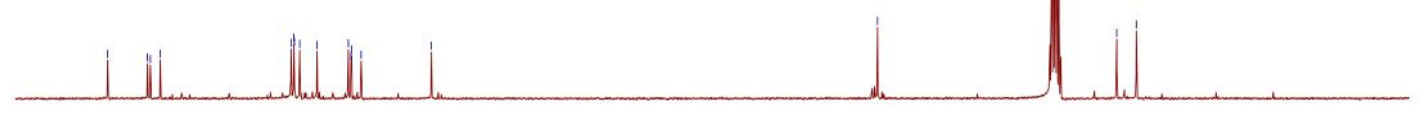

$\begin{array}{lllllllllllllllll}60 & 150 & 140 & 130 & 120 & 110 & 100 & 90 \underset{f 1}{(\mathrm{ppm})} & 70 & 60 & 50 & 40 & 30 & 20 & 10 & 0\end{array}$ 


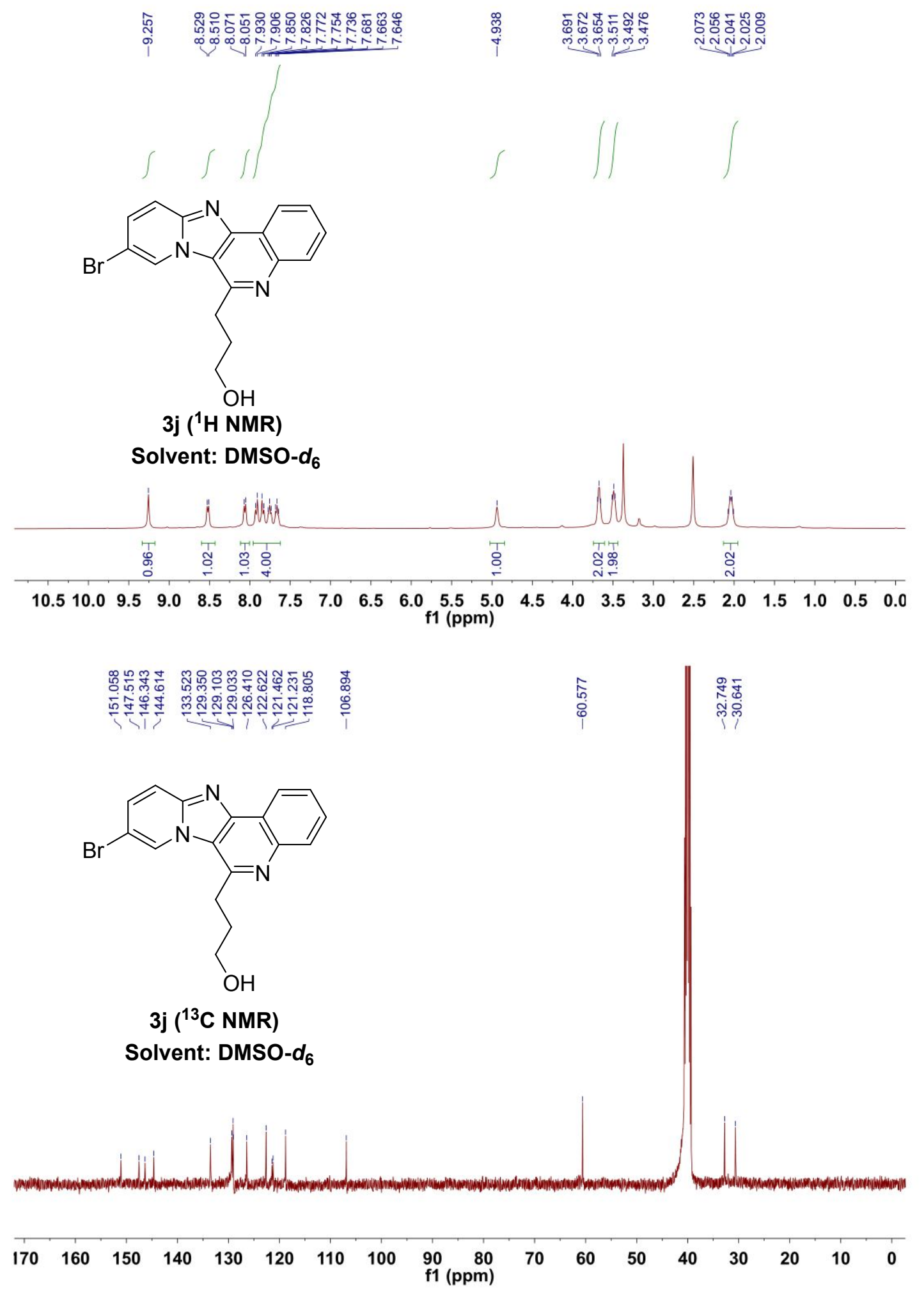




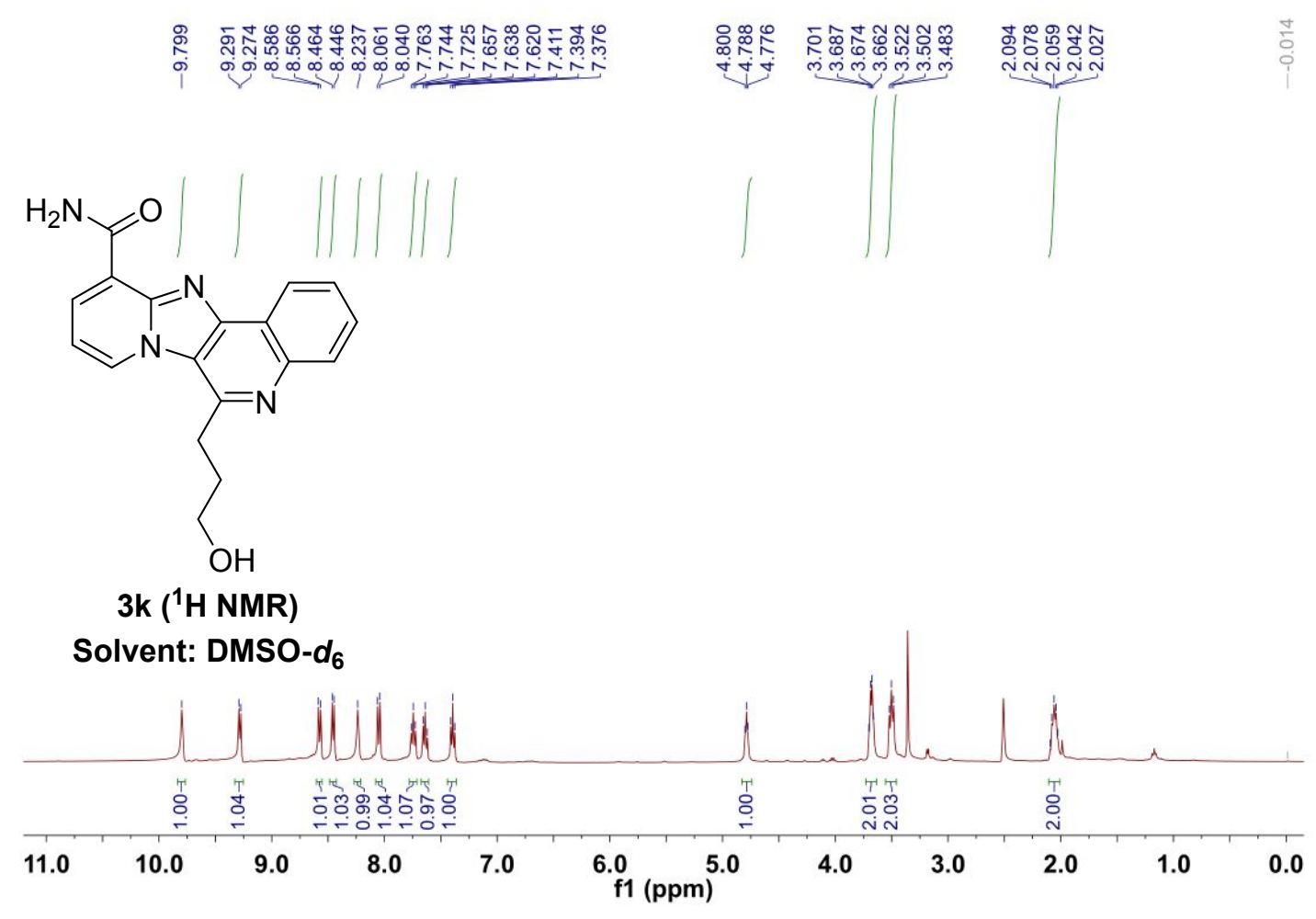

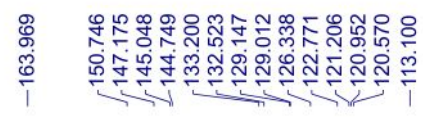

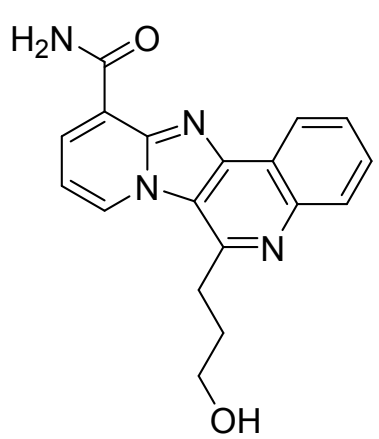

3k ( ${ }^{13} \mathrm{C}$ NMR)

Solvent: DMSO- $d_{6}$

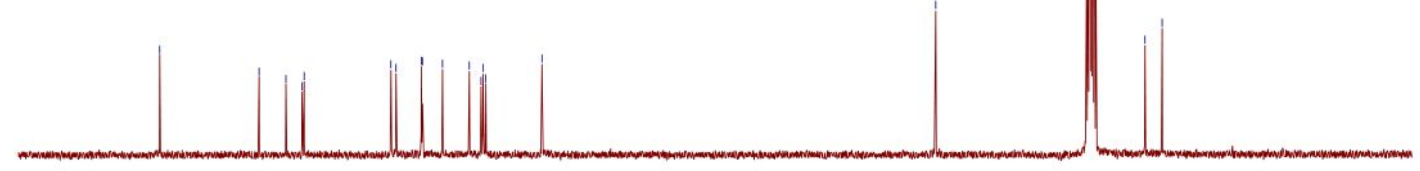

$\begin{array}{lllllllllllllllllllll}180 & 170 & 160 & 150 & 140 & 130 & 120 & 110 & 100 \underset{\mathrm{f} 1(\mathrm{ppm})}{90} & 80 & 70 & 60 & 50 & 40 & 30 & 20 & 10 & 0\end{array}$ 


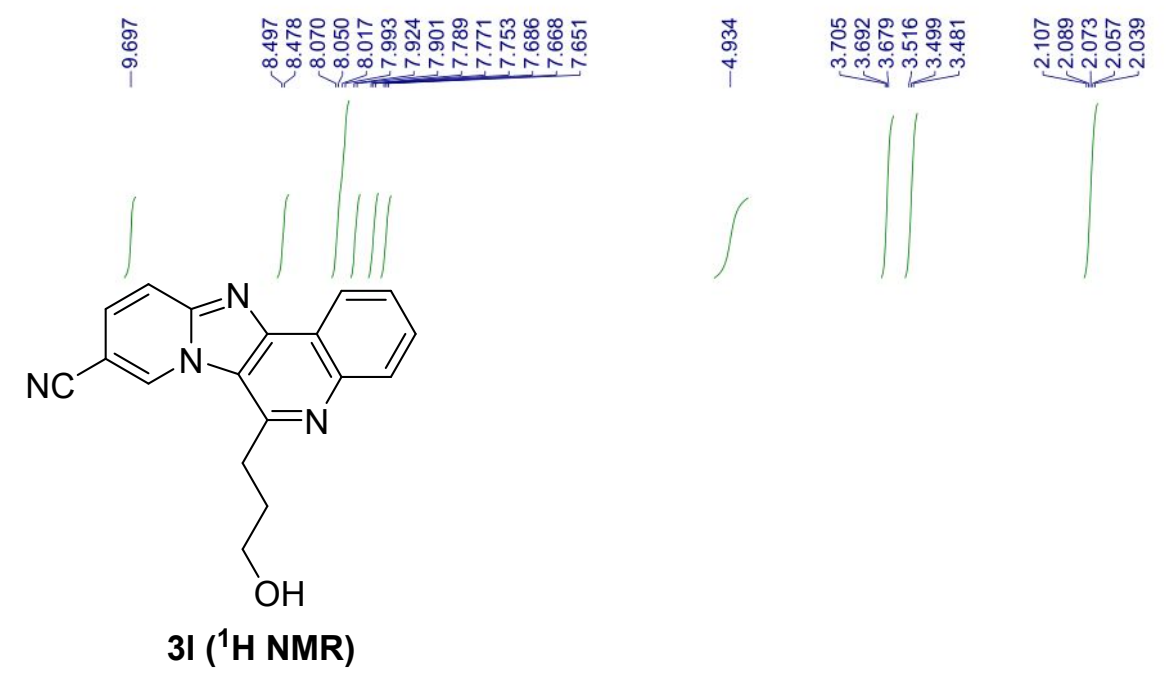

Solvent: DMSO- $d_{6}$

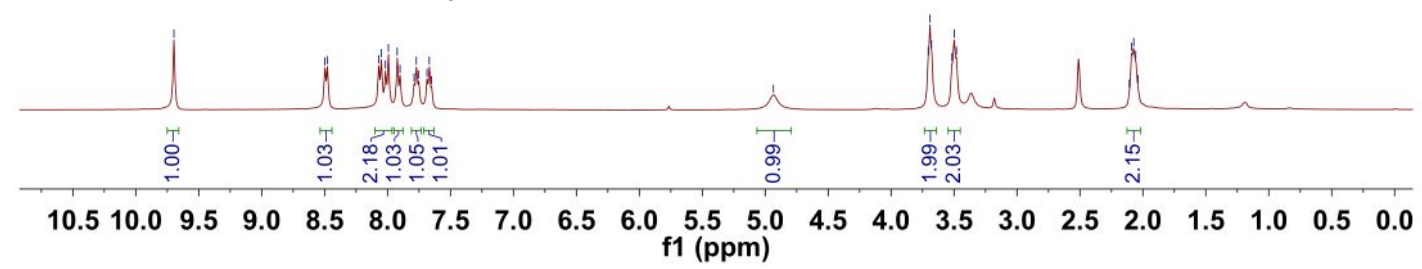

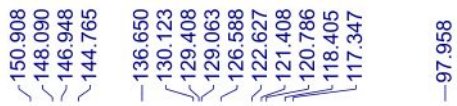<smiles>N#Cc1ccc2nc3c4ccccc4nc(CCCO)c3n2c1</smiles>

3 ( ( ${ }^{13} \mathrm{C}$ NMR)

Solvent: DMSO-d $d_{6}$

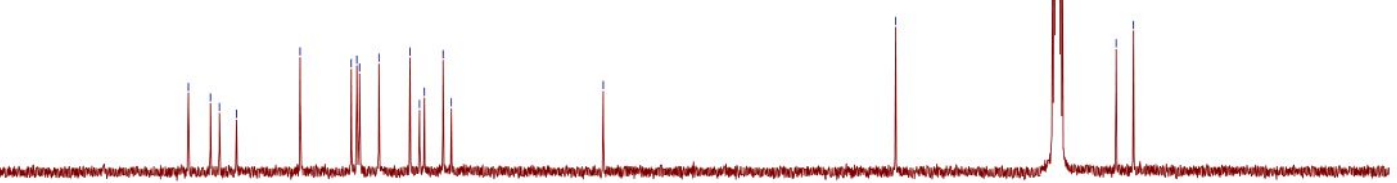

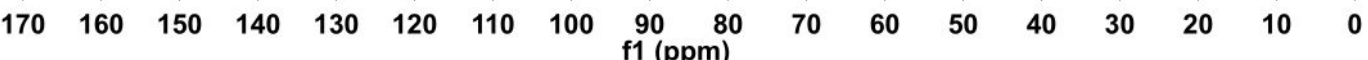



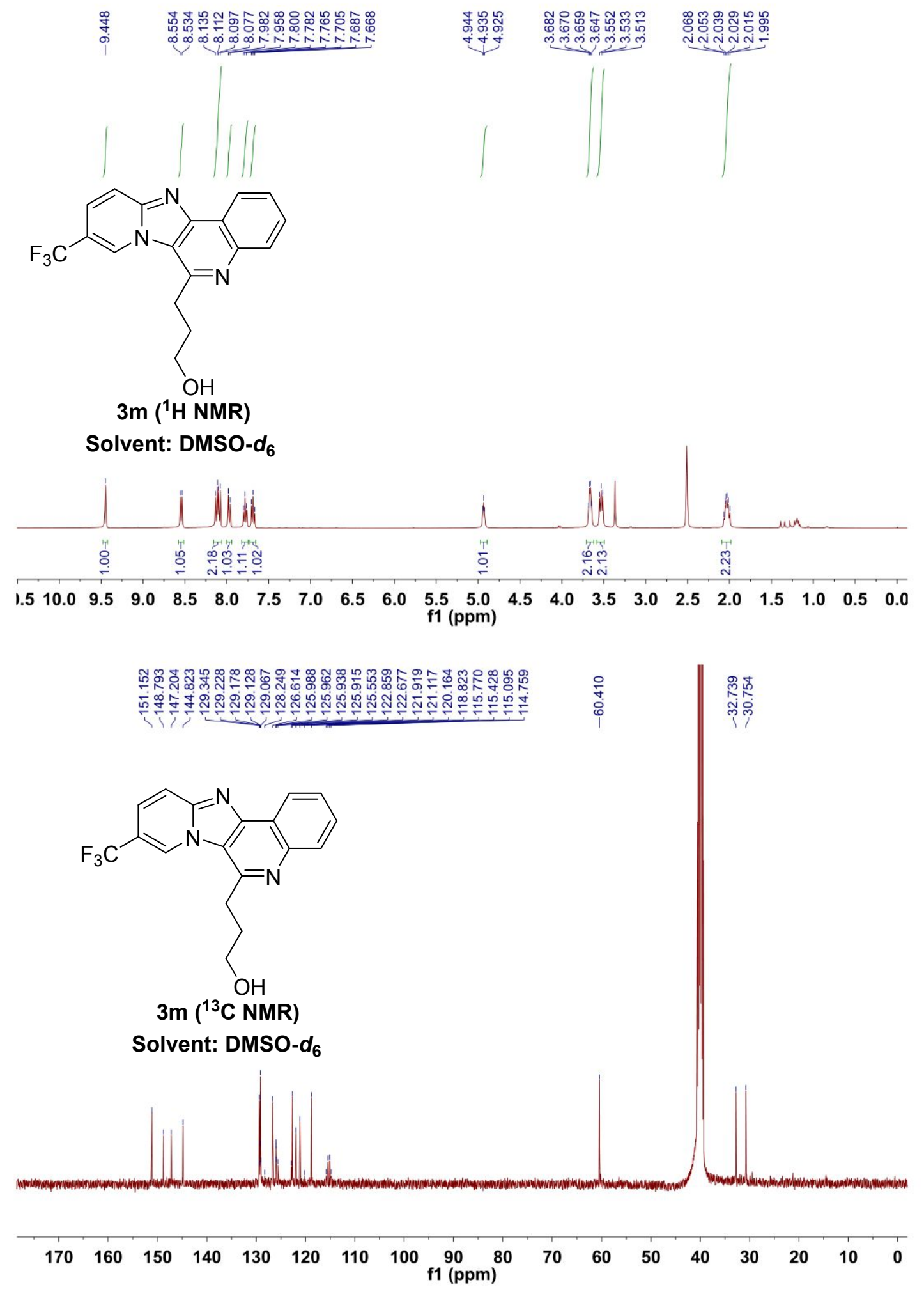

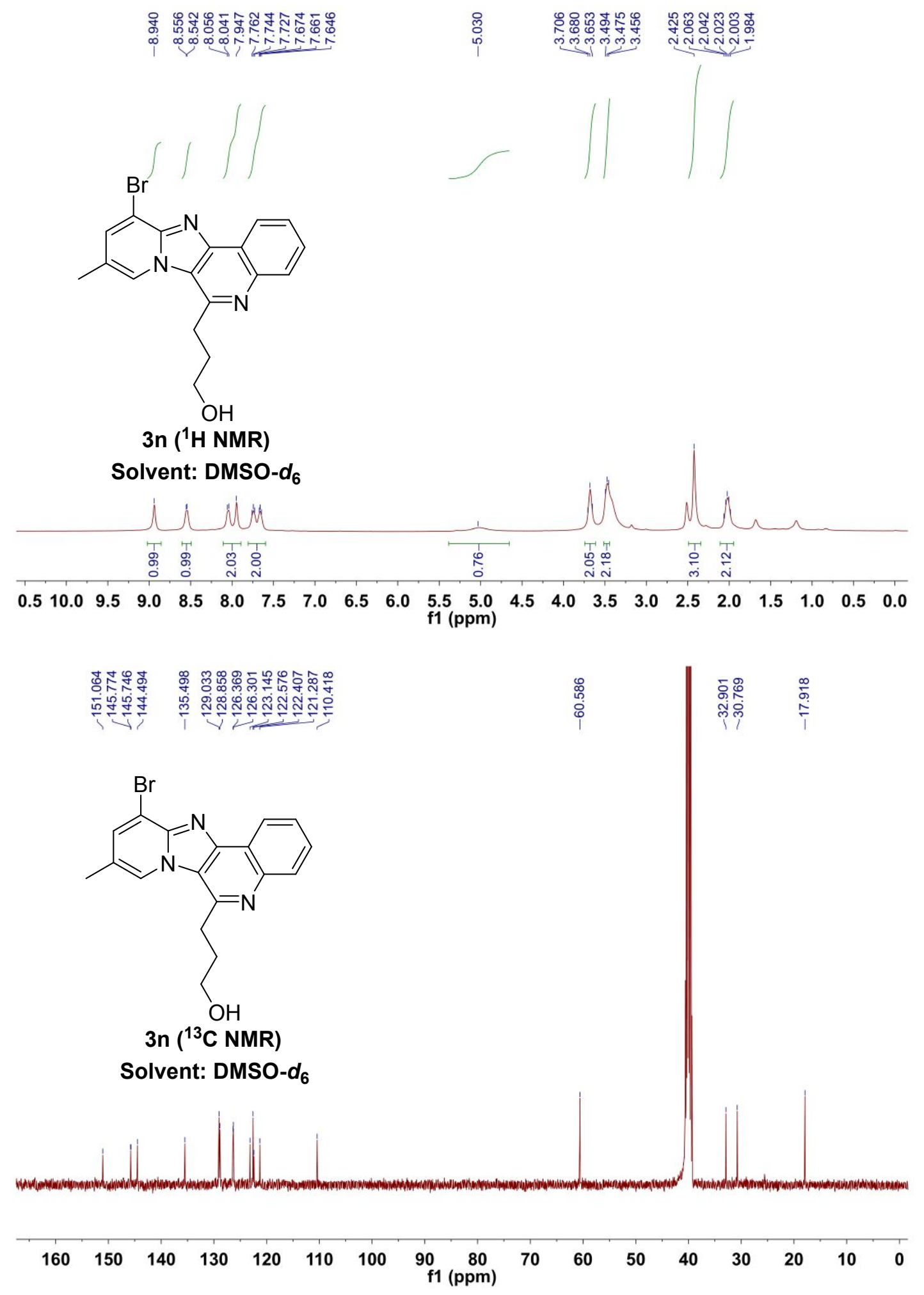

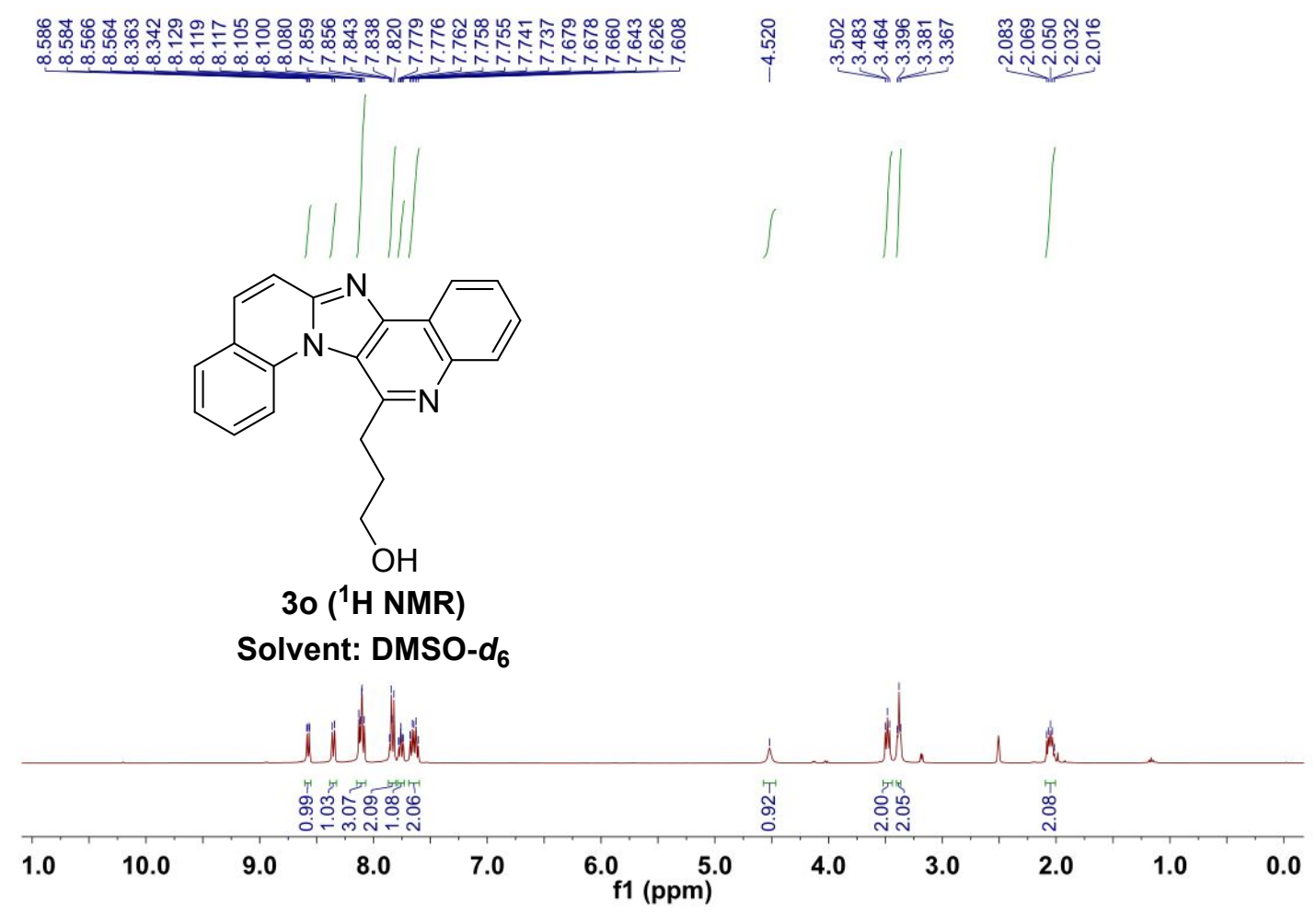

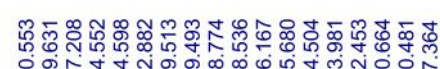

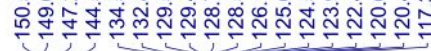<smiles>OCCCc1nc2ccccc2c2nc3ccc4ccccc4n3c12</smiles>

3o ( ${ }^{13} \mathrm{C}$ NMR)

Solvent: DMSO- $d_{6}$

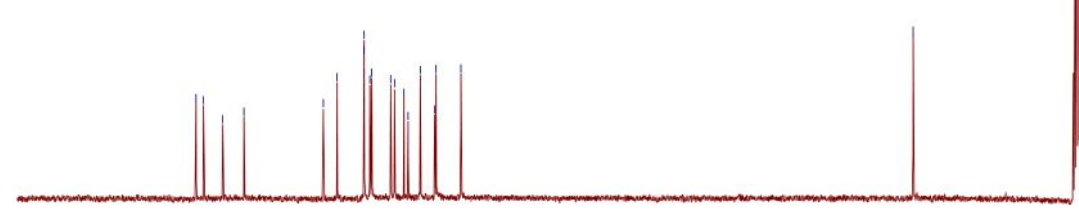

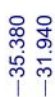

170

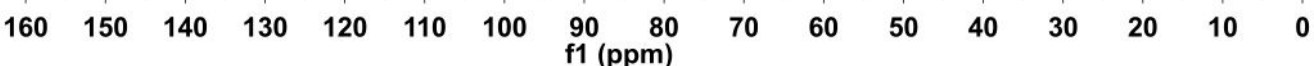




\section{ֻू.}
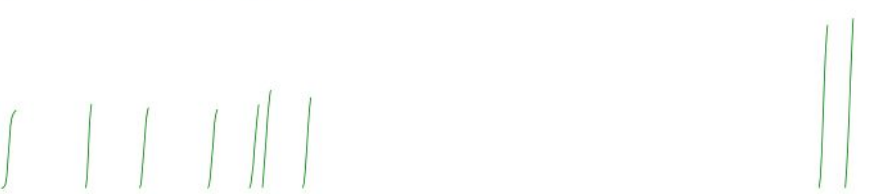<smiles>OCCCc1nc2ccccc2c2nc3ncccn3c12</smiles>

$3 p$ ( ${ }^{1} \mathrm{H}$ NMR)

Solvent: DMSO-d $d_{6}$

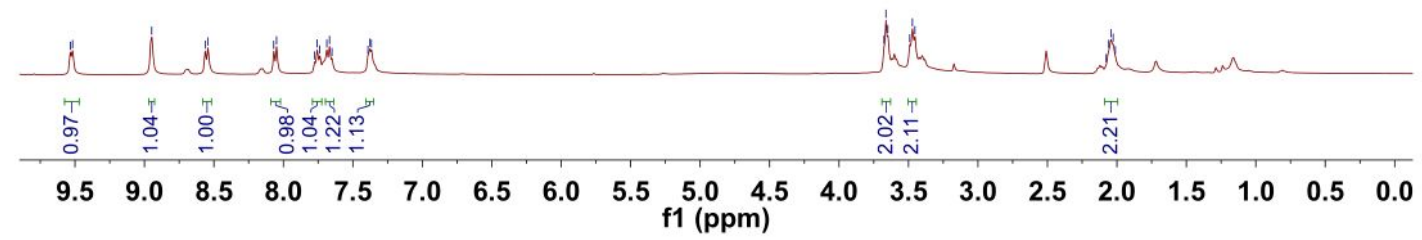

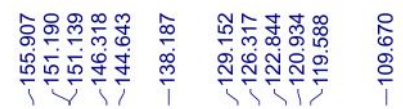

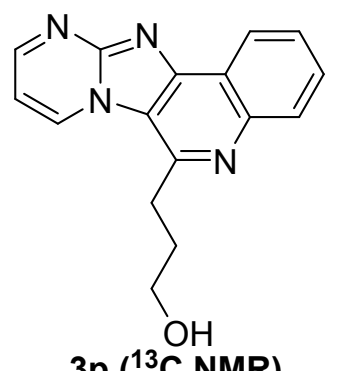

$3 p\left({ }^{13} \mathrm{C}\right.$ NMR $)$

Solvent: DMSO-d $d_{6}$

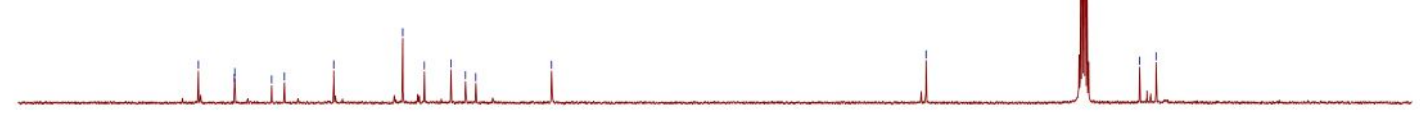

$\begin{array}{lllllllllllllllll}170 & 160 & 150 & 140 & 130 & 120 & 110 & 100 \underset{\mathrm{f} 1}{90(\mathrm{ppm})} \mathbf{8 0} & 70 & 60 & 50 & 40 & 30 & 20 & 10 & 0\end{array}$ 


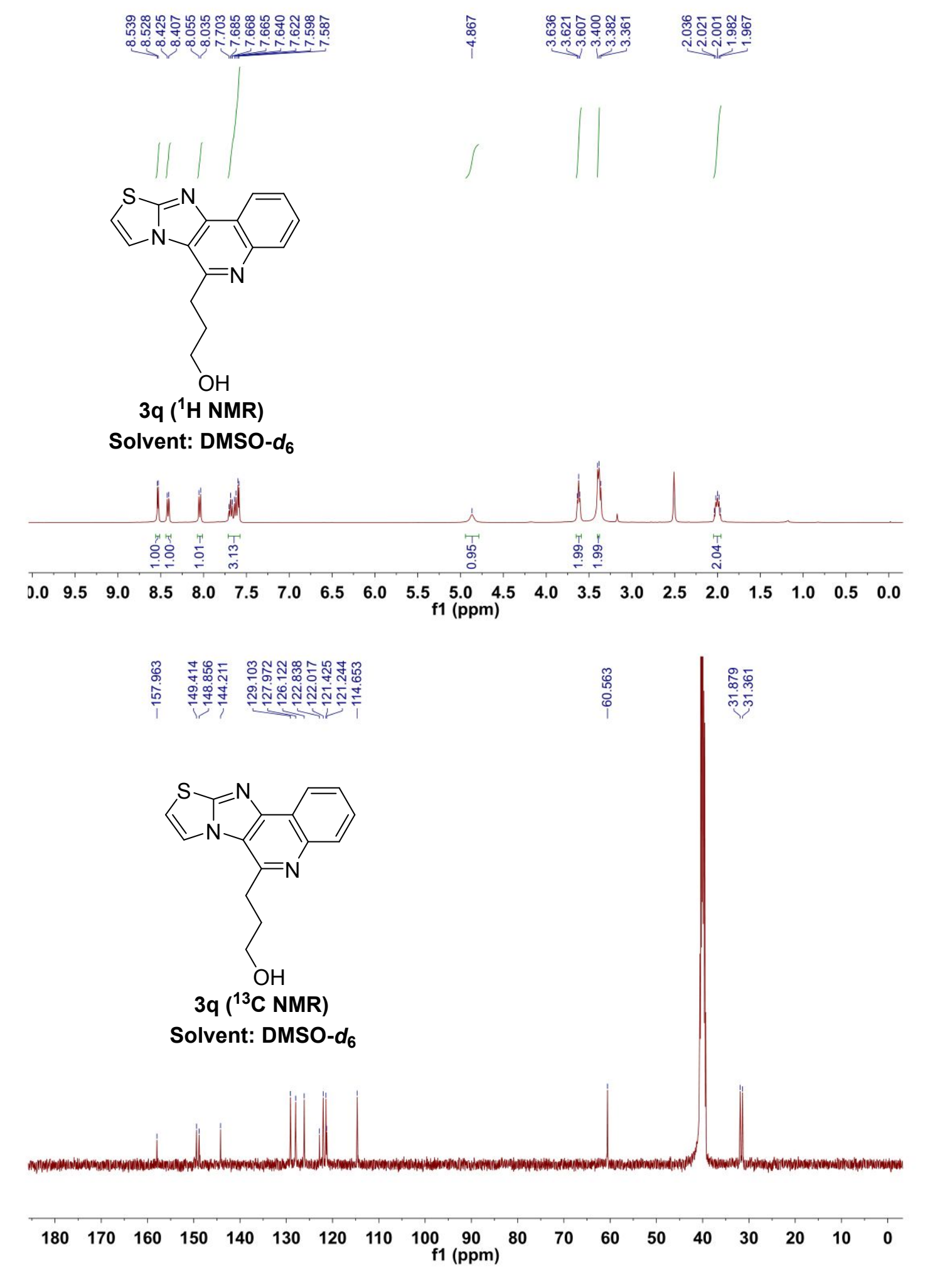



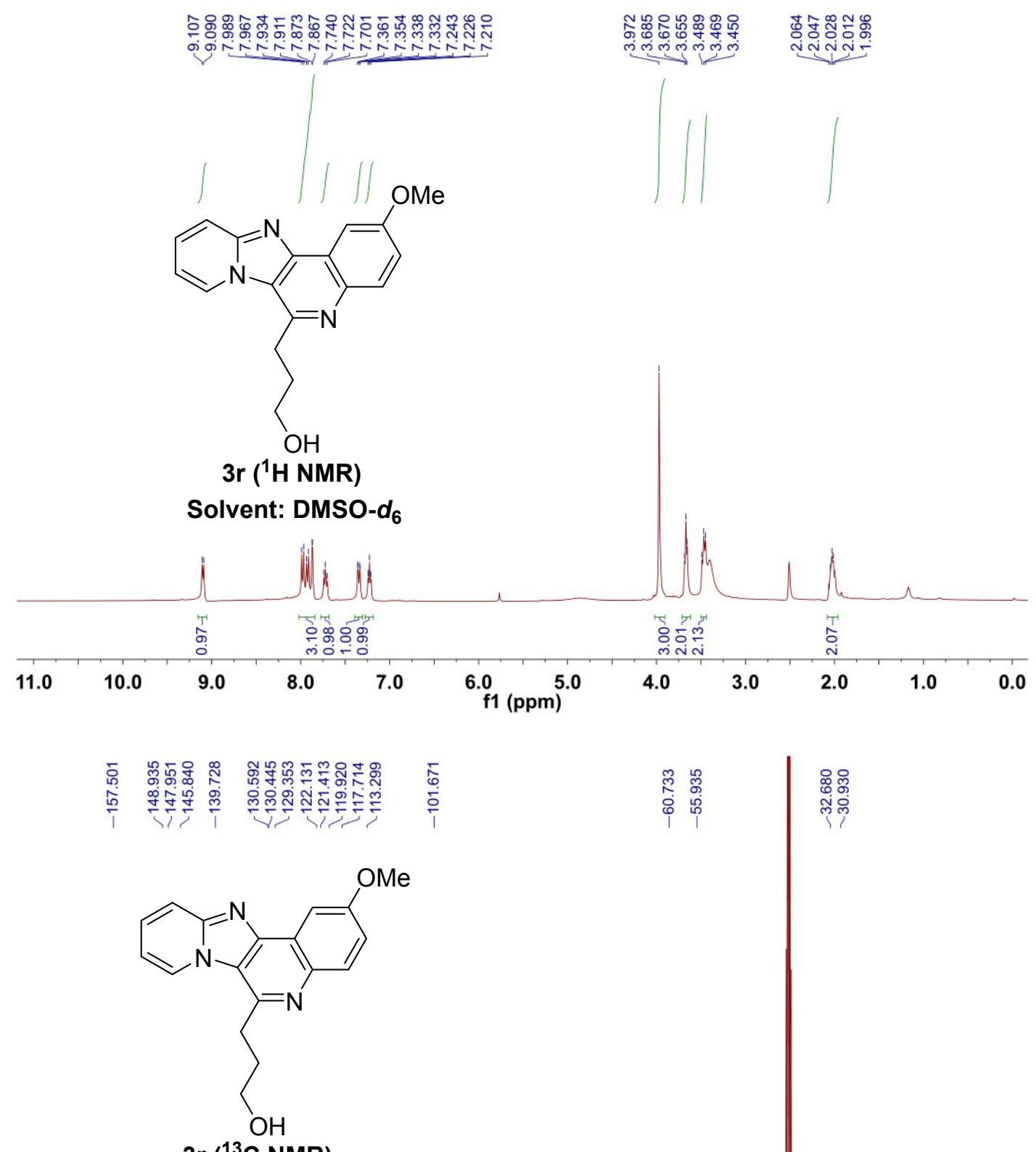

$3 r\left({ }^{13} \mathrm{C}\right.$ NMR)

Solvent: DMSO- $d_{6}$

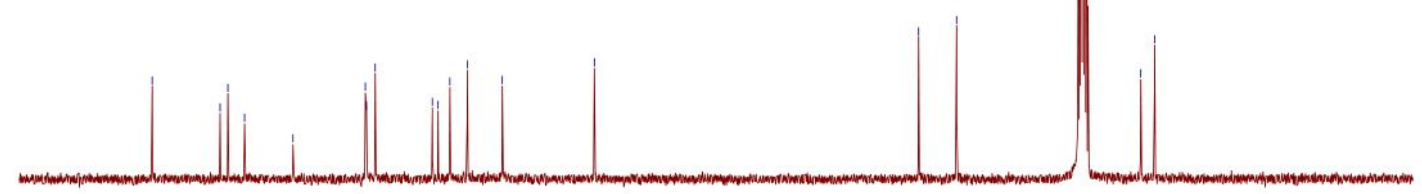

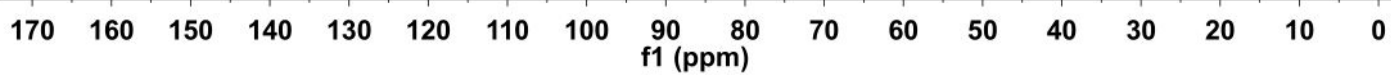



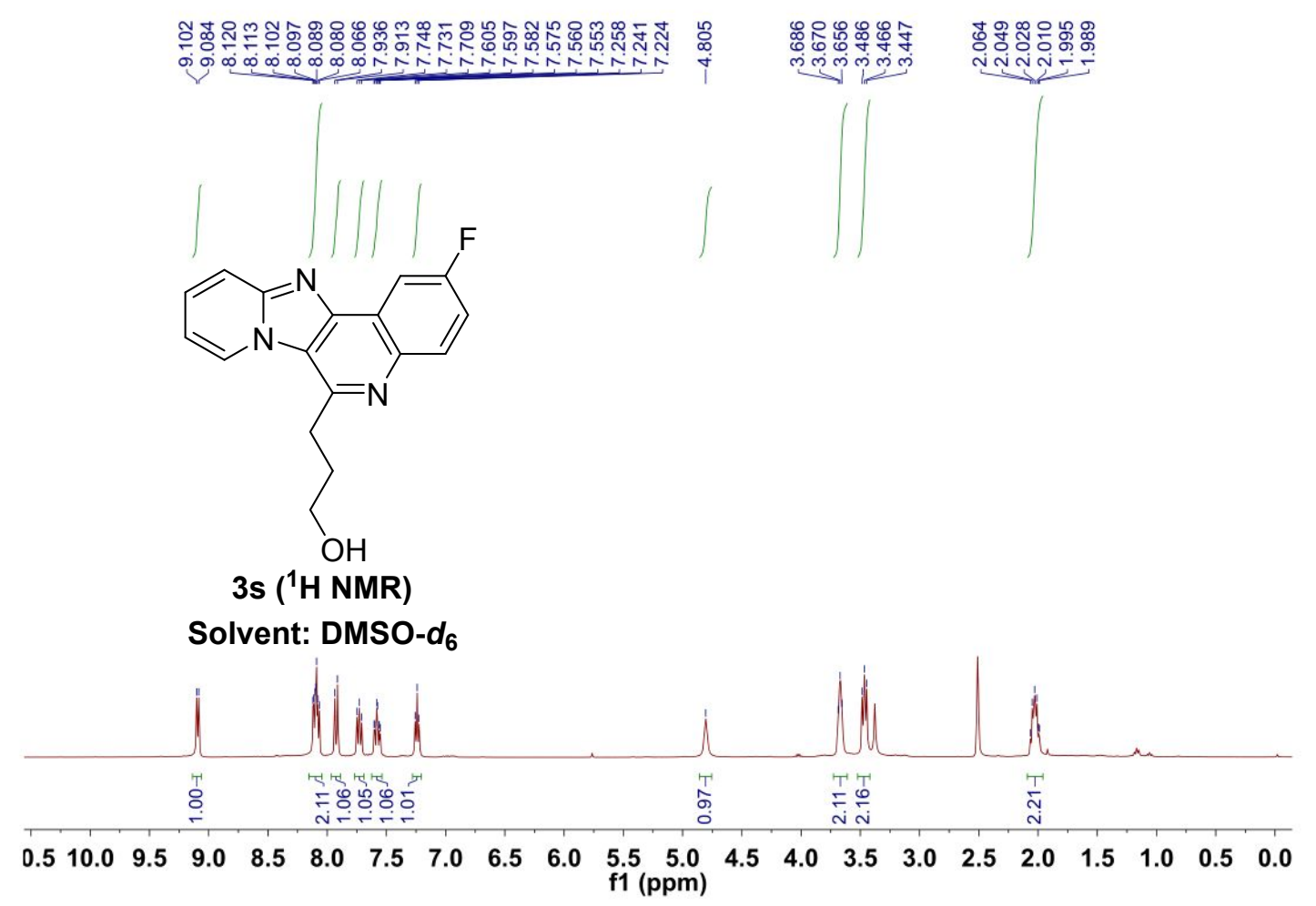

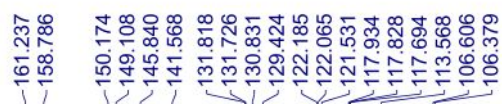

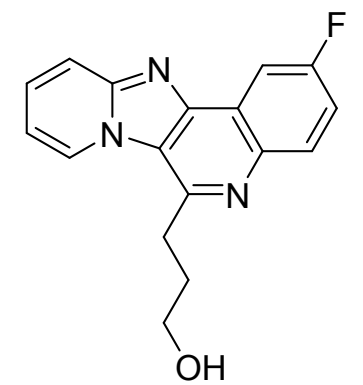

3s ( ${ }^{13} \mathrm{C}$ NMR)

Solvent: DMSO-d $d_{6}$

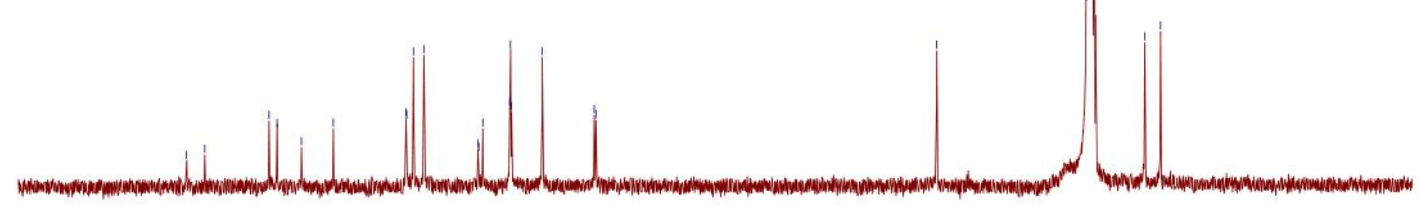

$\begin{array}{lllllllllllllllllll}180 & 170 & 160 & 150 & 140 & 130 & 120 & 110 & 100 \underset{\mathrm{f} 1(\mathrm{ppm})}{90} 80 & 70 & 60 & 50 & 40 & 30 & 20 & 10 & 0\end{array}$ 


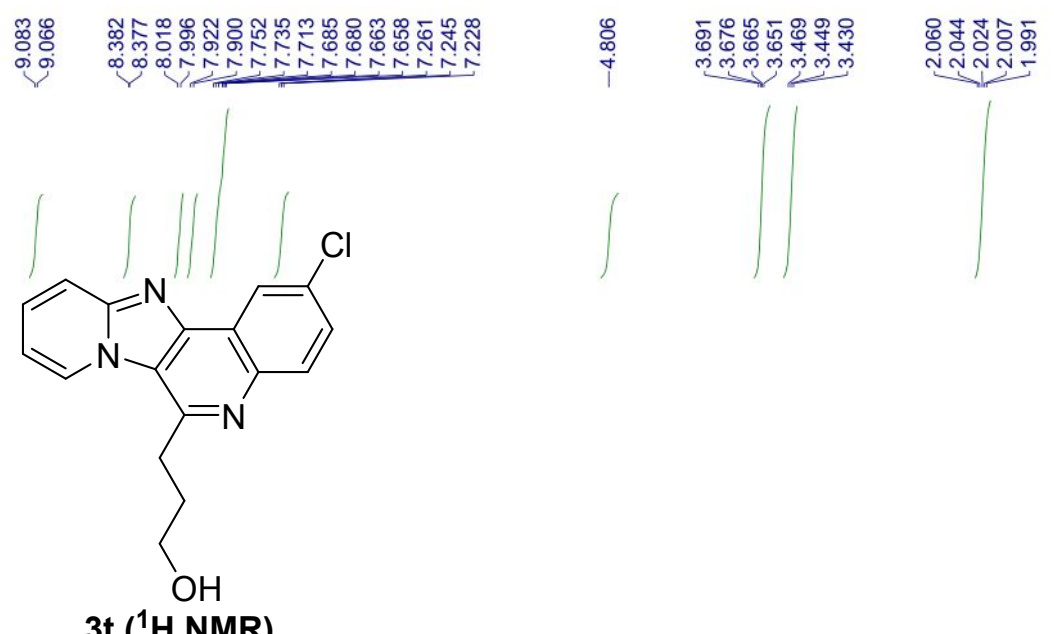

Solvent: DMSO- $d_{6}$

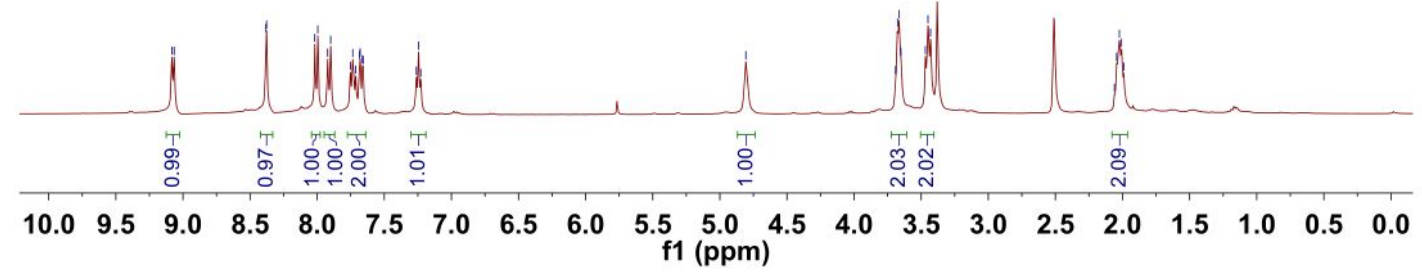

:

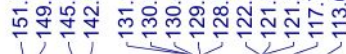

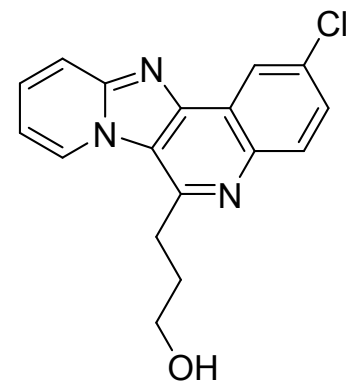

3t $\left({ }^{13} \mathrm{C}\right.$ NMR)

Solvent: DMSO- $d_{6}$
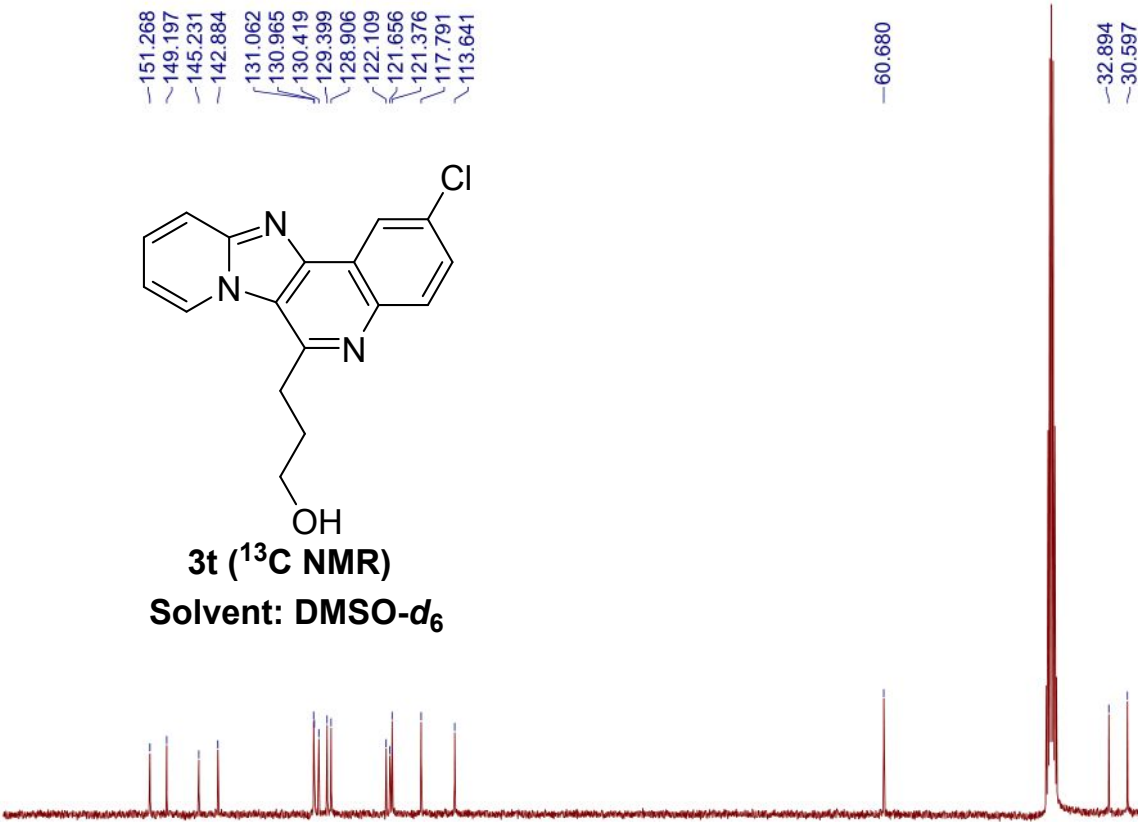

$\begin{array}{llllllllllllllll}160 & 150 & 140 & 130 & 120 & 110 & 100 & \underset{\mathrm{f} 1(\mathrm{ppm})}{90} \underset{(\mathrm{pp})}{70} & 70 & 60 & 50 & 40 & 30 & 20 & 10 & 0\end{array}$ 

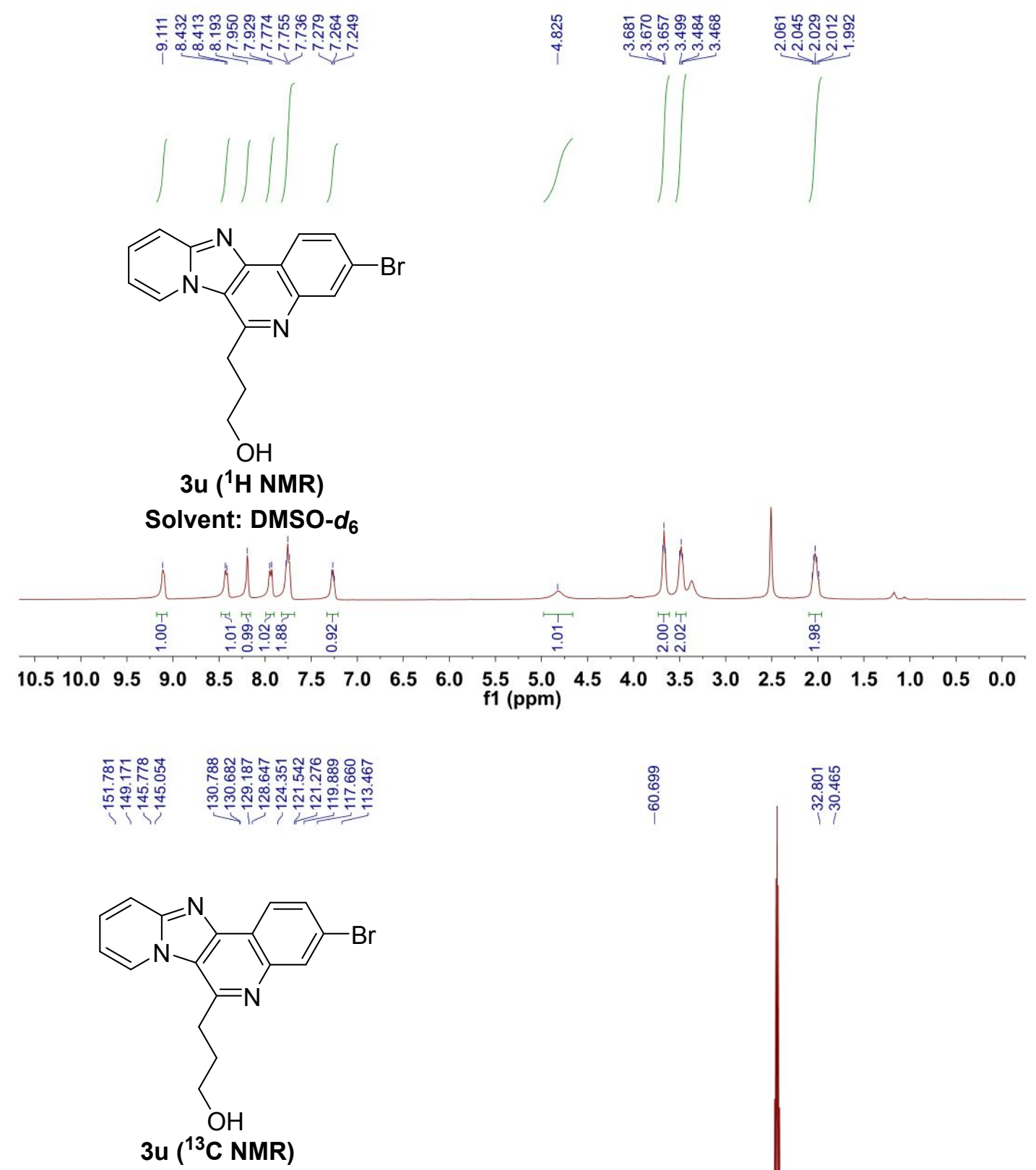

Solvent: DMSO- $d_{6}$

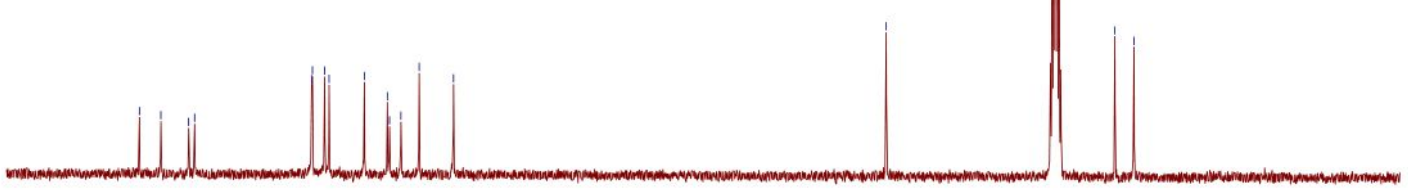

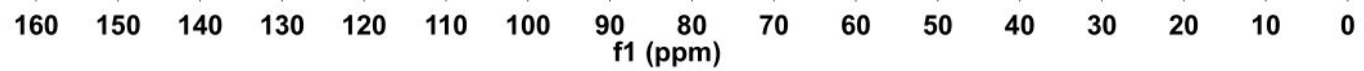



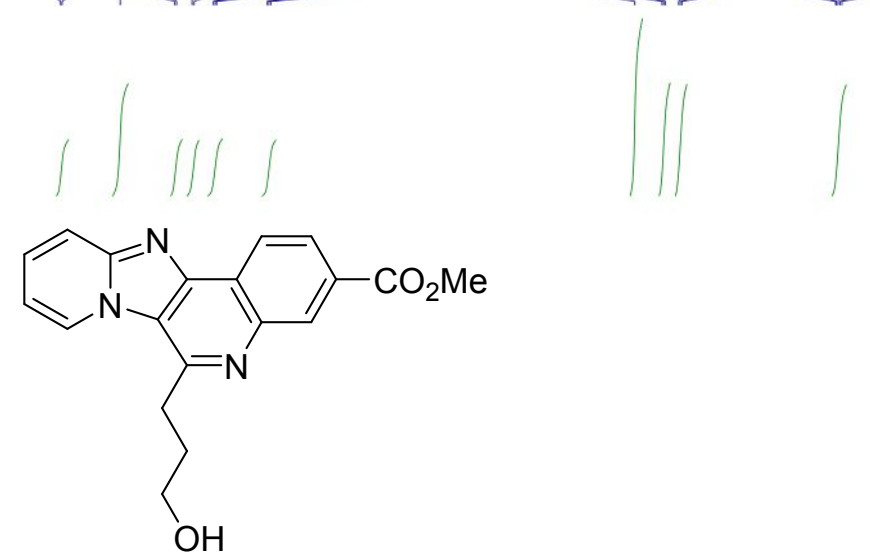

$3 v$ (' ${ }^{1} \mathrm{H}$ NMR)

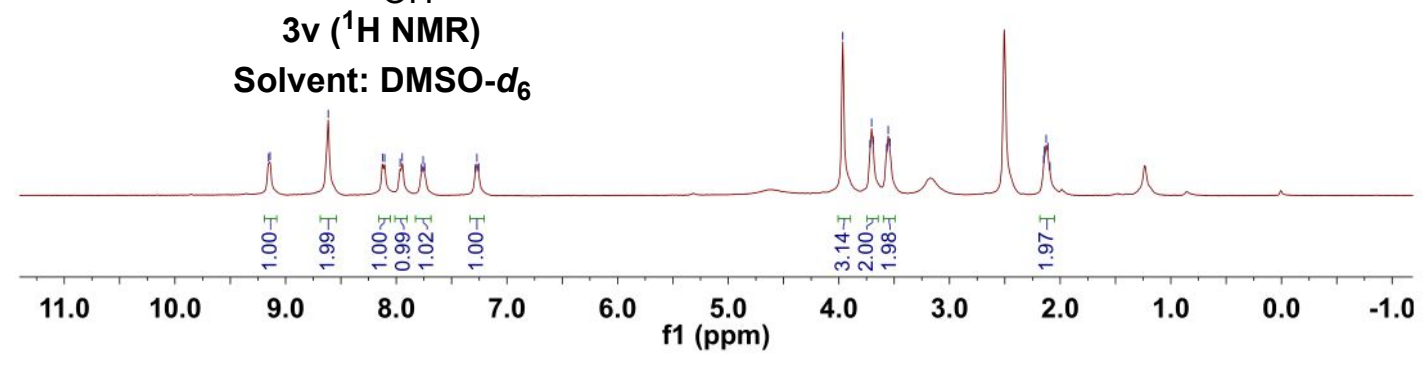

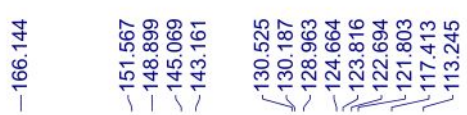

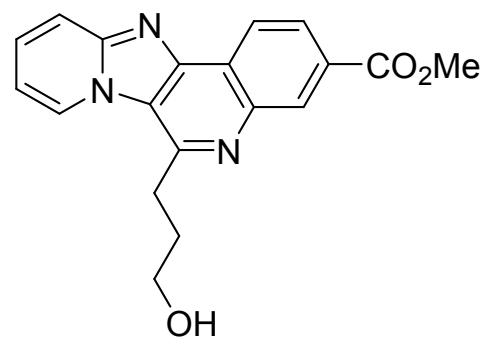

$3 v\left({ }^{13} \mathrm{C}\right.$ NMR)

Solvent: DMSO- $d_{6}$

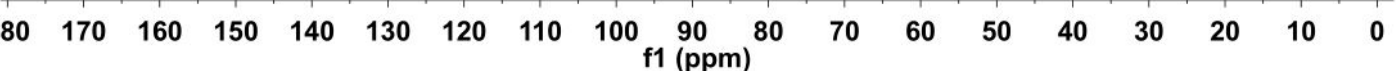




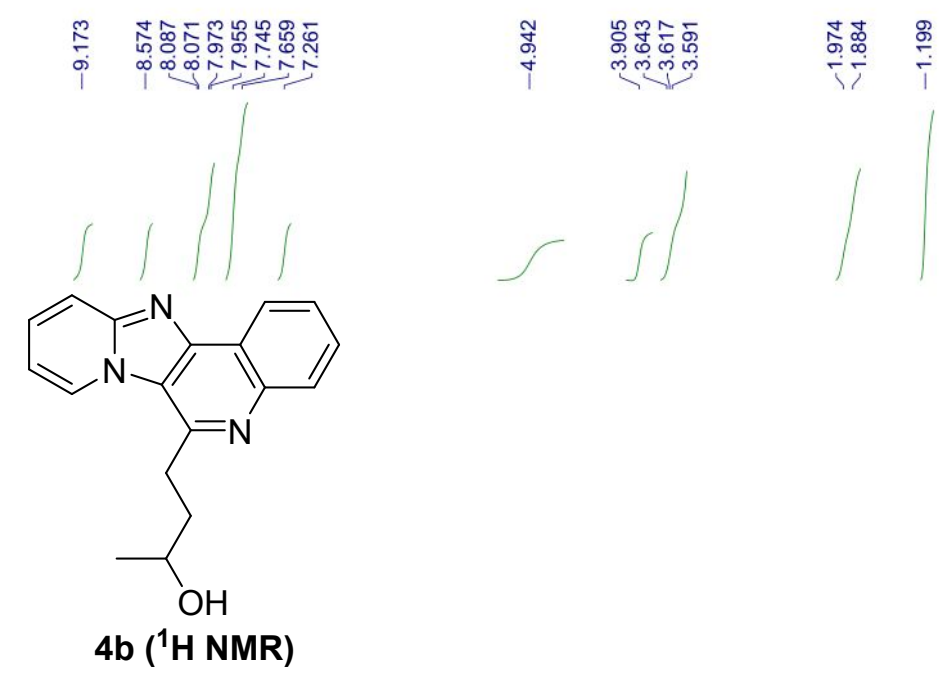

Solvent: DMSO- $d_{6}$

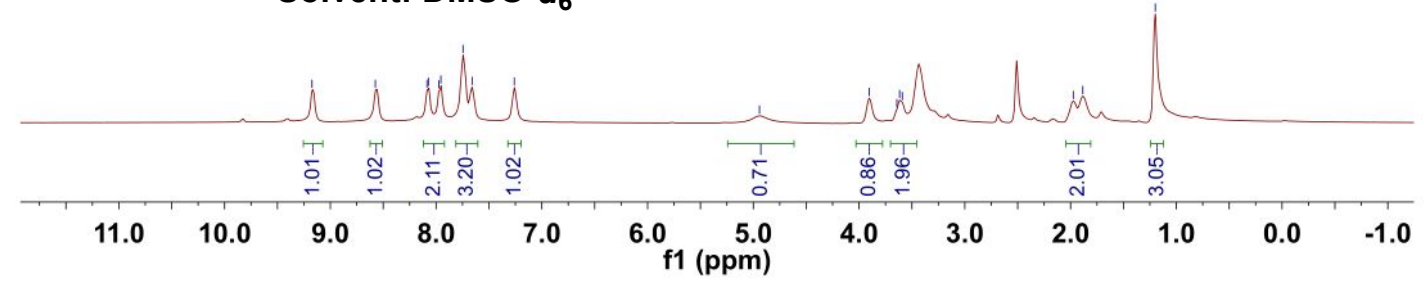

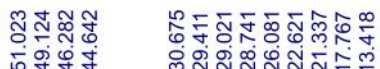

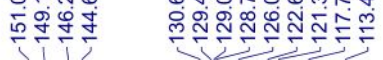

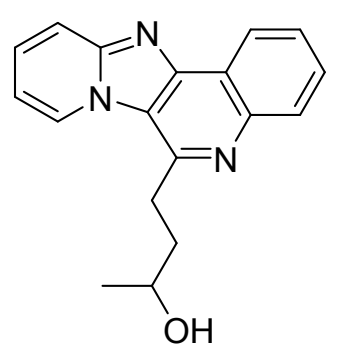

4b ( ${ }^{13} \mathrm{C}$ NMR)

Solvent: DMSO- $d_{6}$

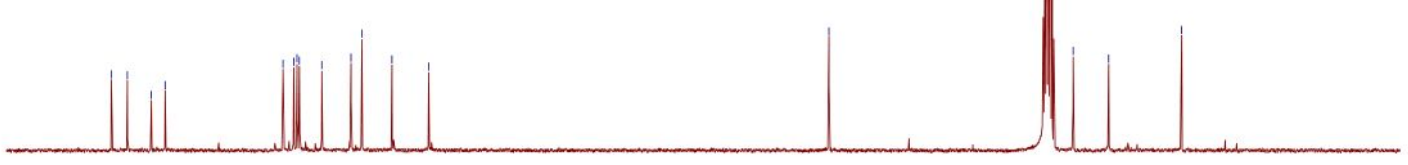

$\begin{array}{lllllll}160 & 150 & 140 & 130 & 120 & 110 & 10\end{array}$

$90 \underset{1(\mathrm{ppm})}{80} 70$

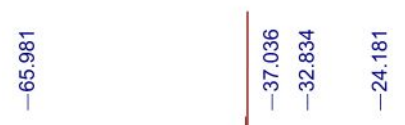

f1 (ppm) 


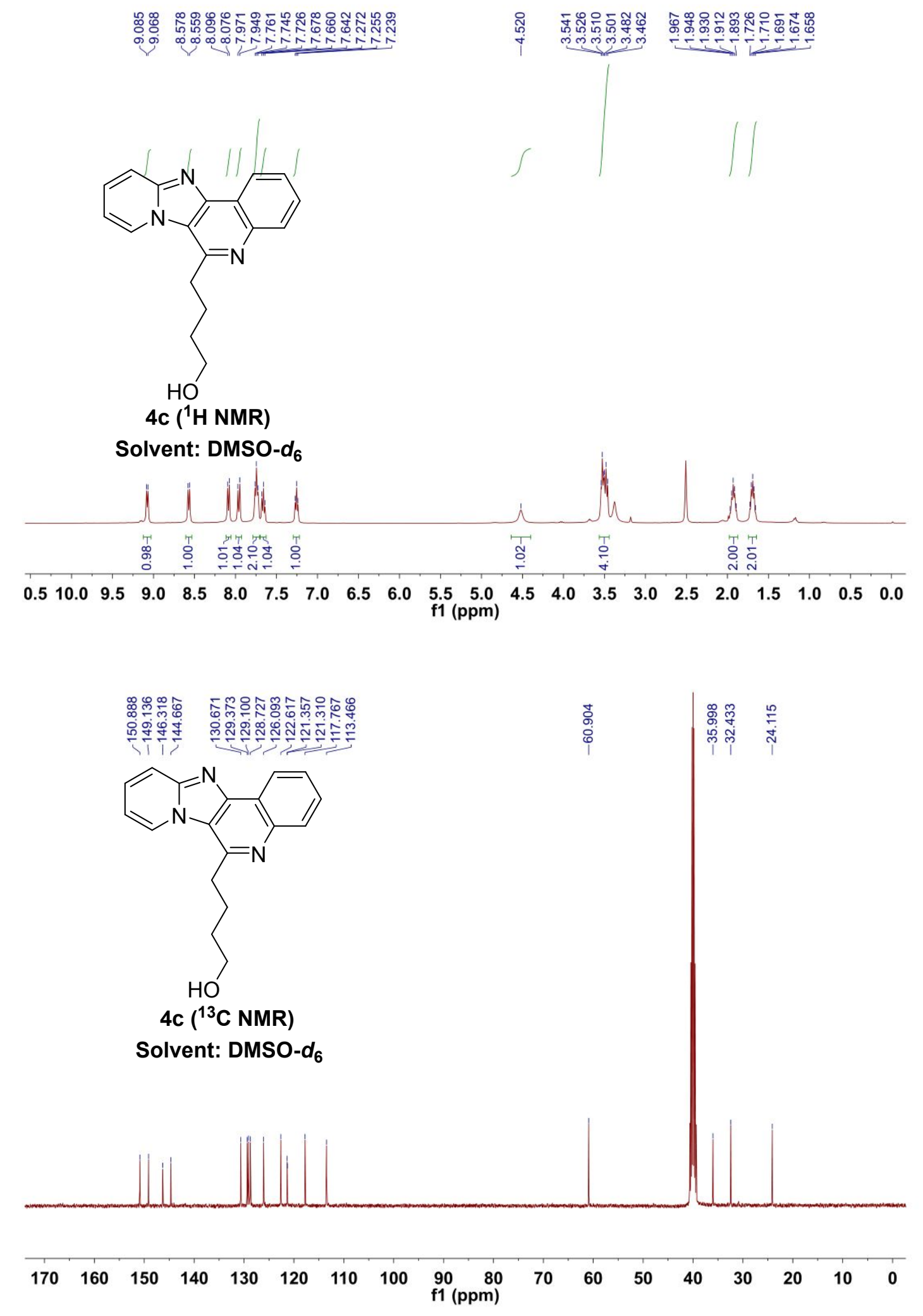




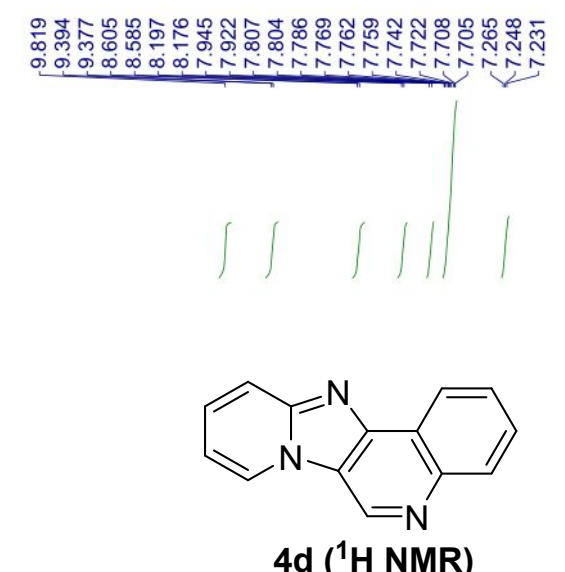

Solvent: DMSO-d
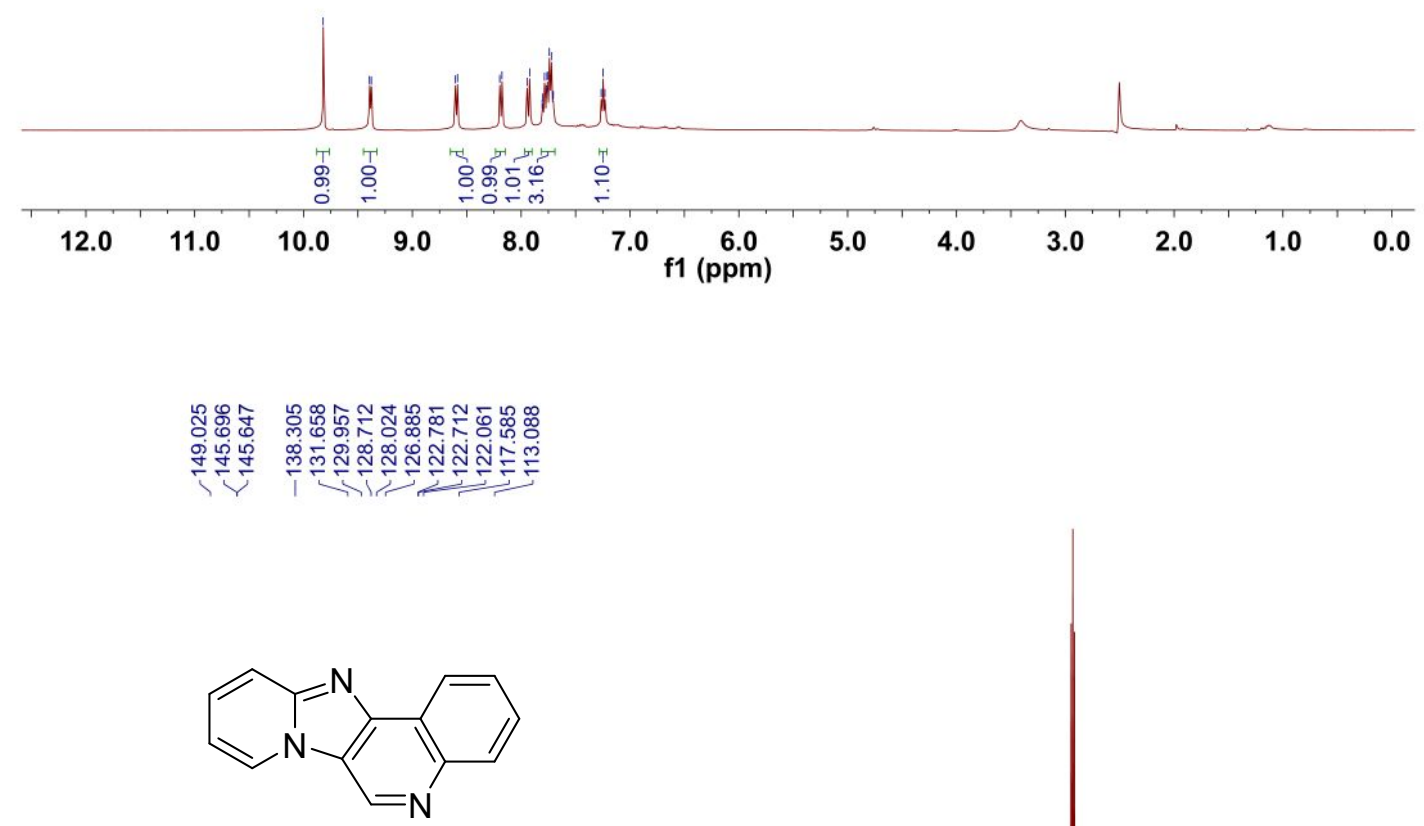

4d ( ${ }^{13} \mathrm{C}$ NMR)

Solvent: DMSO- $d_{6}$

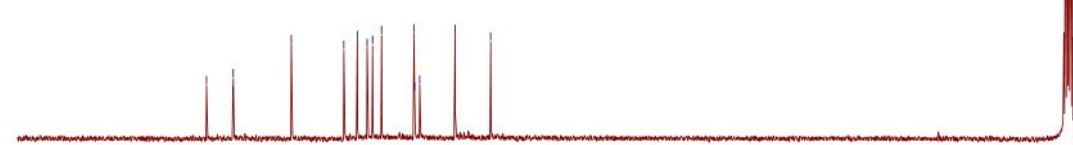

$\begin{array}{rlllllllllllllllll}170 & 160 & 150 & 140 & 130 & 120 & 110 & 100 & 90 & 80 & 70 & 60 & 50 & 40 & 30 & 20 & 10 & 0\end{array}$ 

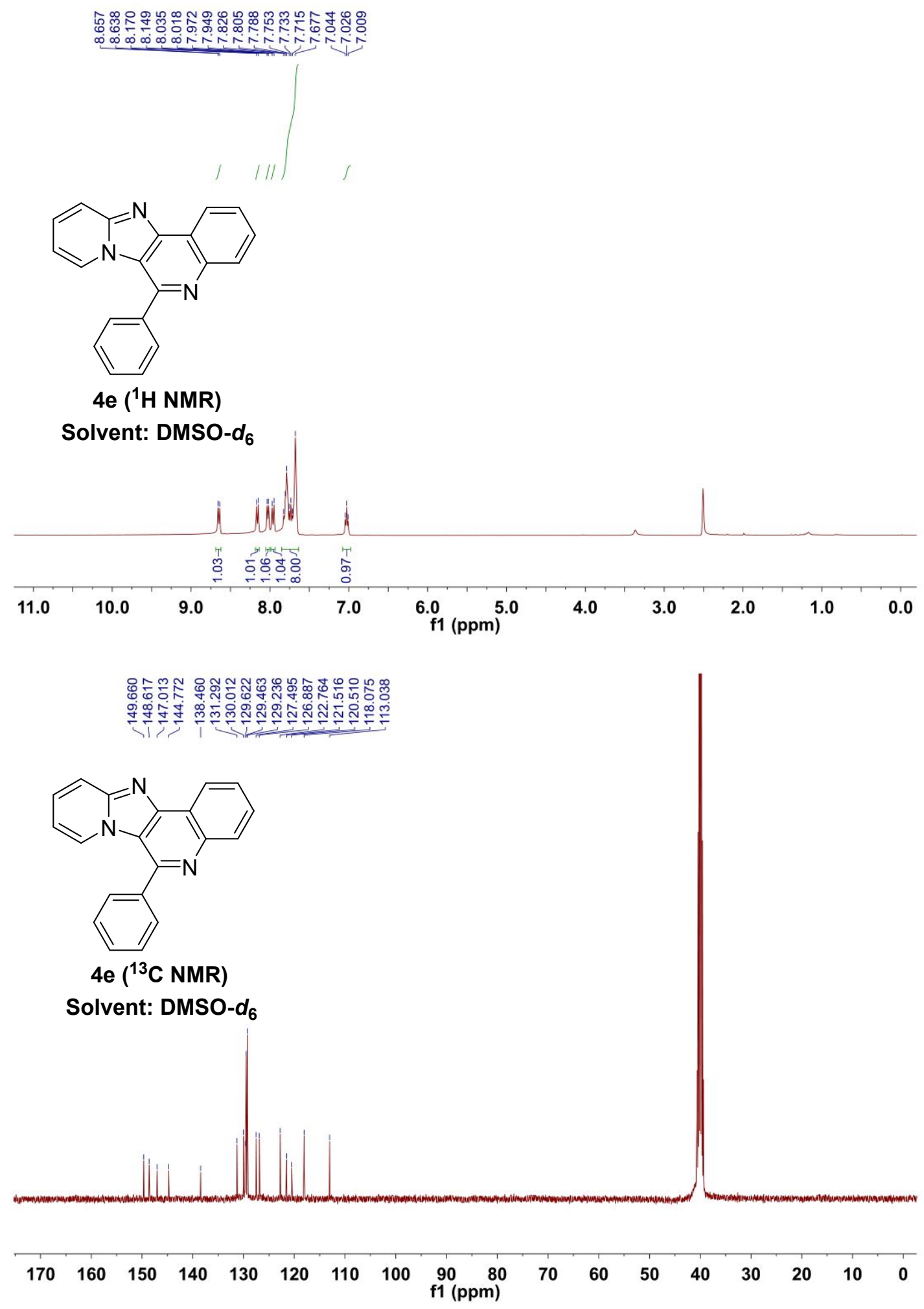


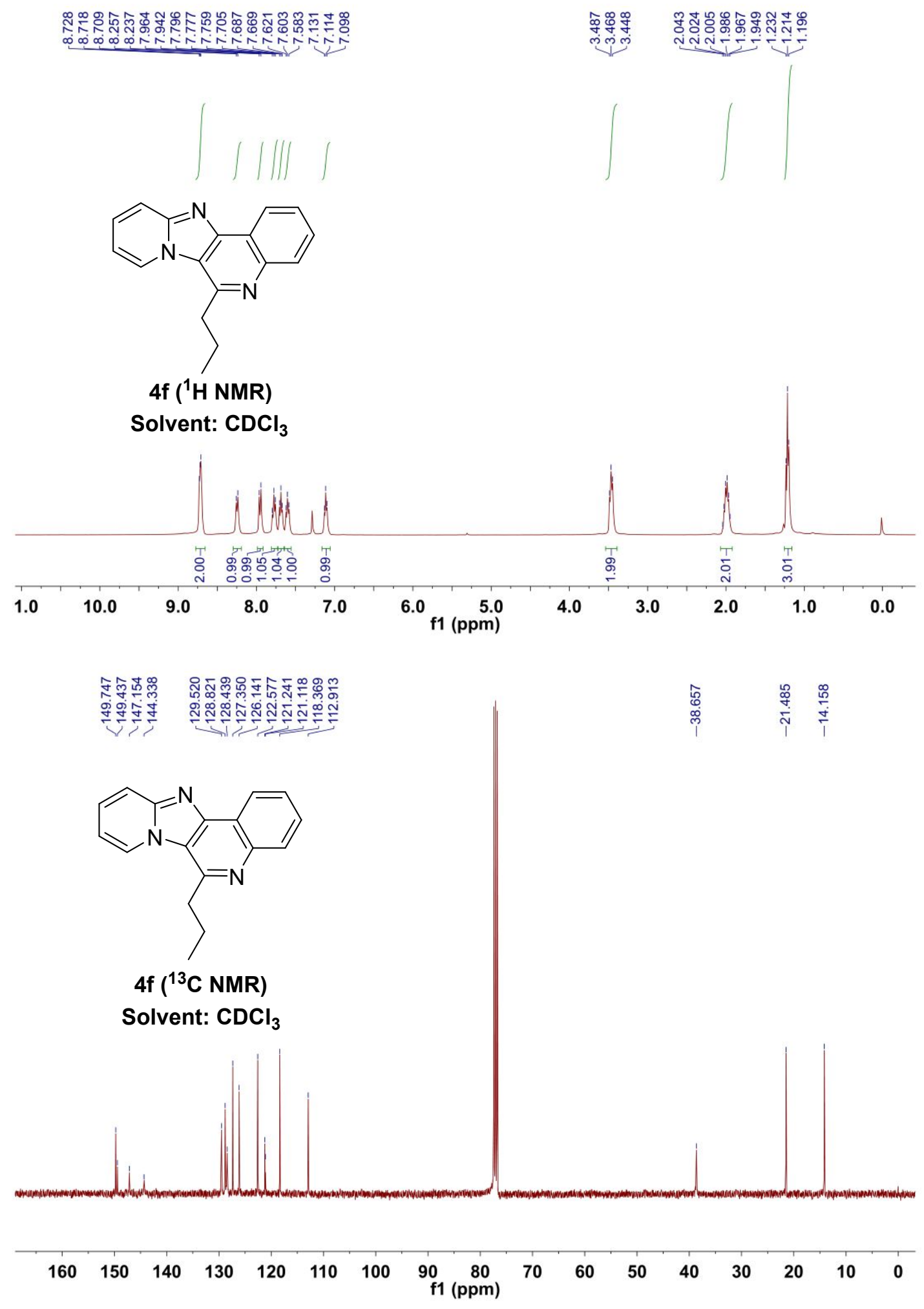

